\title{
Is it justifiable to treat chronic patients by nurse specialists? : evaluation of effects on quality of care
}

Citation for published version (APA):

Vrijhoef, H. J. M. (2002). Is it justifiable to treat chronic patients by nurse specialists? : evaluation of effects on quality of care. [Doctoral Thesis, Maastricht University]. Datawyse / Universitaire Pers Maastricht. https://doi.org/10.26481/dis.20021219hv

Document status and date:

Published: 01/01/2002

DOI:

10.26481/dis.20021219hv

Document Version:

Publisher's PDF, also known as Version of record

\section{Please check the document version of this publication:}

- A submitted manuscript is the version of the article upon submission and before peer-review. There can be important differences between the submitted version and the official published version of record.

People interested in the research are advised to contact the author for the final version of the publication, or visit the DOI to the publisher's website.

- The final author version and the galley proof are versions of the publication after peer review.

- The final published version features the final layout of the paper including the volume, issue and page numbers.

Link to publication

\footnotetext{
General rights rights.

- You may freely distribute the URL identifying the publication in the public portal. please follow below link for the End User Agreement:

www.umlib.nl/taverne-license

Take down policy

If you believe that this document breaches copyright please contact us at:

repository@maastrichtuniversity.nl

providing details and we will investigate your claim.
}

Copyright and moral rights for the publications made accessible in the public portal are retained by the authors and/or other copyright owners and it is a condition of accessing publications that users recognise and abide by the legal requirements associated with these

- Users may download and print one copy of any publication from the public portal for the purpose of private study or research.

- You may not further distribute the material or use it for any profit-making activity or commercial gain

If the publication is distributed under the terms of Article $25 \mathrm{fa}$ of the Dutch Copyright Act, indicated by the "Taverne" license above, 
IS IT JUSTIFIABLE

TO TREAT CHRONIC PATIENTS

BY NURSE SPECIALISTS? 
The studies described in this thesis were performed at the Research Insritute for Extramural and Transmural Healith care (Ex Tra), which participates in the Netherlands School of Primary Care Research (CaRc), acknowledged in 1995 by the Royal Durch Academy of Science (KNAW).

These studies are in part supported by Incentive Programme Health Research (Simuleringsprogramma Gezondheidsonderzoek), Medical Centre Alkmaar (Medisch Centrum Alkmaar), the Foundarion of Hospitals Noord Limburg (Srichting Ziekenbuizen Noord Limburg), and Maastrichx University. Printing of this thesis was financially supported by the Foundarion of Diabetes Care Maastricht, GlaxoSmirhKline, and Novo Nordisk.

Is it juscifiable to treat chronic parienrs by nurse specialists? Evaluation of effects on quality of care. HJM Vrijhoef. Thesis, Maastricht Uniwersiny - wirh references - with summary in Dutch.

MaSH subject headings: Evaluation Studies, Nurse Practitioners, Nurse's Role, Organisarion and Administration, Chronic Disease, Diaberes Mellitus, Pulmonary Disease-Chronic Obstructive, Arthritis Rheumatoid.

ISBN 9052783640

2002, H.J.M. Vrijhoef, Maastricht

Universiteit Maasriche, Department of Health Care Studies, PO Box 616, 6200 MD Maastricht, The Netheriands relephone $+31-43-3881551$; facsimile $431-43-3884162$;

e-matil: b.vrihhoefow.unimaas.n

Lay our and princed by Darawyse.

Cover design by H.J.M. Vrijhoef \& Datawyse based on a drawing by Liane Payne. 


\section{IS IT JUSTIFIABLE \\ TO TREAT CHRONIC PATIENTS \\ BY NURSE SPECIALISTS?}

EVALUATION OF EFFECTS ON QUALITY OF CARE

\section{PROEFSCHRIFT}

ter verkrijging van de graad van doctor aan de Universiteit Maastricht,

op gezag van de Rector Magnificus,

Prof. dr. A.C. Nieuwenhuijzen Kruseman, volgens het besluit van het College van Decanen, in het openbaar te verdedigen op donderdag 19 december 2002 om 14.00 uur

door

HUBERTUS JOHANNES MARIA VRIJHOEF

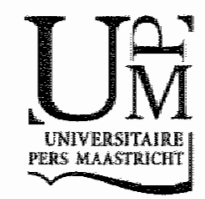


PROMOTOR

Prof. dr. C. Spreeuwenberg

CO-PROMOTOREN

Dr. J.P.M. Diederiks

Prof. dr. B.H.R. Wolffenbuttel

\section{BEOORDELINGSCOMMISSIE}

Prof, dr. E.F.M. Wouters (voorzitter)

Prof. dr. G.A.M. van den Bos (Universiteit van Amsterdam)

Prof. dr. mr. R.P.T.M. Grol

Prof. dr. H. Huijer Abu-Saad

Prof. dr. A.P.W.P. van Montfort (Erasmus Univetsiteit Rotterdam) 
Voor mijn moeder en mijn broer

Ter nagedachtenis aan minn vader

Alterius sic altera poscit opem res et coniurat amica Het een heeft de hulp van het ander nodig en beiden werken vriendschappelijk samen

Horatius (Ars Poetica) 



\title{
CONTENTS
}

\author{
CHAPTER 1 \\ General introduction 9
}

CHAPTER 2

Applying low disease activity criteria using the DAS28 to assess stability in patients with rheumatoid arthritis 23

\section{CHAPTER 3}

Effects on quality of care for patients with type 2 diabetes or COPD when the nurse specialist has a central role: $A$ literature review

\section{CHAPTER 4}

Substitution model with central role for nurse specialist is justified in the care for stable type 2 diabetic outpatients 47

\section{CHAPTER 5}

The nurse specialist as main care-provider for patients with type 2 diabetes in a primary care setting: Effects on parient outcomes

\section{CHAPTER 6}

Transfer of care for outpatients with COPD from pulmonologist to nurse specialist: A randomised controlled trial 85

\section{CHAPTER 7}

Undiagnosed patients and patients at risk for COPD in primary health care: Early detecrion with the support of non-physicians 103

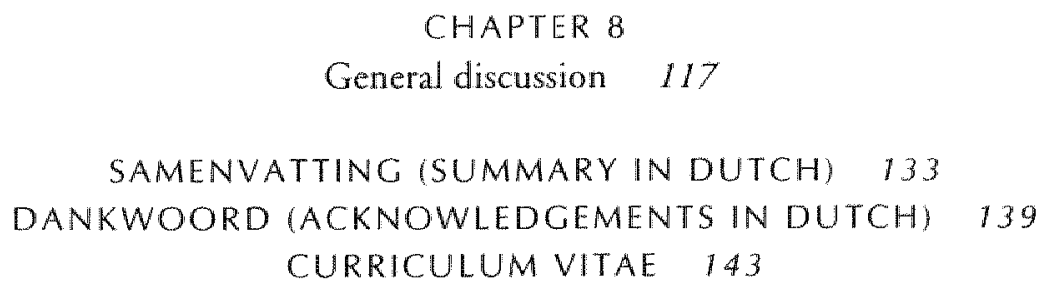


(1) 


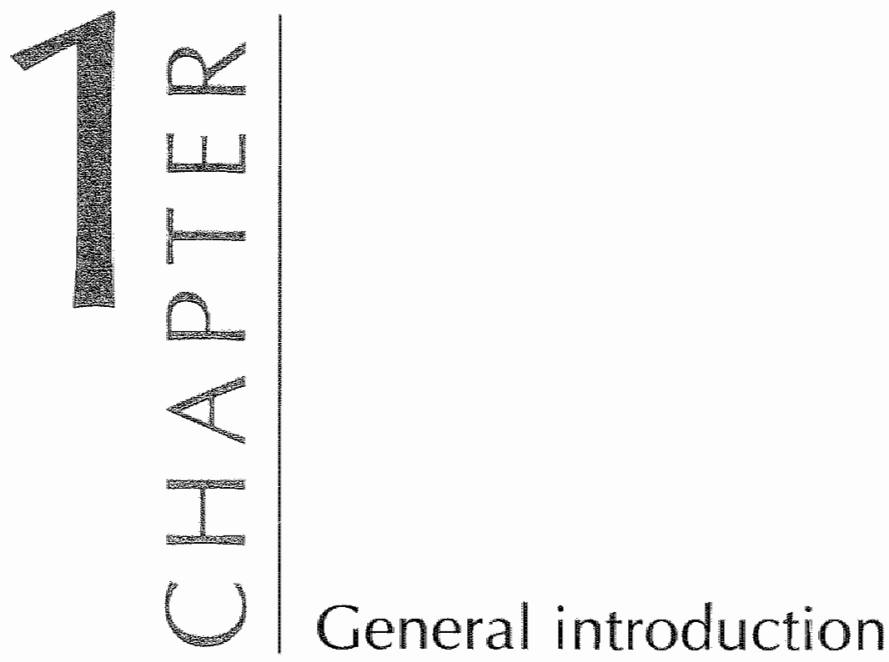


This dissertation focuses on the effects on quality of care for parients with a chronic disease when the nurse speciallist performs the central role in care delivery. Chronic diseases as a group are rather heterogeneous with differences in artiology and symptoms, as well as in the possibilities for their management. Nevertheless, chronic diseases are defined as "all impairments or deviations from normal which have one or more of the following characteristics: are permanent, leave residual disabiliry, are caused by non-reversible parhological alteration, require special training of the patient for rehabilitation, may be expected to require a long period of supervision, observation, or care" (Mayo, 1956). This definition thus distinguishes chronic diseases from acute and sub-acute episodes of illness.

Existing health care systems do not adequately address the specific needs and problems of people with a chronic disease. With the emphasis on diagnosis, ruling out serious disease, and curative or symptom-relieving treatments, health care systems are organised to respond to the acute and urgent needs of patients. Physical, psychological, and social factors need to be included and integrated when caring for chronically ill people (Spreeuwenberg, 1994). Caregivers have to act more like initiators and less like responders so that patients receive preventive interventions, systemanic assessments, education, psychosocial support, counselling, and are followed-up. In addition, patients have to be encouraged to perform self-care tasks (Wagner et al., 1996).

The difficulty of managing chronic disease in a health care system largely oriented to the management of acure episodes of illness is one reason that has prompred the development of alternarive disease management systems that address the unique needs of patients with chronic diseases. Another is the increasing prevalence of chronically ill patients as well as the associared costs of treatment and care (Anonymous, 1997). A review of the literature on the management of chronic diseases identified similarities among organised efforts that improve patient outcomes and grouped them under five headings (Wagner et al., 1996):

- the use of explicir guidelines based on evidence;

- che reorganisation of the practice to meer the needs of patients requiring more time, a broad array of resources, and more systemanic follow-up;

- systematic attenrion to the information, behaviour change, and psychosocial needs of parients;

- ready access to necessary expertise;

- supportive information systems.

At the same time as presenting these characteristics as 'a useful starting point for designing evaluation, research projects, and innovation in chronic illness care (Wagner et al., 1996), the authors urged for 'appropriately targeted health services research' to 'influence the design of medical care for patients with ongoing health 
needs' (Wagner, 1997). Disease management can be regarded as a systematic, population-based approach in which health care professionals work togerher in a co-ordinated and co-operative manner to effect an optimal outcome for a particular patient with a particular disease throughout the entire continum of care (Epstein $\&$ Sherwood, 1996).

In the Netherlands the development of a policy of care for chronically ill started in 1991 with the appearance of a white paper entitled 'Policy for the chronically ill, don "t keep chronic patients our of it' (Ministerie WVC, 1991). Three objectives were set: to promote the effective and efficient approach of chronic diseases and their consequences, to stimulate a situation in which people with a chronic disease experience improved quality of life, and to promore a liveable societal climate for chronically ill people. With regard to the management of the care for chronic diseases, poor co-ordination between need and supply of care was identified (Ministerie WVC, 1991).

Concurrently with the policy papers about chronic care delivery, the National Council of Public Health (1989), an advisory board of the Dutch government, published a report about substitution in health care. To control the costs and to increase the efficiency of care, the message was to transfer tasks or functions and the accompanying responsibility to the lowest level of expertise and competence as possible in a justified way. Today it is believed that medicine, nursing, and allied health professionals are required to provide integrated chronic care in an inter-professional context that supports specialisation, rationalisation, maximisation, and avoids duplication (Leathard et al., 1994).

\section{Interdisciplinary teamwork: substitution and transmurale zorg"}

In an exploration of the development of interdisciplinary practice, McCallin (2001) found that the literature on inter-professional practice is sparse. Current organisation theory derived from the industry suggests that the quality of the product, and the efficiency of production, are dependent on successful teamwork (Andreason et al., 1995; McKenna, 1995). With the introduction of total patient care in the 1990s, the emphasis moved to interdisciplinary teamwork, as health professionals were forced to recognise the need for different professional contributions to patient care in the restructured workplace (Stein et al., 1990). It became apparent that a one-to-one relarionship berween physician and patient was unlikely to be sufficient to maintain health or minimise disability especially for chronically ill persons (Vinicor, 1995).

The team approach required for delivering care to the chronically ill consists of physicians and non-physicians working together (Yawn, 2000). Traditional inter-professional interactions between doctors and nurses are challenged while boundaries shift with this approach (Hopkins et al., 1996; Kernick \& Scott, 2002). 
Tasks or functions performed by nurses on the boundaries with physicians can assume different forms (Starfield, 1992):

- supplementary: rasks or functions that could be done, albeit inefficiently, by physicians:

- complementary: tasks or functions for which physicians often have neither the skills nor the time to do well;

- substitute: tasks or functions that are traditionally performed by physicians.

When tasks or funcrions are transferred between caregivers within one level of expertise, the substitution is horizontal, while the transfer of tasks or functions between caregivers of different levels of expertise is referred to as vertical substitution (Spreeuwenberg, 1994). When these two forms of substitution simultaneously take place, diagonal substitution occurs.

In the Netherlands substitution and 'transmurale zorg' were introduced as ways of enlarging the co-operation and co-ordination in care as well as to improve the effectiveness and efficiency of care (Commissie Modernisering Curatieve Zorg, 1994; NRV, 1989). 'Transmurale zorg' refers to care ('zorg') given 'through the walls' of the segmented Dutch health care system and is tailored to meet patient's needs, being provided on the basis of agreements on co-operation, harmony, and direcrion between general and specialised caregivers, where responsibilities are borne both individually and commonly (NRV/CVZ, 1995). The approach overlaps with the concepts of shared care (UK) and integrated care (US) (Van der Linden, 1997). And although 'transmurale zorg' has been translated in transmural care by Dutch authors, here this concept is indicated as integrated care.

Integrated care in the Netherlands turns to be a concept which consists of a wide and varied range of health services (Persoon et al., 1996). An inventory of integrated care services as mentioned in several sources between 1990 and 1996 identified 352 services which were categorised in three basic forms: integrated care delivered by specialised hospital and general primary care together; integrated care delivered by generalist primary care professionals who are supported by specialist hospital professionals; and integrated care during admission to and discharge from a specialised care organisation, delivered by generalist primary care professionals. Integrated care services are most often aimed at chronically ill people. Integrated care is found to be an interdisciplinary concepr with nurses being the occupational group most often involved (Persoon et al., 1996).

Acknowledging the pivotal role of nurses in the care for chronic patients as well as the differences in health care systems, Temmink (2000) searched the literarure for substitution-related nursing innovations directed at chronic patients. She reported three kinds of innovations: advanced nursing practice, hospital-at-home care, and integrated care setting. The first two kinds were found in primary care oriented countries, while an ongoing process of integration between generalist and specialist health 
care services in both primary and secondary care oriented countries was reported (Temmink, 2000).

\section{Integrated care for chronically ill in the region of Maastricht and allied regions}

In 1994 the Maastricht University Hospital decided to structure and expand activities in integrated care. It was decided to place the organisation of these activities in the existing Diagnostic and Co-ordinating Centre. The improvement of co-operation between general practitioners (GPs) and medical specialists was already one of the main tasks of this centre. Recently, this centre has become the unit for integrated care of the Maastricht University Hospital (Pop \& Spreeuwenberg, 1998).

To control costs and to ascertain high quality care against the background of the predicted rise in the number of chronically ill, tasks were transferred from medical specialists to GPs. The joint consultation session between GPs and orthopaedic surgeons was the first integrated care project with care delivery being based on horizontal substitution (Vierhout et al., 1995). However, with the continual extension of job responsibilities of the GP (Van Duijn \& Mentink, 1998), the idea was launched to transfer tasks or funcrions from physician to nurse specialist in the care for patients with stable diabetes type 2 , stable chronic obstructive pulmonary disease (COPD), or: stable rheumatoid arthritis (RA).

In particular, for patients with a chronic disease in a stable phase, it was believed that the nurse specialist could operate as the main care provider and thus substitute for the physician. In the phase of stability attention should be on the person with the disease - nursing's orientation - as opposed to the disease - medicine's orientation (Taylor, 1995). However, defining stability for RA is not as straightforward as for diabetes type 2 or COPD. To describe the disease status and the efficacy of treatment in type 2 diabetic patients, glycosylated haemoglobin ( $\mathrm{HbA}_{1 c}$ ) is used as main param eter, while in COPD the forced expiratory volume in one second $\left(\mathrm{FEV}_{1}\right)$ is used for this purpose. With regard to RA, there is no such internationally accepted parameter to define stability. Consensus about which endpoints to measure when assessing disease activity of RA exists, but the definition of disease stability still varies. It was agreed that in the case of RA, first the applicability of criteria to assess stability had to be established before introducing a substitution-based model for patients with stable RA.

Supported by research findings from studies outside the Netherlands (Charlton et al., 1991; Foulkes et al., 1989; Hill et al., 1994; Mackinnon et al., 1989; Ramsay et al., 1982), a team approach in the care of patients with stable diabetes type 2 or stable COPD was proposed in the form of a care-nerwork in the first half of 1996 in the region of Maastricht. A variery of health professionals involved in diabetes care agreed upon the delivery of care in an interactive and interdependent way with inter-profes- 
sional substiturion between medical specialist and nurse specialist. Moreover, in the diabetes care-network patients seen quarterly by the medical specialist in the outpatient department of the hospital are transferred to the nurse specialist and receive three quarterly consultations in the practice of their GP. The nurse specialist and the GP hold regular appointments to discuss the management of individual patients. The medical specialist still performs one annual consultation in the hospital. Tasks, activities, and rargets of care delivery are formulated in a protocol between all involved parties. Besides the medical specialists, GPs, and nurse specialists, the parties involved are: parients, dieticians, the 'Green Cross' home care agency, co-ordinators of the care-networlk in Maastricht and of a broader network for the delivery of care to chronically ill patients ('Synchron').

With the availability of two diabetes nurses employed by the universiry hospital Maastricht, the care-network for patients with stable diabetes type 2 was introduced first in the region of Maastricht. The care-nerwork was partly adopted by a co-operation of a primary care health centre (Gezondheidscentrum Withuis) and the general hospital in Venlo ( $\mathrm{Sr}$. Maartens Gasthuis) for patients with stable diabetes type 2 looked after in the primary care seting. The care for these patients was transferred from GP to nurse specialist. A similar care-network was also partly adopted by pulmonologists and nurse specialists in the hospital of Alkmaar (Medisch Centrum Alkmaar) in the care for patients with stable COPD, by transferring care from pulmonologist to nurse specialist in the outpatient department of the hospital. At the same time nurses specialised in COPD were introduced in the region of Maastricht, fulfilling a complementary function to GPs by screening patients at risk for asthma or COPD.

\section{RESEARCH}

\section{Original model of research}

The introduction of the care-nerwork for people with stable diabetes type 2 or COPD was accompanied by scientific evaluation research. Moreover, it was decided to separately perform a process ewaluation and an effect evaluation to assess:

- whether the care-network contributes to the aim of providing care for patients with stable diabetes type 2 or COPD as close as possible to their own environment and to the aim of substitution of the nurse specialist for the physician (process evaluation);

- which factors promote or hamper the above mentioned contributions (process
evaluation);

- the effects on quality of care of the network in terms of patient outcomes (effect
evaluation); 
- the comparability of the findings from the care-networks across diseases (both evaluations).

The design of the part of the research as presented in this dissertarion, the effect evaluation, was influenced by several factors, in particular by the decision to consider patients with diabetes type 2, COPD, and RA. These diseases were chosen because of the predicted rise in the number of patients, the large variation in practice, the potenrial to standardise the delivery of care, the high aggregate costs of which a large portion is due to drug therapy, the availability of measurable health outcomes, and the potenvial gains in health outcomes and cost savings. In addition, from the start it was recognised that the care-nerwork would be refined and adjusted in daily practice. This implied that the context for research was not completely under control and that the design of the evaluation gained shape according to the specific circumstances encounrered.

Before the care-network for RA could be introduced, the applicability of criteria to assess stability of RA had to be established first. Wirh the availability of internationally accepted criteria to assess stability for diabetes type 2 and COPD, it was decided to review the literature for effects on quality of care of care-models with a central role for the nurse specialist. With regard to the care for patients with stable diabetes type 2 in the region of Maastricht, a care-network was introduced: care was referred from outpatient clinic to primary care and from medical specialist to nurse specialist - diagonal substitution. In the region of Venlo, GPs partly applied this care-network by transferring the care for stable diabetes type 2 patients within primary care from $\mathrm{GP}$ to nurse specialist - vertical substitution. For patients with COPD the care-nerwork was also partly applied in the region of Alkmaar by substitution of the nurse specialist for the pulmonologist in the care for patients with stable COPD in the outpatient clinicvertical substitution.

Based on the experiences with the nurse specialist in performing the central role in the delivery of care for patients with stable diabetes type 2 or COPD, it was decided to make use of the services of the nurse specialist in the phase of early detection. The identification of patients at risk as well as the care for patients diagnosed with COPD was organised in a way in which healthcare professionals work together in a co-ordinated and co-operative manner. This facilitated the aim to create an environment of provider accountability to achieve high quality care over several phases of the continuum of care for a patient - disease management.

Furthermore it was decided to make a stricr separation between the development of the care network and the scientific evaluation to secure the independence and objectivity of the research. Finally, the evaluation of the process was distinguished from the effect evaluation, because of the divergent methods of research. 
The study presented in this dissertation tries to answer the following six questions:

1. Can low disease activity criteria using the DAS28 be applied by nurse specialists to assess the degree of disease stability in patients with $\mathrm{RA}$, and are these criteria sufficiently reliable to select stable patients out of an outpatient popularion for enrolment in a care-network?

2. Which outcomes are identified in trials about the effectiveness and efficiency of care-nerwork models in which the nurse specialist performs a central role and are these models effective and efficient?

3. What are the effects on quality of care when the care for patients with stable diaberes type 2 is transferred from medical specialist to nurse specialist and from ourparient dinic to general practice?

4. What are the effects on quality of care when the care for patients with stable diabetes type 2 is transferred from GP to nurse specialist within general practice?

5. What are the effects on quality of care when the care for patients with stable COPD is transferred from pulmonologist to nurse specialist within the outpatient clinic?

6. To what extent is the support offered by nurse specialists to GPs in the early detection of patients with COPD feasible?

Research question 3, 4, and 5 are regarded as the central research questions of this dissertation.

\section{Research bypotheses}

The rationale behind the care-networks mentioned or referred to in research questions $1,2,3,4$, and 5 is that in the care for medically stable chronic patients, physicians can allocate activities to nurse specialists, allowing the physicians to shift their atrention towards managing patients with most complex problems. However, in RA the concept and definition of stability is more troublesome than in diabetes mellitus or COPD. The activity of RA cannot simply be expressed by one single parameter, and the presentarion of RA may vary substantially over time between patients as well as within the same individual, considering the frequent occurrence of flares (Van Gestel et al., 1996). Although not developed for this purpose, it is hypothesised that the low disease activity criteria using the DAS 28 are applicable to assess stability of RA.

Before the implementation of the care-networks in which the nurse specialist performs a central role, a search was made of the literature for trials evaluating such models on their effects on outcomes of care. The hypothesis behind the transfer of tasks from physician to nurse specialist in the care for people with a stable, chronic disease is that the quality of care generated by the nurse specialist is at least equivalent 
to the quality of care performed by the physician. This hypothesis underlies research questions 3,4 , and 5 .

The hypothesis behind research question 6 is that, with the nurse specialist in a complementary function to the GP, undiagnosed patients and patients at risk for COPD are detected in an early phase, thus enlarging the probability that the airway disease of these parients remains (longer) stable.

\section{Research designs}

Following from the different nature of the research questions, different designs were used to answer the questions. Research questions 3,4 and 5 relate to the effects on quality of care in terms of patient outcomes when care is transferred from physician to nurse specialist. Ideally, these questions require a comparison of alternative interventions for outcomes with patients randomly allocated to the interventions. Randomised controlled trials reduce the likelihood of bias in determination of outcomes. While a randomised controlled trial has internal validity, it might lack external validiry (Grimes \& Schulz, 2002). Due to local circumstances, the randomised controlled trial could not be applied in all three main research questions.

The only setting in which the randomised controlled trial could be applied was where we studied the effects on quality of care when care was transferred from pulmonologist to the nurse specialist for outpatients with stable COPD (research question 5). Here, patients were randomly allocated to usual outpatient care by the pulmonologist or to outpatient care by the nurse specialist. The intervention in research question 3 required GPs to provide a work environment for the nurse speciallist in their practice. Thus, instead of randomly allocating parients to the intervention or usual care, only patients from GPs willing to participate in the care-network could be allocated to the intervention group. Patients from GPs who preferred continuing the provision of usual care were allocated to the control group, and therefore use was made of a non-equivalent control group design (Cook \& Campbell, 1979).

The setring in which research question 4 was studied did nor offer the possibility to form a control group. However, with the availability of the control group of outparients with stable diabetes type 2 from the design applied for research question 3, we applied this control group here as well. The design used to answer question 4 is called an untreated comparison group design with pretest and posttest (Cook \& Campbell, 1979). Having the estimates of effects on quality of care derived from different study designs at our disposal, we were able to consider the association between methodological quality and the magnitude of the estimates.

To answer research question 1, the low disease activity criteria using the DAS28 were applied on patients with RA from the outpatient department of the university hospital Maastricht at three different moments during a 6-month period. For research 
question 2, we studied the literature using Medline Express for trials about the effectiveness and efficiency of care-network models with the nurse specialist in a central role, published between 1966 and January 1999. The feasibiliry of the support provided by nurse specialists to GPs in the early detection of COPD - research question 6 - was assessed by measuring the airflow obstruction of patients and differentiating patients diagnosed with COPD from patients without, on the basis of known risk factors. For details about the designs applied, we refer the reader to the following chapters which all include a section in which the design is described in greater detail.

\section{Operationalism and instrumentation}

In the central research questions of this dissertation, effects on quality of care are evaluated in terms of outcomes. According to the definition of quality by Donabedian, who stated that quality is the result of assessing the structures, processes, and outcomes (Donabedian, 1966), the focus here is put on one indicator of quality of health care. The care-network in which care is transferred from physician to nurse specialist is seen as a new structure that influences the processes - what care providers do and how they provide care - and indirectly influences the outcomes - the results of care delivery for parients in terms of outcomes. Processes of care in the care-nerwork with a central role for the nurse specialist are focus of the research by Eijkelberg et al. $(2000 ; 2001)$ and will only be considered in the discussion part of this dissertation. Separation of the assessment of processes and outcomes is induced by the divergent methods of assessment, while it is acknowledged that information from both is needed to reveal the effects on quality of care when delivered in the care-network wherein the nurse specialist performs a central role.

For the purpose of this research the following definition of outcomes is used: "states or conditions of individuals and populations atrributed or attriburable to antecedent health care' (Donabedian, 1992). According to Donabedian (1992), the best way to identify relevant outcomes is to ask: 'if we are successful in what we are doing, what change in patients or populations can we expect to achieve and detect?' A list of more usual outcomes pertinent to quality assessment was presented by Donabedian (1992) as well as by the UK Clearing House for Information on the Assessment of Health Services Outcomes (Long er al., 1993). Based on these classifications, a study group of the Dutch Organisation for Scientific Research (Driessen et al., 1994) presented a set of outcome-indicators with regard to the quality of care for chronically ill patients. This set is based on known objectives in the care for chronically ill people and includes survival, clinical parameters, health status, self-care behaviour, and patient satisfaction (Driessen et al, 1994). While these indicators assess the effectiveness of care, for the assessment of the efficiency of care the ourcomes thave to be related to the inputs. 
Clinical parameters were regarded to indicate if substitution is justified. To assess whether substitution really took place, consultations with main care-providers were assessed. Self-care, knowledge and patient satisfaction were regarded as indicators for the nursing"s orientation, that is attention to the patient with the disease. With the nurse specialist substituting for the physician in the care of parients with a stable chronic disease, survival was not considered as an outcome of the care-networks. General as well as disease specific instruments were applied to assess effects on clinical parameters, health status, self-care behaviour, and patient satisfaction. By measuring medical consumption, an indication for efficiency was provided. Assessing the cost-effectiveness of the care-nerworks was not the aim of this thesis. For details about the instruments applied we refer to the following chapters which all include a secrion in which the instrumentation is described in greater detail.

\section{OUTLINE OF THIS THESIS}

Chapter 2 presents the findings about the applicability of the low disease activity criteria using the DAS28 in assessing the stability of RA in outparients. The aim of this chapter is to assess the credibility of these criteria for selecting patients with stable RA out of an outpatient population with RA for enrolment in a care-network in which consultations are transferred from rheumatologists to nurse specialists.

Chapter 3 introduces chapters 4,5 , and 6 by reviewing the literature in order to answer two questions: (1) which outcomes are identified in publications about the effectiveness and efficiency of models of care for patients with diabetes type 2 or COPD when the nurse specialist has a central role in care delivery, and (2) are these models of care effective and efficient?

The effects on quality of care when care for patients with stable diabetes type 2 is transferred from physician to nurse specialist are reported in chapters 4 and 5 . Chapter 4 presents a study in the region of Maastricht where care for outparients with stable type 2 diabetes was transferred from endocrinologist to nurrse specialist and simultaneously from outpatient department to primary care. In Chapter 5 the findings of a study in the region of Venlo are presented. The study in this chapter evaluates effects on quality of care when care for patients with stable diabetes type 2 is transferred from GP to nurse specialist, both working in general pracrice.

Chapters 6 and 7 focus on the management of parients with COPD. Chapter 6 presents a study in the region of Alkmaar where the care for outpatients with stable COPD was transferred from pulmonologist to nurse specialist. By taking the results of the lung function measurement at the starting point, the predictive value of medical history and symptoms in the identification of parients at risk for airflow obstruction or COPD was assessed, as reported in Chapter 7. Moreover, patients who consulted their 
GP for reasons unrelated to respiratory disease were assessed for their respiratory function by medical students and nurse specialists.

A summary and discussion of the main findings are presented in Chapter 8. From the results of this thesis, recommendations with regard to the structure of care for chronically ill patients and for future research are addressed.

Because chapters 2 to 7 are based on research manuscripts published in scientific journals or submitted to a journal for publication, most of the chapters are written to stand alone and some reperition will be inevitable.

\section{REFERENCES}

Anonymous (1997). The world health report 1997 - conquering suffering, enriching humanity. World Health Forum 18:248-60.

Andreason LE, Coriar B, den Hertog F, Kaplinsky R (eds) (1995). Europe's next step: organisational innowation, competition and employment. Essex: Frank Cass.

Charlton I, Charlton G, Broomfield J, Mullee MA (1991). Audit of the effect of a nurse run asthma clinic on workload and patient morbidity in a general practice. The British Journal of General Practice $41: 227-31$.

Commissie Modernisering Curatieve Zorg (1994). Gedeelde zorg: betere zorg [Commission Modernising Curative Care. Shared care: better care]. Zoetermeer.

Cook TD, Campbell DT (1979). Quasi-experimentation. Design \& analysis issues for field settings. Rand McNally College Publishing Company, Chicago.

Donabedian A (1966). Evaluating the quality of care. The Milbank Memorial Fund Quarterly 44:166-203.

Donabedian A (1992). The role of ourcomes in quality assessment and assurance. Quality Review Bullerin $18: 356-60$.

Eijkellberg I, Mur-Veeman IM (2000). Veranderingsprocessen in de transmurale zorg IChange processes in integrated care]. In: Spreeuwenberg C, Pop P, Beusmans GHMI, Winkens RAG, Van Zurphen $\mathrm{H}$, eds. Handboek transmurale zorg. Maarssen: Elsevier Gezondheidszorg, 37-66.

Eijkelberg IMJG. Spreeuwenberg C. Mur-Veeman IM, Wolffenbuttel BHR (2001). From shared care to disease management: key-influencing factors. International Journal of Integrated Care 1(2). (accessed 4 Junce 2002)

Epstein RS, Sherwood LM (1996). From outcomes research to disease management: a guide for the perplexed. Annals of Internal Medicine 124(9):832-7.

Driessen S, Casparie AF, Van den Bos GAM (1994). Uitkornstindicatoren woor kwaliteitsbewaking en -bevordering in de zorg voor chronisch zieken [Outcome indicators for quality assurance and improvement in the care for chronically ill]. The Hague: Dutch Organisation for Scientific Research (NWO), study 4 from resarch programme Quality of Care.

Foulkes A, Kimmonth A, Frost S, MacDonald D (1989). Organized personal cares an effective choice for managing diabetes in general practice. The Journal of the Royal College of General Practitioners
39:444-7.

Grimes DA, Schulz KF (2002). An overview of clinical research: the lay of the land. The Lancer 359:57-61.

Hill J, Bird HA, Harmer R, Wright V, Lawton C (1994). An evaluation of the effectiveness, safery and acceptability of a nurse practitioner in a rheumatology outparient clinic. British Journal of
Rheumatology $33: 283-8$. 
Hopkins A. Solomon I, Abelson ] (1996). Shifting boundaries in professional care. Journal of the Royal Society of Medicine $89.364-71$.

Kernick D, Scott A (2002). Economic approaches to doctor/nurse skill mix; problems, pitfills, and partial solutions. The British Journal of General Practice $52: 42,-6$.

Leathard A, ed (1994). Groing Interprofessional: Working rogether for Health and Welfare. Rourledge, London.

Long AF, Dixon $P$, Hall R, Carr-Hill RA, Sheldon TA (1993). The outcomes agenda: contribution of the UK clearing house on health ourcomes. Quality in Health Care 2:49-52.

Mackinnon M. Malcolm R, Hardisry CA. Ward JD (1989). Novel role for specialist nurse in managing diabetes in the communiry. Bricish Medical Journal 299:552-4.

Mayo L (1956). Problem and challenge. In: Guides to acrion in chronic illness. New York: National Health Council.

McCallin A (2001). Interdisciplinary practicema manter of teamwonk: an integrated literature review. Journal of Clinical Nursing 10:419-28.

McKenna HP (1995). Nursing skill mix substiturions and quality of care: an exploration of assumprions from the research literature. Journal of Advanced Nursing 21:452-9.

Ministerie van Welzijn, Volksgezondheid en Cultuur Ministerie WVC] (1991). Notitie chronisch ziekenbeleir, chronische patiënten nier buiren spel [Ministry of Well-being, Public Health, and Culture. Policy for chronically ill, do not leave chronic pacients out of ic]. Den Haag: SDU uitgewerij.

Nationalle Raad voor de Volksgezondheid [NRV] (1989). Substiturie in de gezondheidszorg, discussienota [National Council of Public Healdh. Substitution in health care, discussion paper]. Zoetermeer.

Nationale Raad woor de Volksgezondheid/College voor Ziekenhuiswoorzieningen [NRV/CVZ] (1995). Transmurale, somatische zorg [Narional Council of Public Health/College for Hospital Services. Integrated, somatic care]. Zoetemeer.

Persoon A, Francke A, Temmink. D, Kerkstra A (1996). Transmurale zorg in Nederland: een inventarisatie op basis van bestandle gegevensbestanden [Integrated care in the Netherlands: an inventory based on. existing data files]. Urrecht: NIVEL.

Pop P. Spreewwenberg C(1998). Transmurale zorg in de tegio Mastricht IIntegrated care in the region of Maastricht]. Medisch Contact 53:91-4.

Ramisay JA, McKenzic JK, Fish DG (1982). Physicians and nurse pracritioners: do they provide equivalent health care? American Journal of Public Healn 72(1):55-6.

Starfield B (1992). Primary care: concept, evaluation, and policy. New Yortk: Oxford Universiny Press, 1992.

Spreuwenberg C (1994). (Net)werken voor chronisch zieken-inangurete rede [Neworking for chronically ill-inaugural lecture]. Universiteit Maastricht.

Stein LI, Warr DT, Howell T (1990). The doctor-nurse game revisited. New England Journat of Medicine $322: 546-9$.

Taylor C (1995). Rethinking nursing's basic comperencies. Journal of Nursing Care Qualicy 9:1-13.

Temmink D (2000). Transmural clinics: a nursing innovation explored. Dissertation. University of Maasrricht, Maastricht.

Van der Linden, BA (1997). Transmural care, facts and future, In: Schrijwers AJP editor. Health and health care in the Netherlands: a critical self -assessment of Dutch experts in the medical and health sciences. Urecht: de Tijdstroom, pp. $181-8$.

Van Duin NP, Menrink S (1998). We moeten langzamerhand wel erg veel. . Over het actief controleren van chronisch zieken (commentaar) [Gradually we really have to do allot... About active inspection of chronically ill (commentary)]. Huisarts \& Wetenschap 41:558-60.

Van Gestel AM, Prevoo MLL, Wan 't Hof MA, Van Rijswijk MH, Van de Parte LBA, Van Riel ILLM (1996). Development and validation of the European League Against Rheumatism response criteria for theumatoid arthritis: comparison with the preliminary American College of Rhematology and 
the World Health Organization/ Intemational League Againsw Rheumatism criteria Arthritis and Rhewmatism $39.34-40$.

Verhou WPM, Knomerus JA, Van Ooil A, Crebolder HFM, Pop P. Wesselingh-Mertens AMK, Betsmans GHMI (1995). Effectiveness of joine consultavon sessions of general practitioners and orthopaedic surgeons for locomotor-system disorders. The Lancet $346: 990-4$.

Vinicor $F$ (1995). Interdisciplinary and intersectoral approach: a challenge for integrated care. Patient Education and Counseling $26: 267-72$.

Wagner EH, Austin BT, Von Korf M (1996). Organising care for parients with chronic illness. The Milbark quarterly $74: 511-44$

Wagner EH (1997). Managed care and chronic illness: health serwices research needs. Healnh Service Research 32:702-14.

Yawr BP (2000), Who should care for people with chronic diseases? Wextern Journal of Medicine $172.77-8$. 


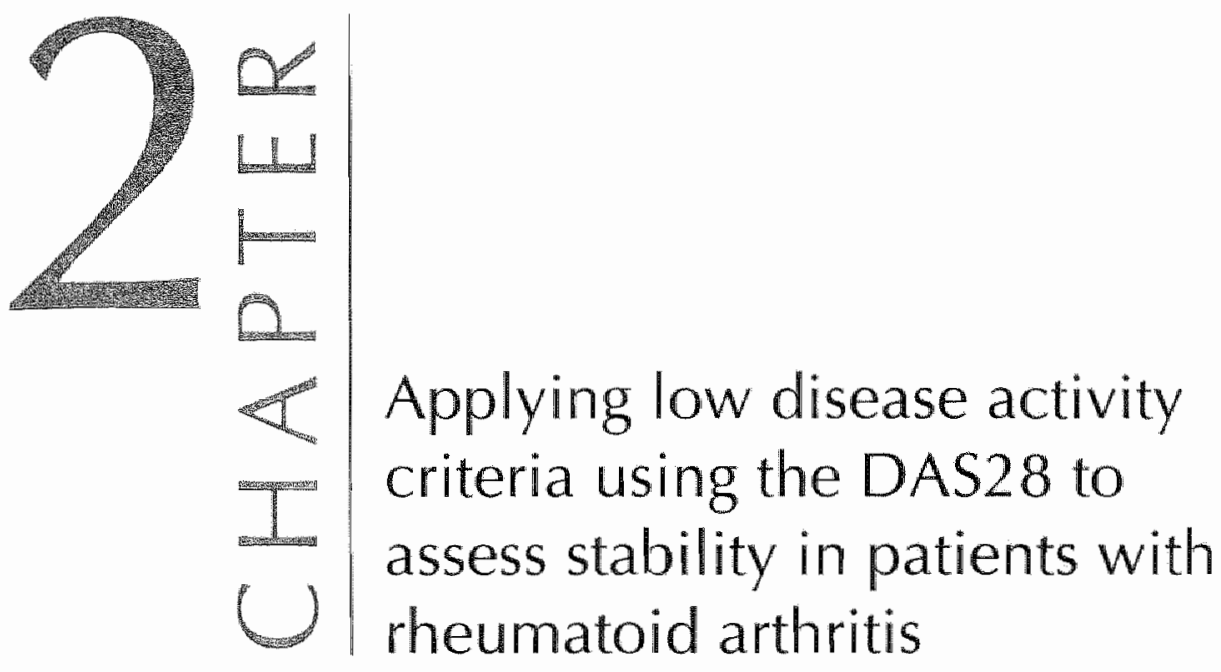

by Vrijhoef HIM, Diederiks JPM, Spreeuwenberg C, Van der Linden Sj.

Based on paper accepted by Annals of Rheumatic Diseases. 
This study examines whether low disease acrivity criteria using the DAS28 can be applied to identify a reasonable large number of patients with a stable low disease activity over a 6 -monch period with the ultimate intention to include these patients into a substitution based integrated care model. Also the reliability of the DAS28 for selecting stable patients out of an ourpatient population was assessed.

Patients regularly seen at the rheumatology outpatient department of the university hospital Maastricht, were invited for assessment of the stability of their theumatoid arthritis. The integrated care model was intended to provide care to patients with stable, Jow disease activity of rheumatoid arthritis by nurse specialists. For this, patients underwent assessments using the DAS28 at entry, three and six months later. Test-retest reliability was assessed for composing measures as well as for the DAS28.

Of the 97 outpatients included, one third (31 parients) did not complete the study. Patients with missing data were older and assessed their disease activity higher than patients with complete data. Applying the low disease activity criteria to assess stability over a period of six months (DAS28(T0) $\leq 3.2$ and DAS28(T6)-DAS28(T0) $\leq 1.2$ ) resulted in a proportion of patients with stable, low disease activity of rheumatoid arthritis of $39.3 \%$. Good similarity score (ICC $=0.82$ ) for the DAS28 was found.

The low disease activity criteria using the DAS28 seem to be applicable to select patients with stable, low disease activity of rheumatoid arthritis our of a rheumatic outpatient population.

\section{INTRODUCTION}

Recently different new models of organising care for chronic parients have been introduced to optimise the treatment of the growing number of chronically ill people in Western countries (Van der Linden, 1997). In the care for medically stable chronic parients, medical specialists can allocate activiries to other health professionals, allowing them to shift their attention towards managing patients with more 'serious" problems (Jenkins-Clarke et al., 1998; Richards et al., 2000; Vrijhoef et al., 2001). Stable in this conrext means constant low activity of the chronic disease, i.e. without flares. These substitution-based models are believed to be better approaches to planning and delivering health care to the chronically ill (Davis et al., 2000).

In rheumatoid arthritis (RA) the concept and definition of stability is more troublesome than in chronic diseases like diabetes mellitus or chronic obstructive pulmonary disease. The activity of RA cannor be simply expressed by one single parameter and the presentation of RA may vary substantially over time between patients as well as within the same individual, considering the not infrequently occurrence of flares (Van 
Gestel er al., 1996). Nevertheless, for RA too-a chronic disease for which the number of patients is predicted to rise-substiturion-based models of care are gaining interest (STG 1991; Davis et al., 2000).

Disease stabilicy is derived from measurements of disease activity, which have a central place in the management of RA, because reducing disease acrivity is the paradigm of treatment of RA. Measures of rheumaric disease activiry can be classified as both process and outcome measures (Kirwan, 1992). Kirwan (1992) defined process as "the abnormal physiological consequences that follow from the cause of the disease" and outcome as the suffering or loss of health (death, disability, discomfort, iatrogenic, economic) of the parient caused by the disease process.' Agreement on what to measure to assess disease activity in RA has been reached borh in Europe (European League Against Rheumatism - EULAR-core-set) as well as in the USA (American College of Rheumatology - ACR - core-set) (Boers et al., 1995).

Notwithstanding the consensus about which endpoints to measure when assessing disease activity (both core-sets comprise process measures), the definition of rheumatic stability, as derived from subsequent measurements of rheumatic activity, still varies. Disease stability can be defined as the lack of - within certain limits-changes or flucruations in parameters of a disease within a defined period of rime. For assessing disease stability a time component has to be included in the measure: based on subsequent measures of disease activity, the degree of disease stability can be assessed.

From the EULAR core-ser the so-called EULAR response criteria were derived, while based on the ACR core-set criteria for improvement have been developed. The latter define change as a difference of $20 \%$ or more in subsequent measurements of tender and swollen joint counts and a difference of $20 \%$ or more in at least three out of five remaining measures (Felson et al., 1995). The EULAR response criteria make use of a disease activity score (DAS28) derived from four measures and, in addition to change in disease acrivity from baseline, also takes the level of disease activiry attained during follow-up into account when defining response (Van Gestel et al., 1996; Van Gestel et al., 1998). Considering these definitions within the context of assessing stability in this study also a low disease activity at baseline is necessary. Otherwise patients with severe RA are classified as having stable, low disease activity of RA and consequently not managed adequately. Thus, only the EULAR response criteria seem to allow application to assess stability although they thave not originally been developed for this purpose. Besides, although the use of these criteria to include patients has been advocated before (Van Gestel et al., 1996), no study is yet known to report the results of this particular application.

This study examines whether low disease activity criteria using the DAS28 can be applied to identify a reasonable large number of patients with a stable low disease activity over a 6 -month period with the ultimate intention ro include these patients into a substitution based integrated care model. 


\section{Patient selection}

All patients, who were receiving care by rheumatologists at the rheumarology outpatient department of the university hospital Maastricht and known to have RA, according to the criteria of the ACR (Amett et al., 1988), were identified.

An explanatory letter with informed consent form and postage-free envelope were mailed to parients with RA. Only those parients were invited who had been referred by general praccitioners willing to have the RN in their practice in case the model would be implemented in clinical practice after completion of this feasibility study. After having given their informed consent, patients were scheduled for assessment of disease acrivity by a RN in the outpatient department of the hospital. Three assessments were scheduled: at entry (T0), three months (T3) and six months later (T6). Just before every assessment patients were sent a self-report form and asked to complete this on the day of assessment and to hand it in to the RN. Three months was chosen as the interval berween measurements of stability because this period of time is often applied by many physicians when seeing stable chronic parients. Assessments were performed berween April 1998 and February 1999.

\section{Measures of disease activity}

The number of swollen and the number of tender joints were borh assessed by 28 joint counts (Prevoo et al., 1993). For this a mannequin, consisting of a stick figure drawing of a person with each joint indicated by a circle, was used. In case of a tender or swollen joint the RNs ticked the appropriate circle (range 0-28). A five-point Likert scale (1 = asymptomatic, 2 = mild, $3=$ moderate, $4=$ severe, 5 =very severe) was used for global assessment of disease activity by the patient (Scott et al., 1993). Blood samples were taken to determine Westergren erythrocyte sedimentarion rate (ESR in mm after 1 hour). The Disease Activiry Score (DAS28) was calculated using ESR, number of tender and swollen joints assessed by the nurse, and patient's global assessment of disease activity (Prevoo et al., 1995; Van Gestel et al., 1996; Van Gestel et al., 1998). This score may range from 0 to 9.3, where a DAS28 score $\leq 3.2$ is considered to reflect low discase activity and a DAS28 score $>5.1$ high disease activity (Van Gestel et al.,
1998

\section{Stability criteria}

Applying the DAS28 to define a low and stable disease activity, patients are classified as having stable RA if at baseline the DAS28 was $\leq 3.2$ (low current disease activity) 
and between baseline and last post-measurement the difference in DAS28 scores was $\leq 1.2$. This difference is two rimes the measurement error and is considered to be a statistically significant change in disease activicy (Van Gestel et al., 1998).

\section{Statistical analysis}

Baseline comparisons berween parients with and without complete data were performed with Student's i-test, Pearson chi-square and Mann-Whirney U-test. Test-retest reliability was assessed with the intraclass correlation coefficient (ICC), using the scores obtained at the three measurements (Bravo \& Potvin, 1991). The findings from the application of the DAS28 assess stability were expressed as proportions.

Data processing and analyses were conducted with SPSS (Windows Release 9.0).

\section{RESULTS}

\section{Patients}

One hundred and nine patients were eligible for the study, of whom 97 gave informed consent. Reasons for not giving informed consent were lack of interest $(n=4)$ or unknown ( $\mathrm{n}=8)$. After giving informed consent 66 patients $(68 \%)$ completed the study. The reasons for 31 patients $(32 \%)$ dropping out were loss of interest $(\mathrm{n}=9)$ or unknown $(n=22)$.

Comparison of groups with and withour data at all measurements revealed a statistically significant difference in that older patients with missing data on average reported a higher mean score for both global assessment of disease activity and DAS28 (Table 1). The presence of data at all measurements does not imply complete data. Moreover, for 56 patients complete data were available, while for 10 patient the score on one or more variables at one or more measurements was absent.

\section{Reliability of measurements for stability assessment}

Assessment of reliability of measurements at the three measurements showed moderate ICCs (0.6-0.8) for tender and swollen joints assessed by the nurse (Table 2 ). Good ICCs ( $>0.8-0.9)$ were found for global assessment of disease activity, and DAS28, while very good ICC $(>0.9)$ was found for ESR. 
Table 1

Baseline characteristics of patiens with all measurements and parients with missing measurements

\begin{tabular}{|c|c|c|c|}
\hline $\begin{array}{l}\text { Chancteristic } \\
\text { (mean } \pm \text { sd) }\end{array}$ & $\begin{array}{l}\text { Complete } \\
\text { measurements } \\
(n=66)\end{array}$ & $\begin{array}{l}\text { Missing } \\
\text { measurements. } \\
(n=31)\end{array}$ & $p$-value \\
\hline Age (yrs) & $62.7 \times 12.4$ & $68.6 \pm 11.9$ & $0.030^{\pi}$ \\
\hline Sex (\% male) & 43.9 & 54.8 & $0.316^{b}$ \\
\hline Tender joints & $2.7 \pm 3.2$ & $3.9 \pm 4.4[27]$ & $0.165^{\text {a }}$ \\
\hline Swollen joints & $3.3 \pm 3.1$ & $4.1 \pm 2.9[28]$ & $0.275^{\mathrm{a}}$ \\
\hline $\mathrm{ESR}(\mathrm{mm} / \mathrm{hr})$ & $18.3 \pm 17.0[63]$ & $24.5 \pm 25.0[27]$ & $0.176^{\mathrm{a}}$ \\
\hline Global DAd & $3.0 \pm 1.0[62]$ & $3.5 \pm 0.9[24]$ & $0.035^{\mathrm{a}}$ \\
\hline$D A S 28$ & $2.9 \pm 1.0[6]\rfloor$ & $3.5 \pm 1.0[22]$ & $0.050^{\circ}$ \\
\hline
\end{tabular}

[1 number of parients for whom data is used in case data was not available for whole group; "Student"s t-test; "Pearson Chisquare; "Mann-Whitney U-test; " Global assessment of disease activity

Table 2

Intraclass correlation coefficient (ICC) for measurements of activiry

\begin{tabular}{|c|c|c|c|c|c|c|}
\hline \multirow[t]{2}{*}{ Measurement } & \multirow[t]{2}{*}{ N } & \multicolumn{3}{|l|}{ Mean $\pm s d$} & \multirow{2}{*}{$\begin{array}{l}\text { Intraclass correlation } \\
\text { coefficient }^{d}\end{array}$} & \multirow[t]{2}{*}{$95 \% \mathrm{Cl}$} \\
\hline & & $10^{a}$ & $\mathrm{~T} 3^{\mathrm{b}}$ & $76^{\circ}$ & & \\
\hline Tender joints & 65 & $2.8 \pm 3.2$ & $3.2 \pm 3.3$ & $3.4 \pm 3.8$ & 0.74 & $0.61-0.83$ \\
\hline Swollen joints & 65 & $3.4 \pm 3.1$ & $2.8 \pm 2.9$ & $2.7 \pm 3.0$ & 0.80 & $0.70-0.87$ \\
\hline ESR (mm/hr) & 60 & $18.6 \pm 17.4$ & $20.4 \pm 19.2$ & $22.5+17.6$ & 0.94 & $0.91-0.96$ \\
\hline Global DA ${ }^{\circ}$ & 62 & $6.4 \pm 1.4$ & $6.5 \pm 1.6$ & $6.4 \pm 1.7$ & 0.86 & $0.79-0.91$ \\
\hline DAS28 & 56 & $3.0 \pm 1.0$ & $3.2 \pm 0.9$ & $3.2 \pm 1.1$ & 0.82 & $0.72-0.89$ \\
\hline
\end{tabular}

"T0 measurement at start; ${ }^{\text {b } T 3}$ measurement three months after statt; ${ }^{c} \mathrm{~T} 6$ measurement six months after start; ${ }^{\mathrm{d}} \mathrm{p}<.001 ;{ }^{\mathrm{c}}$ global assessment of distase acrivity

Table 3

Scores of parients on DAS28 at baseline, six months later, and differences berween scores at baseline and six months later

\begin{tabular}{|c|c|c|c|c|c|}
\hline \multirow[t]{2}{*}{$\mathrm{TO}^{\mathrm{in}}$} & \multirow[t]{2}{*}{ T6- To } & \multicolumn{3}{|l|}{$166^{\circ}$} & \multirow[t]{2}{*}{ Total } \\
\hline & & $\leq 3.2$ & $>3.2$ but $\leq 5.1$ & $\geq 5.1$ & \\
\hline \multirow[t]{2}{*}{$\leq 3.2$} & $\leq 1.2$ & 18 & 4 & 0 & 22 \\
\hline & $>1.2$ & 0 & 4 & I & 5 \\
\hline \multirow[t]{2}{*}{$\$ 3.2$ but $\leq 5.1$} & $\leq 12$ & 11 & 15 & 0 & 26 \\
\hline & $>1.2$ & 0 & 1 & 0 & 1 \\
\hline \multirow[t]{2}{*}{$>5.1$} & $\leq 1.2$ & 0 & 0 & 2 & 2 \\
\hline & $>1.2$ & 0 & 0 & 0 & 0 \\
\hline Toul & & 29 & 24 & 3 & 56 \\
\hline
\end{tabular}

"To measurement at start; 16 measurement six months afver start 


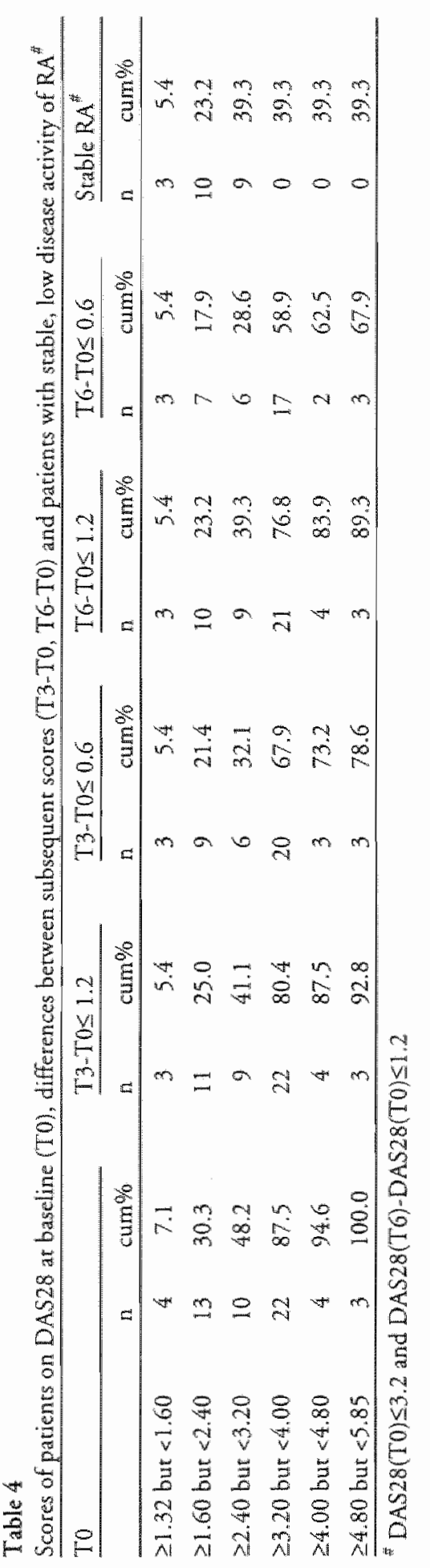


Applying the DAS28 resulted in low disease activity in almost half $(n=27 ; 48.2 \%)$ of the patients at baseline (Table 3). The difference in DAS28 between baseline measurement and last post-measurement was for most patients $(n=50 ; 89.3 \%)$ under the 1.2 . At T6 18 patients (32.1\%) can be classified as having stable, low disease activity of RA, while 11 patients $(19.6 \%)$ changed from having medium activity of RA to having low disease activity of RA.

Four patients with low disease activity of $\mathrm{RA}$ at baseline did not change more than 1.2 DAS28-points but had medium disease activity of RA six months after baseline measurement. Berween baseline and first post measurement $92.8 \%$ did not change more than 1.2, while between baseline and last post measurement $89.3 \%$ of patients did not change more than 1.2 DAS28-points (Table 4). When the allowed change was ser at 0.6 (one times the measurement error), these proportions were $78.6 \%$ and $67.9 \%$ respectively. Applying the low disease activity criteria, that is a DAS2 8 baseline score $\leq 3.2$ and a difference $\leq 1.2$ between DAS28 scores at baseline and last post-measurement, tesulted in stable low disease activity of RA in $39.3 \%(\mathrm{n}=22)$ of the patients.

\section{DISCUSSION}

The disease activity of outpatients with RA was assessed on several occasions with the ultimate intention to include these patients in an integrated care model. For this assessment, low disease acrivity criteria using the DAS28 were applied. The DAS28 is developed to measure a clinically relevant decrease in disease activity resulting from a treatment. In this study, however, the DAS28 was used for a different purpose, that is to assess disease stability by defining stability as "the lack of - within certain limits changes or fluctuations in parameters of a disease within a defined period of time,' where the 'limits' were defined by the EULAR response criteria. Without the existence of a golden standard to assess stability in RA, the findings of these study are not always unambiguous to interpret.

In this study it was found that 22 patients (39.3\%) could be classified as having stable, low disease activity of RA. The defined extent of change (1.2 DAS28-points) raises an important issue. A patient with an initial DAS28 of 3.2 and 4.4 at last follow-up has, according to this change, srable RA while his/her index-score increases between first and last measurement by $37.5 \%$. When the defined extent of change was 0.6 DAS28-points, 16 patients (28.6\%) at T6 showed stable, low disease activity of RA. When applying the DAS28 baseline score at all measurements (DAS28(T0) $\leq 3.2$ 
and DAS28(T3) $\leq 3.2$ and DAS28(T6) $\leq 3.2)$, the same 16 parients $(28.6 \%$ ) showed stable RA.

The result of assessing about $39.3 \%$ of patients as having stable, low disease activity of RA might be regarded as remarkable in a disease like RA. Furthermore, in the lighr of substituting care this finding gains importance with an increase in the number of patients with RA treated on a rheumatology outpatient department.

The interwal of three months berween measurements was derived from medical practice in which patients usually do not see the physician more often than four times a year. Borh for establishing the oprimal number of consultarions for patients with stable RA, and for the purpose of stability assessment, furcher research into the length of the interval between measurements should be initiated.

The loss of one third of the group of patients needs attention. The parients with missing data were older, reported a higher mean DAS28 score, and higher mean global disease activity. It is conceivable to assume that these parients had more often non-stable RA. If data had been available for these non-stable patients, the ICCs would have been smaller.

With respect to the ICC, it might well be that identical scores are obtained in successive administrarions, thus resulting in high value for the ICC, but that the actual units checked differ greatly. Based on the ICCs of the response criteria, a rather stable group of parients was identified.

In conclusion, this study shows the feasibility of assessing disease acrivity of outpatients with RA. Although developed to measure response we applied the DAS28 to assess stabilicy, i.e. low disease activity in RA of patients for the purpose of including parients in another study. A minority of outpatients could be classified as having stable, low disease activity of RA. This finding suggests that RA is a suitable chronic disease to unfold a substitution based model of care delivery.

\section{ACKNOWLEDGEMENTS}

This study was supported by a grant from Stimuleringsprogramma Gezondheidsonderzoek [Incentive Programme for Health Care Research] and Nationale Commissie Chronisch Zieken [National Committee Chronically III]. The authors gratefully acknowledge the help of Yvonne van Eijk and Ilse Klein Goldewijk in measuring parients' stability and their assistance with data processing. 
Arnet FC, Edworthy SM, Bloch DA, McShane Df, Fries JF, Cooper NS, er al. (1988). The American Rherumatisn Association 1987 revised criteria for the cilassification of theumatoid arthritis. Arthritis Rheurnatism $31: 315-24$.

Boers M, Van Riel PLCM. Felson D. Tugwell P (1995). Assessing the activiry of rheumaroid arthritis. Cinical Rheumatology 9:305-17.

Bravo $G$, Potvin $\mathbb{L}$ (1991). Estumating the reliabiliry of continuous measurements with Cronbach's alpha or the intraclass correlation coefficient: Toward the integration of two traditions. Journal of Chinical Epiderniology $44: 381-90$.

Davis RM, Wagner EG, Groves T (2000). Advances in managing chronic disease. Brivish Medical Journal $320: 525-6$.

Fetson DT, Anderson ]J, Boers M, Bombardier C, Furse D, Goldsmith C, et al (1995). American College of Rheumarology preliminary definition of improvement in rheumatoid arthritis. Arthris $\&$. Rheumarism $38: 727-35$.

Jenkins-Clarke S, Carr-Hill RA, Dixon P (1998). Teams and sems: skill mix in primary care, Journal of Advanced Nursing 28:1120-6.

Kirwan JR (1992). A theoretical framework for process, outcome and prognosis in theumatoid ardhrits. Journal of Rheumatology 19:333-6.

Prevoo MLL, Van Riel PLCM, Van ' HofMA, Van Rijswijk MH, Van Leeuwen MA, Kuper HH, er al. (1993). Validity and xeliabiliry of joint indices. A longitudinal study in patients with recent onset theumatoid arthritis. Brirish Journal of Rheumatology 32:589-94.

Prevoo MLL, Van " Hof MA, Kuper HH, Van Leuwer MA, Van de Putre LBA, Van Riel PLCM (1995). Modified discase activity scores that include twenty-eighe joint counts. Development and validarion in a prospective longitudinal study of patients with rheumatoid arthritis. Arthritis \& Rheumarism 38:44-8.

Richards A, Carley J, Jenkins-Clarke S, Richards DA (2000). Skill mix berween nurses and doctors working in primary care-delegation or allocation: a review of the literature. International Journal of Nursing Studies 37:185-97.

Scotr DL, Van Riel PL, Van der Heide D, Benke AS (1993). Assessing disease activity in theumatoid arthritis. The EULAR handbook of standard methods.

Stuurgroep "Toekomstscenario's Gezondheidszotg (STG) (1991). Chronische ziekten in her jaar 2005: scenario"s over reumatoide artritis 1990-2005. [Steering Committee on Projections in Health Care. Chronic illnesses in the year 2005: projections for rheumaroid arthricis 1990-20051. Houren: Bohn Staflew wan Loghurm.

Varu der Linden BA (1997). Transmural care. Facrs and future. In: Schrijvers AJP eds. Health and health care in the Netherlands: a critical self assessment of Dutch experts in the medical and healet sciences. Ureche: De: Tijdstroom, 181 1.8.

Van Gestel AM, Prevoo MLL, Van "t Hof MA, Van Rijswijk MH, Van de Putte LBA, Van Riel PLCM (1996). Development and validation of the European League Against Rheumatism response criteria for theumaroid anthritis: comparison with the preliminary American College of Rheumatology and the World Health Organization/Intemarional League Against Rheumatism criteria. Arthritis $8 x$
Rheumatism $39: 34-40$.

Van Gestel AM. Haagsma C., Van Riel PLCM (1998). Validation of rheumatoid arthriris improvement criteria that include simplifed joint counts. Arthritis \& Rheumatism 41:1845-50.

VrijhoefHJM, Spreeuwenberg C, Eijkelberg IMJG, Wolffenbuttel BHR, Van Merode GG (2001). Adoption of disease management model for diaberes in region of Maastricht. British Medical Journal
$323.983-5$. 


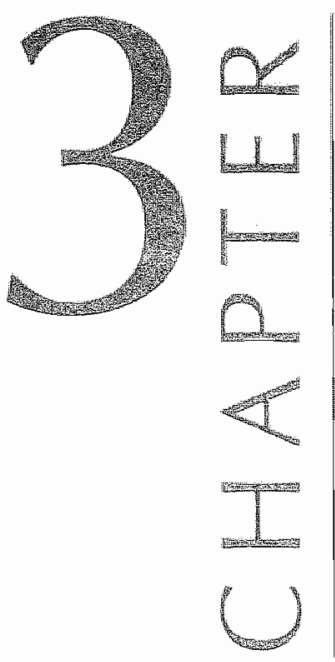

Effects on quality of care for patients with type 2 diabetes or COPD when the specialised nurse has a central role: A literature review

by Vrijhoef HIM, Diederiks IPM, Spreeuwenberg $C$.

Based on paper published in Patient Education and Counseling 2000:41:243-50. 
Chronic care has to be organised in a way that care from any one caregiver is linked up to that provided by others so that disturbing gaps, contradictions and overlaps are avoided. In the search for the most effective and efficient combinarion of health professionals to deliver care to chronic patients, the role of the specialised nurse has become important. This article reviews a Medline search for publications about effects of models of care for patients with diabetes type 2 or COPD in which the specialised nurse has a central role. Main features of the models are identifted and related to expected and statistically significant effects. In this young domain of effect evaluation ten publications met our criteria. Depending on the division of tasks between care providers improvements are seen in self-care, quality of life, parient satisfaction as well as increased medical consumption. More, methodologically suitable evaluations with the use of only valid measures are needed.

\section{INTRODUCTION}

New concepts about the care for chronically ill patients require changes in existing health care systems. The growing number of patients with a chronic disease such as diaberes mellitus or chronic obstructive pulmonary disease (COPD) leads to an increase in the costs of care. The world's diabetic population will probably have doubled from an estimated 110 million in 1994 to 221 million in 2010 (Amos et al., 1997) and despite less reliable statistics for COPD across countries, the prevalence rates of COPD are expected to increase as well (Siafakas et al., 1995).

This has resulted in pressure on the limited resources available for health care. Moreover it is recognised that the needs of chronically ill people place specific demands on health care systems. In addition to the treatment of the disease, attention for the total functioning of the sick person has to be assured. Caregivers have to be more initiators and less respondents so that patients receive preventive interventions, systematic assessments, education, psychosocial support and counseling (Wagner et al., 1996). Parients have to be encouraged to execute self-management tasks (Wagner et al., 1996). And to achieve compliance with long term care follow-up is required (Wagner et al., 1996).

The way medical care is organised at present in Western countries is to meet the acute and urgent needs of patients. However, chronically ill people need general and specialised care simultaneously. To meer the needs of chronic parients, different caregivers and patients themselves have to be involved in care. Co-ordination and continuity of care are needed so that all these parts of care and the caregivers mesh well to achieve "tailor-made" or 'high-quality' care. This means that chronic care has to be 
organised in a way that care from any one caregiver is linked up to that provided by others so that disturbing gaps, contradictions and overlaps are avoided (Van Achterberg, 1997).

These developments have resulted in the introduction of different forms of organising chronic care. Integrated care (United States of America), shared care (United Kingdom) and 'transmuralle zorg' (The Nerherlands) are models of organising care that pay heed to the pressure on the quality and costs of chronic care (Van der Linden, 1997). In all these models the kind of relationships between caregivers involved can be characterised. A distinction can be made between complementary relationships and substirution relationships (McGillis Hall, 1997; Scheffler et al., 1996). In complementary relationships the performance of tasks of care is divided between caregivers of different categories in accordance with their level of expertise (McGillis Hall, 1997). When the performance of tasks of care is divided between caregivers by transferring tasks, the relationship is substitution-based (McGillis Hall, 1997; Scheffler et al, 1996). Horizontal substitution refers to the transfer of tasks between caregivers within one level of expertise. Tasks can be transferred from specialist to generalist or from inside the hospital to outside the hospital. The transfer of tasks between caregivers of different levels of expertise is referred to as vertical substitution (Spreeuwenberg, 1994).

In the search for the most effective and efficient combination of health professionals to deliver care for chronic patients, the role of specialised nurses has become important. Specialised nurses perform tasks that traditionally belonged to the domain of the physician, and work inside the hospital - specialised care - as well as outside general care. In their review of the literature, Scheffler et al. (1996) expect a major contribution of substitution models of care in terms of productivity. They also mention "the challenges in measuring variations in patient outcomes associated with specific outpur measures.'

We looked at models of care for chronic patients where the nurse has a central role in order to answer two questions: (1) which outcomes are identified in publications about the effectiveness and efficiency of these models, and (2) are these models of care effective and efficient? After searching for publications about these models in the literature, we compared the models on their main features. We selected the identified or expected effects as well as the statistically significant effects on quality of care, then relared these to each other and related the significant effects to the main features of the models. Our interest was generated by the start of a pilot project in Maastricht (The Netherlands) in which the specialised nurse has a central role in the care for patients with diabetes type 2 or chronic obstructive pulmonary disease (COPD). 
A search of Medline Express was made for studies published between 1966 and January 1999 , although a review of only published sources may be subject to bias (Dickersin, 1990). Medline Express contains all citations published in Index Medicus and also corresponds in great part to the International Nursing index. 'Nurse' was entered as keyword and combined with 'effect,' 'outcome(s)' and 'effecriveness.' Studies had to meet four criteria. First they had to be published in English or Dutch or have an abstract in these languages. Second, the design had to be a clinical trial or a randomised clinical trial. Third, patients were restricted to those with diabetes type 2 or COPD and they had to be adults. Finally, the intervention had to deal with nursing care as its main aspect.

The comparability of care models was assessed by looking at several characteristics: type and number of patients, type of care, main caregiver, tasks of the main caregiver, frequency of planned contact with patients, period of intervention and context or country in which the intervention took place. Four tasks of the main caregiver we distinguished based on the intervention planned in Maastricht: direct patient care, organisation and co-ordination of care for individual patients, consultation, and promotion of expertise. Direct parient care includes: anamnesis, physical examination, laboratory requests, giving information and the administration of findings from these activities. Organisation and co-ordination of care refer to activities concerning the continuiry of care between caregivers. Consultation refers to those consulrs given to caregivers or parients in the case of complex situations. Promotion of expertise is about teaching other caregivers or patients and one's own education. If one or more of these activities were mentioned, we assumed the presence of the task.

The publications we examined for expected outcomes and statistically significant differences in outcomes between the experimental and the control group. Expecred and significant outcomes were related to each other and to the characteristics of the models. Finally conclusions were formulated with regard to effects on the qualiry of care of models for chronically ill where the nurse fulfils a central role.

\section{RESULTS}

\section{Selected publications}

Entering the keywords and using the criteria yielded ten publications (Aubert et al., 1998; Beck et al., 1997; Blake et al., 1990; Brewin \& Hughes, 1995; Cockitoft et al., 1987; Estey et al., 1990; Kirkman et al., 1994: Litrlejohns et al., 1991; Mulloy et al., 1996; Weinberger et al., 1996). Of these studies eight included patients with one 
specific disease (Aubert et al., 1998; Blake et al, 1990; Brewin \& Hughes, 1995; Cockroft et al., 1987; Estey et al., 1990; Kirkman er al., 1994; Littlejohns et al., 1991; Mulloy et al., 1996) while two studies included patients with different diseases (Beck et al., 1997; Weinberger et al., 1996) (Table 1). The biggest numbers of respondents were reported in the studies with different diagnoses. Response rates in these studies were lowest and did not reach $50 \%$.

\section{Organisation of care}

All interventions consisted of a nurse as the main caregiver in the experimental group (Table 1). Interventions were compared with 'usual care' in the control group which consisted of education in one study (Estey et al., 1990), of primary care in two studies (Aubert et al., 1998; Kirkman et al., 1994) of outpatient care in six studies (Beck et al., 1997; Blake et al., 1990; Estey et al., 1990; Littlejohns et al., 1991; Mulloy et al.. 1996; Weinberger et al., 1996), of inpatient care in one study (Brewin \& Hughes, 1995) and of a combination of impatient and outpatient care in one study (Cockroft et al., 1987).

In three studies (Aubert et al., 1998; Littlejohns et al., 1991; Weinberger et al., 1996) we identified the performance of three or four tasks by the main caregiver to patients of the experimental group (Table 2). The effects of an intervention wirh a single task - promotion of expertise - were evaluated in four studies (Blake et al., 1990; Brewin \& Hughes, 1995; Cockroft et al., 1987; Mulloy et al., 1996). In the remaining three studies promotion of expertise was accompanied by consultation (once) (Estey et al., 1990) or organisation and co-ordination (twice) (Beck et al., 1997; Kirkman et al., 1.994).

Promotion of the expertise of patients was present in all studies. Organisation and co-ordination of care was executed by the nurse in five studies (Aubert et al., 1998; Beck et al., 1997; Kirkman et al., 1994; Littlejohns et al. 1991; Weinberger et al., 1996). Consultation and direct patient care came less frequently under the work of the nurse. Direct patient care was mentioned in two studies and in both of studies was accompanied by the tasks organisation and co-ordination and promotion of expertise (Aubert et al., 1998; Littlejohns et al., 1991).

The studies identified took place in different countries: the United States of America five (Aubert et al., 1998; Beck et al., 1997; Blake et al., 1990; Kirkman er al., 1994; Weinberger et al., 1996), Great Britain three (Brewin \& Hughes, 1995; Cockroft et al., 1987; Littlejohns et al., 1991), and Canada and Ireland one each (Estey et al., 1990; Mulloy et al., 1996). In the studies in Canada and in the United States (except one (Blake et al., 1990)) nurses fulfilled two or more tasks, while in studies in Ireland or Great Britain nurses mostly fulfilled just one task: promotion of expertise. 


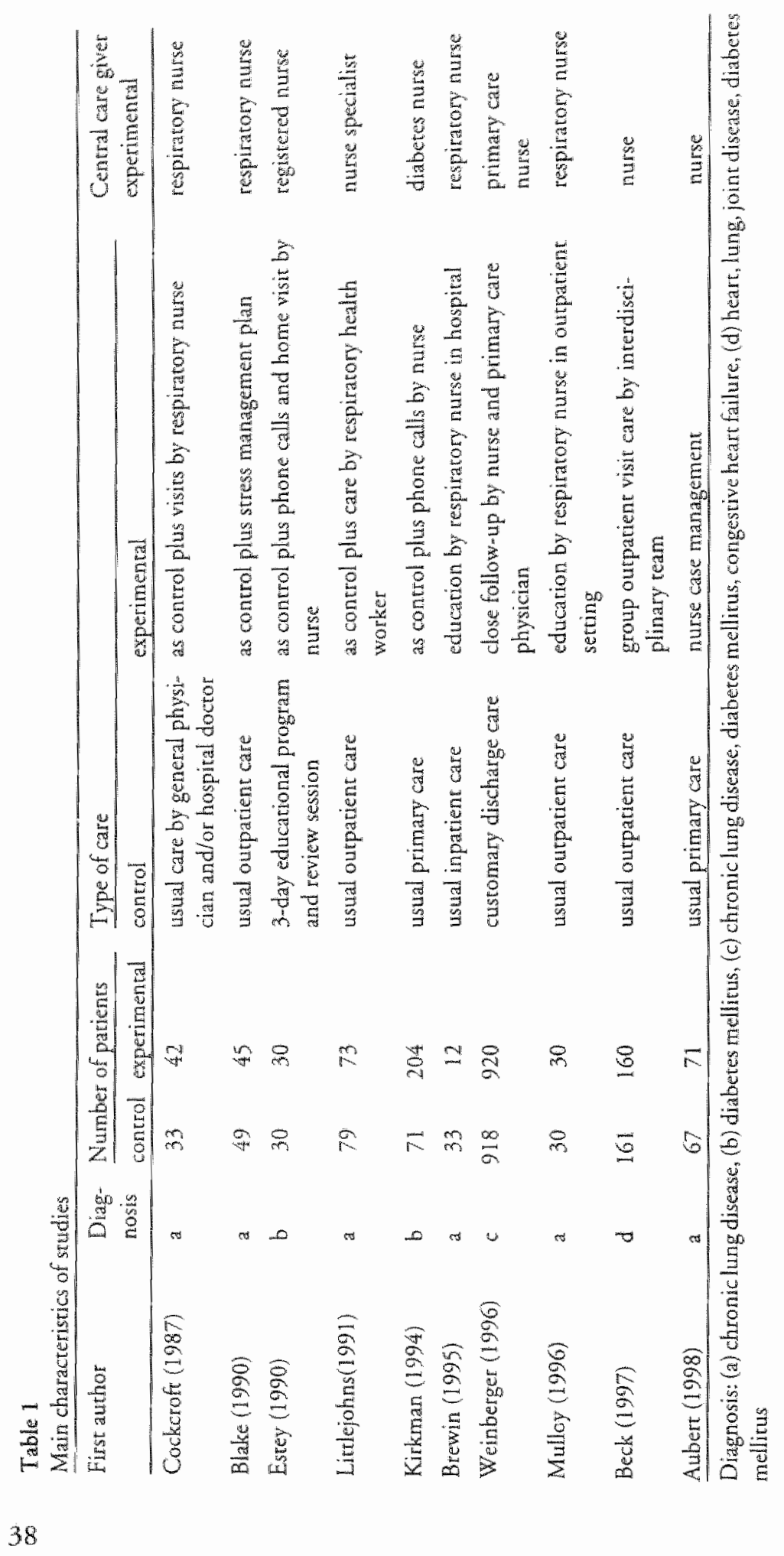




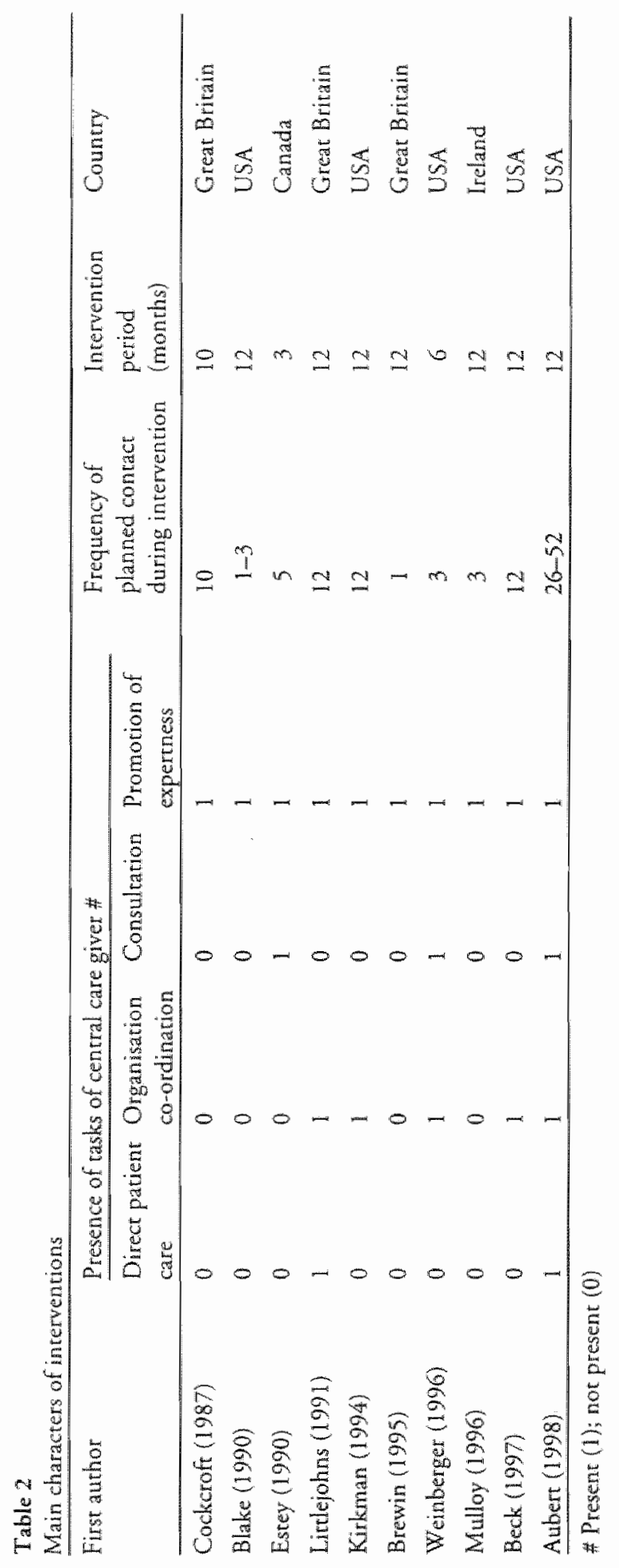


Twelve months seemed to be the most common length of intervention (seven studies) (Aubert et al., 1998; Beck et al., 1997; Blake et al. 1990; Brewin \& Hughes, 1995; Kirkman et al., 1994; Lirtlejohns et al., 1991; Mulloy et al., 1996). The frequency of planned contacts berween the main caregiver and patients ranged from weekly to yearly. In six studies the planned visit was once or twice monthly (Beck et al, 1997; Cockroft er al., 1987; Estey et al., 1990; Litulejohns et al., 1991; Kirkman et al, 1994; Weimberger et al., 1996).

\section{Effects on quality of care}

In the selected studies, effects in one or more of the following ourcomes were expected: survival, clinical parameters (for example: forced expiratory volume, glycosylated haemogllobin), quality of life, self-care and knowledge, patient satisfaction, medical consumption. Medical records were used to assess survival and medical consumption. Clinical parameters were measured in standardised ways and documented in reports as well. To assess quality of life, self-care, and patient satisfaction questionnaires or interviews were used. Quality of life is in all studies measured with validated instruments. To assess self-care and patient satisfaction not always use is made of validated instruments. Self-care is assessed in different ways depending on the activities inwolved. Patient sarisfaction is measured with self designed instruments in two studies (Kirkman et al., 1994; Weinberger et al., 1996). In all studies statistically significant effects were found in at least one outcome (Table 3).

Improvement in self-care and quality of life were found most often (in four (Brewin et al., 1995; Cockroft et al, 1987; Estey et al., 1990; Mulloy et al., 1996) and three sudies (Aubert et al., 1998; Blake et al, 1990; Estey et al., 1990) respectively). Lower costs were reported once (Beck et al., 1997), and improvements in survival (Cockroft et al., 1987; Littejohns et al., 1991), clinical paramerers (Aubert et al., 1998; Brewin \&x Hughes, 1995) and parient satisfaction (Beck et al., 1997; Weinberger er al. 1996) were found twice. In four studies parients who received care from a nurse showed higher medical consumption than patients who received usual care (Becket al. 1997; Cockroft et al., 1987; Littlejohns et al, 1991; Weinberger et al., 1996). Less medical consumption when cared for by a nurse was reported twice (Beck et al., 1997; Kirkman et al., 1994). In one study patients cared for by a nurse were found to consume less of some services and more of other services, while costs of care had decreased (Beck et al., 1997).

In all studies ar least one identified outcome was evaluated in which no significant difference was found. In seven studies effects in clinical parameters were expected (Aubert er al., 1998; Brewin \& Hughes, 1995; Cockroft et al., 1987; Estey et al., 1990; Littlejohns er al., 1991; Kirkman et al., 1994; Mulloy et al., 1996) while these were reported only twice (Aubert et al., 1998; Kirkman et al., 1994). Effects were found in 


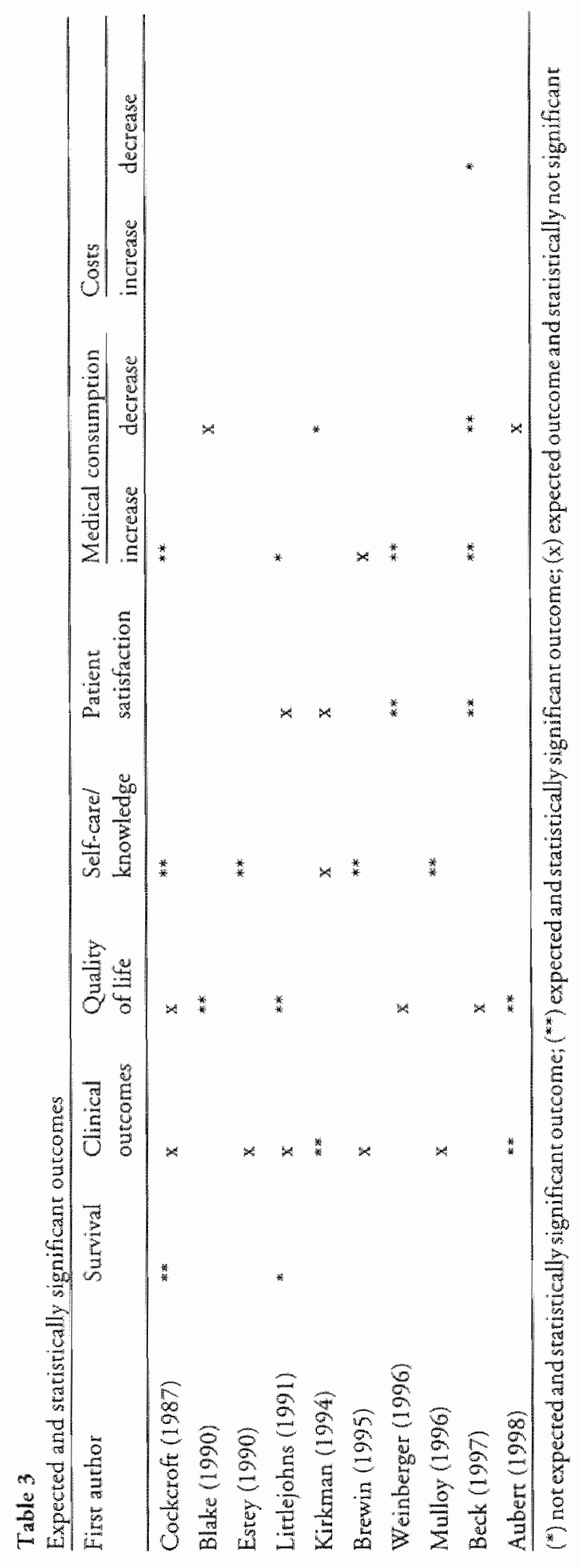


survival (once (Littlejohn et al., 1991)), medical consumption (twice (Littlejohns et al., 1991; Kirkman et al., 1994)) and costs (once (Beck et al., 1997)) while these had not been mentioned beforehand.

Promotion of the expertise of patients comes under the work of the nurse in all ten studies. When this is the only task of the nurse, in three (Brewin \& Hughes, 1995; Cockroft et al., 1987; Mulloy et al., 1996) out of four studies improvement is found in self-care and in two of the studies only in self-care (Brewin \& Hughes, 1995; Mulloy et al., 1996).

When organisarion and co-ordination is also a task of the nurse, in four out of five studies effects in medical consumption were reported: twice a decrease (Beck et al., 1997; Kirkman et al., 1994) and three times an increase (Beck et al., 1997; Litrlejohns et al., 1991; Weinberger et al., 1996). When direct patient care is also the task of the nurse, patients seem to perceive a higher quality of life (Aubert et al., 1998; Lirtlejohns et al., 1991). Survival, clinical parameters, parient satisfaction and costs show no relation with the presence of task(s) in the selected studies. The number of effects is smaller or equal to the number of tasks performed in eight publications (Aubert et al., 1998; Blake er al., 1990; Brewin \& Hughes, 1995; Estey et al., 1990; Kirkman et al., 1994; Littlejohns et al., 1991; Mulloy et al., 1996; Weinberger et al., 1996).

In studies performed in the Unired States no improvements in self-care were found. Where no relation was found with the presence of tasks, effects on survival were only found in two studies performed in Great Britain (Cockroft et al., 1987; Littlejohns et al., 1991), and effects in clinical parameters (Aubert et al., 1998; Kirkman et al., 1994) and patient satisfaction (Beck et al., 1997; Weinberger et al., 1996) only in two studies performed in the United States. No relation seems to exist between the length of the intervention or the frequency of planned contacts and the number of significant effects found. Only in the studies where parients with different diagnoses were included and with the biggest number of patients were effects found in patient satisfaction (Beck et al, 1997; Weinberger et al., 1996).

\section{DISCUSSION}

What ourcomes are expected in evaluations of health care models for the chronically ill in which the nurse has a central role? Are these models effective and efficient in terms of patient ourcomes? Our search for published studies in Medline revealed little evidence to answer these questions: only ten publications met our criteria. This is not surprising, considering the rather young status of the role of the specialised nutse. It is questionable, therefore, whether more publications would be identified by using alternative keywords or sources in a domain of health care organisation where different approaches have been implemented only very recently. Lengacher et al. (1997) 
confurms this: "the use of outcome measures of nursing practice is not new; however, testing the effects of new delivery models through outcome research is very limited. 'In addition McGillis (1997) mentions 'the lack of evaluation of existing (staffing) models while new models emerge rapidly."

The difficulty of establishing the effectiveness of complex interventions is another possible explanation for the modest number of publications found. All selected publications note the several methodological limitations when the randomised clinical trial is used as research design. Notwithstanding, the randomised controlled trial is the optimal design to tackle the issue of causal inference (Oakley, 1998). Expending the criterion of design to the pretest-posttest design would probably result in a larger number of publications, but would not gain equally valid evidence. Under these circumstances the performance of a meta-analysis will hardly be possible.

We searched in Medline for studies investigating the effects on the quality of chronic care when this care is organised in models where the nurse has a central role. The content of this role differs. In four care models the nurse performs one task: promotion of expertise. In another three care models the nurse performs one orher rask as well (organisation and co-ordination or consultation). Direct patient care is the task of nurses who perform at least two other tasks as well. Models with multiple tasks for the main caregiver seem to be more prevalent in the United States and Canada than in Great Britain or Ireland. Because the traditional role of nurses is different from one country to another, as is their posirion in health hierarchy (Stallknecht, 1992), differences in models and in the role of the nurse herein exist between countries. In spite of the degree of centrality, organising chronic care to meet the needs of parients by placing the nurse in a more central role, means a shift in primary attention from pathology to the person with the chronic disease (Taylor, 1995). Together with more room for the interpersonal and moral competencies of nurses, more attention is paid to the interactive process of parient education and counseling.

The targets of care define an intervention and the content of an intervention defines which effects can be expected. All selected publications deal with chronic care in which the nurse has a central role. Therefore all interventions included try to meer the targets of care for chronic patients in general and for patients with DM or COPD specifically. We classified the ourcomes mentioned in the selected studies according to the distincrions of patient outcomes made by Donabedian (1992), Long et al. (1993) and Driessen et al. (1994). They seem to agree on which patient outcomes have to be evaluated when the goal is to assess the effects of an intervention on the quality of care. Medical consumption and costs of care are related to the aspect of efficiency, while all other outcomes - survival, clinical parameters, quality of life, self-care and patient satisfaction - are seen as indicators for the aspect of effectiveness.

One important limitation of the literature reviewed is that not always use is made of validated measures ro assess the effects on quality of care. Dara about survival, 
medical consumption and clinical parameters are obtained from medical records of which the content validity is often poor especially when they are hand written. For the assessment of patient satisfaction in two studies use is made of self designed instrumenrs of which nothing is mentioned about the reliability and reliability.

Depending on the task(s) performed by the nurse, significant effects were reported. Promotion of expertise scems to improve self-care. When the nurse organises and co-ordinates care, it has an effect on medical consumption. Direct patient care performed by the nurse seems to improve the quality of life perceived by patients. In eight of the publications the number of effects is smaller or equal to the number of tasks performed by the nurse.

The results of this review allow us to draw the following conclusions. First of all the domain of effect evaluation of models of chronic care where nurses have a central role is young. Together with the difficulties of using the randomised clinical trial as research design for these health care models, our search in Medline yielded only a modest number of publications. Comparing the selected publications showed effects on the quality of care for chronic patients. The type of effect that can be expected seems to depend on the content of the intervention. Interventions for patients with DM or COPD in which the nurse fulfils a central role do not seem to affect clinical parameters as often as is expected. However, one could ask if it is realistic to expect changes in clinical parameters within the modal research period of one year. More likely, these interventions would improve self-care and quality of life. Higher patient satisfaction and more medical consumption by patients who received care in these models are effects one can have reasonable confidence in. These effects were found in larger studies although not always use was made of validated measures. Higher costs of care or higher medical consumption may be necessary to achieve 'tailor-made' care and may therefore not be undesirable.

More, methodologically suitable and valid evaluations of the effects and the process of chronic care are needed to provide knowledge about how to structure chronic care in a way to achieve "high-quality' care.

\section{REFERENCES}

Amos Al: McCarty DJ, Zimmer P (1997). The rising global burden of diabetes and its complications: estimates and projecrions to the year 2010. Diabetic Medicine 14(suppl 5):S1-85.

Auber RE, Herman WH, Waters J, Moore W, Sutton D, Peterson BL, Bailey CM, Koplan JP (1998). Nurse case management to improve glycemic control in diabetic patients in a healrh maintenance organization. Annals of Internal Medicine 129:605-612.

Beck A, Scont I. Williams P, Robertson B, Jackson D, Gade G, Cowan P (1997). A randomized utial of group outpatiene wisirs for chronically ill older HMO members: the cooperative health care clinic. Joumal of the American Geriatrics Society 45:543-549. 
Blake RL, Vandixer TA. Braun S, Bertuso DD, Sraub V (1990). A randomized controlled evaluation of a psychosocial intervention in aduls with chronic lung disease. Family Medicine 22:365-370.

Brewin AM. Hughes JA (1995). Effecr of patient education on asthma management. Brirish Journal of Nursing 4:81-82,99-101.

Cockcroft A, Bagnall I", Heslop A, Andersson N, Heaton R, Batstone J, Allen J, Spencer P, Guz A (1987). Controlled trial of respiratory health worker visiting patients with chronic respiratory disabiliny. British Medical Journal 294:225-228.

Dickersin $K(1990)$. The existence of publication bias and risk factors for its occurrenca. Journal of the American Medical Association 263:1385-1389.

Donabedian A (1992). The role of outcomes in quality assessment and assurance. Quality Rewiew Bullerin $11 ; 356-360$.

Driessen S, Casparie AF, Van den Bos GAM (1994). Uikomstindicatoren woor kwaliteirsbewalking en -bewordering in de zorg woor chronisch zieken [Outcome indicators for quality assurance and improvement in the care for chronically ill. Study 4 from Research programme Qualiry of Care. Durch Organisation for Scientific Research [NWO], The Flague 1994.

Estey AL, Tan MH, Mann K (1990). Follow-up intervention: its effect on compliance behaviour to a diaberes regimen. The Diabetes Educator $16: 291-295$.

Kirkman MS, Weinberger M, Landsman PB, Samsa GP, Shortlife EA, Simel DL, Feussner JR (1994). A telephone-delivered intervention for patients with NIDDM. Diaberes Care 17:840-846.

Lengacher CA, Maba PR, Heinemann D, VanCort ML, Kent $K_{*}$ Swymer $S$ (1997), Collaboracion in research: resting the PIPC model on clinical and nondinical ontcomes. Nursing Connection $10: 17-30$.

Littlejohns P, Baweystock CM, Parnell H, Jones PW (1991). Randomised controlled rrial of the effectiweness of a respiratory health worker in reducing impairment, disabiluty, and handicap due to chronic airflow limitation. Thorax 46:559-564.

Long AF, Dixon P. Hall R, Carr-Hill RA, Sheldon TA (1993). The ourcomes agendan contribution of the UK clearing home on health outcomes. Quality in Health Care 2:49-52.

MeGillis Hall, L (1997). Staff Mix Models: Complementary or substicurion roles for nurses. Mursing Administration Quartedy 21:31-39.

Mulloy E, Donaghy D, Quigley C, Mc Nicholas WT (1996). A One-year prospective audit of an asthma education programme in an out-patient setring. I rish Medical Journal 89:226-228.

Oakley A (1998). Experimentarion and social interventions: a forgotten but important history. British Medical Journal 317:1239-12.

Scheffier RM, Waiczman NJ, Hillman JM (1996). The productivity of physician assistants and nurse practirioners and healih work force policy in the era of managed health care. Journall of Alied Heald $25: 207-217$

Siafakas NM, Vermeire P, Pride P, Paoleri P, Gilason J, Howard P, a al (1995). Optimal assessmenr of chronic abstructive pulmonary disease (COPD). A consensus statement of the European Respintory Society (ERS). European Respirarory Journal 8:1398-1420.

Spreeuwenberg C (1994). (Net) Werken voor chronisch zieken-inaugurele rede INetworking for chronically ill-inaugural lecture) Universiteit Maastricht, Maastricht.

Srallknechr K (1992). Nursing in europe. British Medical Journal $304: 561-2$.

Taylor C (1995). Rethinking nursing"s basic competencies. Journal of Nursing Care Qualiry 9:1-13.

Wan Achrerberg, Th. (1997). Continuity of care and client satisfaction in the community. A study of professional and non-professional care for the chronically ill. Dissertation. Universiteir Maastricht. Maastricht.

Van der Linden BA (1997). Transmural Care. Facts and future. In: Schrivers AJP, ed. Health and health care in the Netherlands: a critical self-assessment of Dutch expers in the medical and health sciences. Utrecht: De Tijdstroom $181-188$. 
Wagner EH, Austin BT, Korff M von (1996). Organizing care for patients with chronic illness. Th: Mibank Quarterly $511-544$.

Weinberger M, Oddone EZ, Henderson WG (1996). Does increased access to primary care reduc thospital admissions: New England Jourmal of Medicine 334:1441-1447. 


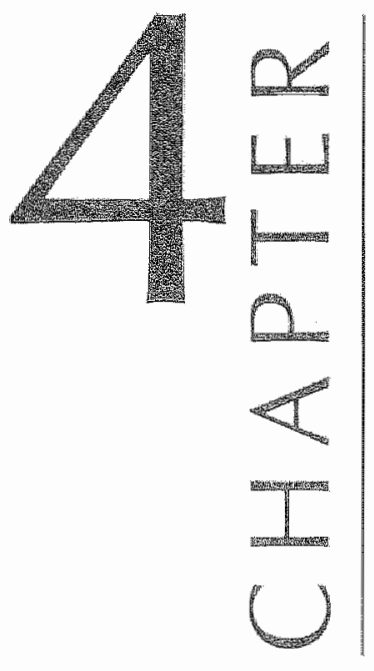

Substitution model with central role for nurse specialist is justified in the care for stable type 2 diabetic outpatients

by Vrijhoef HIM, Diederiks IPM, Spreeuwenberg C. Wolffenbuttel BHR.

Based on paper published in Journal of Advanced Nursing $2001 ; 36(4): 546-555$. 
Aim of the study. Assessment of effects on quality of care, in terms of parient outcomes, when tasks in the care for outpatients with stable type 2 diaberes are transferred from internist to nurse specialist and from outpatient clinic to general practice.

Background. For the management of chronic diseases with a high prevalence and requiring current monitoring, it is suggested that substiturion of care may be an appropriate solution ro safeguard high quality care.

Design of Methods. A 12-month non-equivalent control group design was used. General practitioners (GPs) referring diabetes patients to the university hospital Maastricht were asked to choose for the traditional model or the nurse specialist model. Informed consent was obtained from patients with stable diabetes type 2 attending these practices. All patients received care according to the model chosen by their GP. Identified outcomes were: clinical status, health status, self-care behaviour, knowledge of diabetes, patient satisfaction, and consultation with care-providers.

Results. In the control group no patients were treated with oral hupoglycaemic agents (OHA) only. The control group was compared with an intervention subgroup $(n=52)$ also without patients receiving OHA only. Clinical data were available for all patients. Patients without complete data from questionnaires had better mean concentration of $\mathrm{HBA}_{\mathrm{I}}$ than patients with complete data $(\mathrm{p}=0.004)$. The traditional care model and the nurse specialist model achieved equal outcomes, while glycaemic control of patients in the nurse specialist model improved (from $8.6 \%$ to $8.3 \%$ ) but deteriorated in the rraditional model (from $8.6 \%$ to $8.8 \%$; p-value between groups $=0.001$ ), Conclusions. The model with nurse specialists taking on roles and tasks beyond those traditionally regarded as their remit as well as new ones, is effective for the care of stable diabetic outpatients.

\section{INTRODUCTION}

The world's diabetic population will probably have doubled from an estimated 135 million now to 300 million in 2025 (WHO, 1997). As a result all European countries, the International Diabetes Federation and the World Health Organisation have declared a commitment to maximising the management of care for patients with diabetes mellitus (WHO/IDFE, 1990). As in other Western countries, the Netherlands is faced with a growing number of people with diabetes in combination with a limited capacity of health care resources. The latter are also being stretched by a policy of cost control. One of the challenges for the health care system is to provide this growing diaberic population with high quality care that is cost-effective, widely available and easily accessible. 
At the moment, patients with type 2 diabetes in the Netherlands receive care from a general practitioner (GP) or an internist (a medical specialist in internal medicine). More than $90 \%$ of consultations given by both sets of care-providers are repeat consultations (Mooy \& Vondeling, 1996). For the management of chronic diseases with a high prevalence and many recurring checks, it is suggested that substitution of care may be an appropriare solution.

Substitution of care can be divided into horizontal and vertical substitution. Horizontal substitution refers to the transfer of tasks berween care-providers within one level of expertise. This means that tasks can be transferred from specialist to generalist or from inside to outside the hospital. Vertical substitution refers to the transfer of tasks between care-providers with different levels of expertise. Substitution does not automatically imply a complete transfer, but it can also mean that professionals share tasks and responsibilities to remove deficiencies in care (Spreeuwenberg, 1994).

For outpatients with stable type 2 diabetes, who are now treated by an internist, an alternative treatment programme was proposed. This alternative includes both forms of substitution: a transfer of tasks to the nurse specialist as well as to the general practice. The involvement of the nurse specialist in the care of patients with a chronic disease can be justified on the basis of several arguments. Training programmes for nurses focus more on the behavioural and preventive aspects of health care than training programmes for physicians. Nursing skills are increasingly in demand in an environment, like diabetes care, that is moving more towards outpatient care and that requires its health care-providers to function as teams and to assume managerial responsibilities (IFTF, 2000).

The effecriveness of the nurse specialist in the care of chronically ill parients can be well evaluated in terms of the structure-process-outcome model (Donabedian, 1980). Exaluation studies regarding process and/or outcome variables are limited, mainly due to the -as yet-underdeveloped nature of this field of study (McGillis Hall, 1997; Lengacher et al., 1997; Temmink et al., 2000; Vrijhoef et al., 2000). The research issue addressed here concerns effects on outcomes of a change in the structure of care for "stable" type 2 diabetic patients receiving care from an internist in an outpatient department of a hospital. For this, a quasi-experimental design was used to compare the substitution model with the traditional model in terms of patient ourcomes. The substitution model can only be justified if the quality of generated care is at least equivalent to the qualiry of outpatient diabetes care performed by the internist. 


\section{Study design and patients}

Effects on outcome were measured in a non-equivalent control-group design (Cook \& Campbell, 1979). In the Maasrricht region about $82 \mathrm{GPs}$ refer patients with type 2 diabetes to the university hospital Maastricht. These GPS were asked to choose between three models of diabetic care for those patients currently referred to the internist. These models are:

- the traditional model of outpatient care, in which patients receive quarterly consultations from the internist in the hospital as well as education and self-management skills by the nurse specialist in the hospiral;

- a new model in which the GP and the medical specialist jointly consult patients in general pracrice (being evaluated at the moment);

- a new model in which the nurse specialist plays the central role as described below (see: (ntervention).

Twenty-nine GPs opted to continue with the tradirional outpatient model, while 22 GPs opted for the nurse specialist model. From the participating $22 \mathrm{GPs}$ a survey of patients with type 2 diaberes receiving outpatient care was compiled by the hospital. The internists were asked to assess which diabetes patients could be assumed to have "stable' diabetes as defined by a set of criteria (Figure 1). This assessment took place in two phases, firsty by looking at medical records and, secondly, by examining patients.

When patients were assessed as being eligible, they received information about the substitution model from their internist and written informed consent was requested. For the patients receiving traditional outpatient care the same procedure to assess stability and receive informed consent was followed. Clinical data were collected on commencement and at each subsequent consultation within one year. Data on other aspects of quality of care were collected by questionnaire on commencement of the study (TO), and after six (T6) and 12 months (T12). To facilitate response, questionnaires could be returned in pre-paid envelopes, assistance was offered in a covering letter and, if necessary written reminders were sent two and four weeks after the questionnaire had been sent out. The study was approved by the ethics committee of the university hospital Maastriche.

\section{Interiention}

The nurse specialist model is designed for those patients with stable type 2 diabetes who receive outpatient care from the internist. In the substiturion model, patients receive three quarterly consultations from a nurse specialist in general practice. Annually, parients receive an extensive check-up by the internist in the hospital. The 
Fingure 1

"Srability" criteria

Inclusion criteria:

- diagnosed with non-insulfin dependent diabetes mellitus (World Health Organisation crimeria):

- ancentracion of glycared hanemoglobin $(\mathrm{HbA} / \mathrm{C}<10.5 \%$ for the preceding 6 months ar least. Measurement of $\mathrm{Hb}$ A $\mathrm{l}$, has to take place at three different and successive moments in time The most recent concentration has to be within the range of $1 \%$-point of the mean for all three measurements.

Exclusion criteria:

- presence of acrive complications (micro and macro-angiopathy);

- presence of other diseases not related to diabetes mellitus for which care of a medical specialise is received;

- presence of psychosocial problems (assessed by physician).

nurse specialist is a registered nurse with the highest level of qualification and specialised in a disease. Nurses involved in this study are specialised in diabetes and have long-rerm work experience.

The care is based on a protocol developed by all parties involved in the care of patients with type 2 diabetes. In this protocol the tasks of each provider are clearly defined. Tasks (activities) of the nurse specialist are concerned with direct patient care (medical history taking, physical examination, interpretation of laboratory tests, administration and assimilation of findings), organisation and co-ordination of care for individual patients (identification of shortcomings in care, referral to and communication with care-providers), consultation (providing advice to patients and other care-providers), and advancement of expertise (education of patients, themselves and other care-providers). If complications or other problems arise, the nurse will consult the GP or the internist. During office hours the nurse specialist is the first care-provider to contact.

Once a year the internist performs a complete check-up. If necessary he draws the nurse's attention to particular aspects of care. The GP provides the nurse with a working place in the practice. Every consultation performed by the nurse is briefly discussed with the GP. Outside office hours the GP is the first care-provider to contact.

\section{Outcome measures}

For the purpose of this study, indicators were selected which are considered to be essential when looking ar outcomes in quality of care research for chronically ill (Donabedian, 1992; Long et al., 1993; Driessen er al., 1994). These are:

- Clinical status was determined by glycated haemoglobin concentration ( $\left.\mathrm{Hb} \mathrm{A}_{\mathrm{d}}\right)$. levels of fasting total cholesterol, HDL-cholesterol and triglycerides, body mass 
index (BMD), systolic (SBP) and diastolic blood pressure (DBP). Measurement of lipid levels, weight and blood pressures occurred annually, while $\mathrm{HbA}_{\text {Ic }}$ concentrarion was measured quarterly.

- Health status was measured using the Dutch wersion of the COOP/WONCA charts and a visual analogue scale (VAS) (Maxwell, 1978; Nelson et al., 1987; Van Weel, 1993). The charts consist of six single-item measures: physical fitness, feelings, daily activities, social activities, change in health and overall health. Each charc represents a distinct domain, refers to fortnightly period, and has a fwe-point Likert scale where five designates the worst level. These charts have been extensively used in chronic diseases, have proven acceptability by patients as well as satisfactory clinical validity (Nelson et al., 1987; Van Weel, 1993). The visual analogue scale was used as single-item measure of quality of life. It consists of a 10 centimetre long horizontal line with "low qualiry of life" at its left-hand extremiry and "high quality of life' at irs right-hand extremiry. It is simple to use, largely acceptable and regarded as a valid and reliable instrument to measure quality of life (Maxwell, 1978). For both instruments Dutch versions were used.

- Self-care behaviour was measured with a Dutch disease specific instrument, the Self-Care Behaviour Check-list (SCBC) which consists of four factors: self-regulation ( 3 items), bodily observation and conditioning ( 3 items), recording activity of condition ( 4 items), and diet application and commitment ( 8 items) (Pennings-van der Eerden, 1992). Every item is measured with a five-point Likert scale ranging from 'never' to 'always.' Scores for each factor were computed by summing the valid answers and dividing this sum by their number (range 1-5). The toral score of self-care was achieved by adding together the scores of all answered items and dividing it by their number (range 1-5). The SCBC was found to be a valid instrument to measure self-care amongst diabetes patients (Pennings-van der Eerden, 1992).

- For the measurement of disease specific knowledge of patient, use was made of a Durch diabetes specific instrument containing 12 multiple choice questions (Ripken et al., 1990). Each correcr answer yields one point. The total score was achieved by adding together the correct answers (range 0-12). No information about the reliability of the instrument used was found and thus evidence was gathered during this study.

- Patient satisfaction about received diabetic care was measured by asking patients to grade their satisfaction with a score (between 1 for "low quality of care" and 10 for 'high quality of care'), if they would recommend the care they had received to other parients ('yes' or 'no') and if they intended to continue making use of this care in the furure ('yes,' 'no,' 'no preference'). These items are derived from industrial marketing management and have been applied earlier in the same area of research (Cockroft et al., 1987; GRASSIC, 1994). 
- The number of consultations of patients for their diabetes was derived by asking patients about the number of consultations received from nurse specialist, GP, and/ or internist.

Data on clinical parameters were derived from the clinical notes taken by the nurse and/or internist. Data on all other outcomes were obtained directly from patients by questionnaires.

\title{
Statistical analysis
}

Differences between intervention group and control group and between patients with complete data and patients with missing data were tested, using chi-square test and Student's t-test for independent samples. The distribution of parients wirh missing data and of deceased patients were tested with chi-square test.

To assess differences in $\mathrm{HbA}_{1 \mathrm{c}}$ within and between groups, one facror repeated-measures analysis of variance was used. Correlation between change in $\mathrm{HbA}_{1 \mathrm{c}}$ and change in the units insulin prescribed, change in dose OHA prescribed, or change in self-care behaviour were rested with Pearson correlation. 'Change" was obtained by subtracting the final value from the original value. Comparison of groups for lipids, BMI and blood pressures was performed with Student's t-test for independent samples, while within group comparisons were performed with Student's t-test for paired samples.

One factor repeated measures analysis was used to compare measurements within groups and between groups for COOP/WONCA charts, VAS for qualiry of life, self-regulation, knowledge, and satisfacrion score. Recommendation of care and future use were described in percentages. Comparisons of the number of consultations with main care-providers within groups was performed with Friedman test, while Kruskal-Wallis one-way analysis of variance was used for between group comparisons.

All data were analysed on the basis of intention to treat: patients who did not adhere to the management plan in which they initially participated, were still assumed to have done so for the purpose of analysis. A significance level, $p=0.05$ (two tailed) was used. Data processing and analyses were conducted with SPSS (Windows Release 8.0).

\author{
RESULTS
}

\section{Patients}

Of the 22 participating GPs, 237 outpatients with type 2 diabetes wete available of whom 105 patients had stable diabetes. Of these 105 patients, 74 patients gave 
informed consent (intervention group). Of the 29 GP's who continuted to use the traditional model, 105 ourpatients with type 2 diabetes were available, of whom 60 patients had stable diabetes. Of these 60 patients, 47 gave informed consent (control group).

Reasons for not giving informed consent in the control group were: too much difficulry (1 partent), too old (2), no interest (4), and unknown (6). In the intervention group: no interest (1), moving house (1), preference for internist as care-provider (18), and unknown (11). Depending on the model chosen by their GP, patients who did nor gave informed consent received care according to traditional model or the nurse specialist model.

Comparison of patients in the intervention group with the control group on relevant baseline characteristics showed fairly comparable groups except for diabetes therapy (Table 1). Without patients in the control group being treated with oral hypoglycaemic agents (OHA) only, further analyses were performed between patients receiving similar treatment, i.e. OHA and/ or insulin. The part of the intervention group treated with OHA and/ or insulin $(n=52)$ - hereinafter referred to as intervention subgroup - was comparable on baseline characteristics with the control group (Table 1).

Not all patients complered the study. Data from all questionnaires were available for 54 patients. The distribution of patients in the intervention subgroup and in the control group for whom data were complete $(59.6 \%$ and $48.9 \%$ respectively) and incomplete, did not differ significantly. For parients for whom incomplete data were available only clinical data were obtainable. Comparison of groups with and without complete data on baseline characteristics revealed that groups were similar except for $\mathrm{HbA}_{\mathrm{I}_{\mathrm{c}}}$. Mean concentration of $\mathrm{Hb} \mathrm{A}_{I_{c}}$ was $0.7 \%$ lower for patients without complete data $(7.8 \pm 1.2 \%$ versus $8.6 \pm 1.3 \% ; \mathrm{p}=0.004)$. Main reasons for non-response were a lack of interest in returning the questionnaire(s) and death. Of the patients in the intervention subgroup three died during the study, while two parients in the control group died $\left(\chi^{2}=0.118, p=0.731\right)$. In all cases, the cause of dearh was not directly related to diabetes.

\section{Outcomes}

The findings from baseline comparisons led to an assessment of the outcomes between parients for whom complete data were available for the intervention subgroup and for the control group. For clinical parameters analyses were also performed without the restriction of complete dara.

Changes in mean $\mathrm{HbA}_{1 \mathrm{c}}$ levels are shown in table 2. The first two means of $\mathrm{HbA}_{10}$ level in the intervention subgroup were derived when the central care role was performed by the internist, while last three means were derived when the nurse performed the central role. 
Table 1

Baseline comparisons for patients in the intervention group, intervention subgroupand the concrol group

\begin{tabular}{|c|c|c|c|c|c|}
\hline Patient characteristics & $\begin{array}{l}\text { Intervention } \\
\text { group }(n=74)\end{array}$ & $\begin{array}{l}\text { Inrervention } \\
\text { subgroup }(n=52)\end{array}$ & $\begin{array}{l}\text { Control } \\
\operatorname{group}(n=47)\end{array}$ & p-value & p-valute \\
\hline Age (years) & $66.4 \pm 10.7$ & $68.2 \pm 9.7$ & $66.4 \pm 9.3$ & $0.973^{\mathrm{d}}$ & $0.354^{d}$ \\
\hline o (No) male sex & $43.2(32)$ & 63.5 & $51.1(24)$ & $0.400^{\circ}$ & $0.213^{\circ}$ \\
\hline $\begin{array}{l}\text { Duration of diabetes } \\
\text { (years) }\end{array}$ & $10.9 \pm 6.5[67]$ & $12.6 \pm 6.2[48]$ & $12.6+9.1$ & $0.241^{\mathrm{d}}$ & $0.926^{13}$ \\
\hline \multicolumn{6}{|l|}{$\%(N o)$ inerapy } \\
\hline $\begin{array}{l}\text { oral hypoglycaemic } \\
\text { aggents }\end{array}$ & $26.8(19)$ & & - & & \\
\hline $\begin{array}{l}\text { oral hypoglycaemic } \\
\text { agents and insulin }\end{array}$ & $11.3(8)$ & $15.4(8)$ & $255(12)$ & & \\
\hline insulin & $62.0(44)[71]$ & $846(44)$ & $74.5(35)$ & $0.000^{c}$ & $0.209^{\circ}$ \\
\hline $\mathrm{HbA}_{\| c}(\%)$ & $7.9 \pm 1.6$ & $8.3 \pm 1.5$ & $8.2+1.1[46]$ & $0.171^{n^{2}}$ & $0.898^{\mathrm{d}}$ \\
\hline $\begin{array}{l}\text { Total cholesterol } \\
\text { (mmolfl) }\end{array}$ & $5.6 \pm 1.1[69]$ & $5.7 \pm 1.1[51]$ & $5.6 \pm 1.3 \llbracket 35 \rrbracket$ & $0.81 \mathbb{1}^{\mathbb{d}}$ & $0.706^{\mathrm{at}}$ \\
\hline $\begin{array}{l}\text { HDL-cholesnerol } \\
\text { (mmolli) }\end{array}$ & $1.1 \pm 0.3[67]$ & $1.1=0.3[49]$ & $1.1=0.3[27]$ & $0.567^{d}$ & $0.68 \mathbb{I}^{d}$ \\
\hline Triglycerides (mmol/1) & $1.9 \pm 1.2[67]$ & $2.0 \pm 1.3[49]$ & $2.1 \pm 1.3[27]$ & $0.533^{\mathrm{d}}$ & $0.769^{d}$ \\
\hline Body mass index $\left(\mathrm{kg} / \mathrm{m}^{2}\right)$ & $28.5 \pm 5.7[58]$ & $29.7 \pm 4.3[4.1]$ & $31.0 \pm 6.2[28]$ & $0.068^{\mathrm{d}}$ & $0.311^{\mathrm{d}}$ \\
\hline $\begin{array}{l}\text { Systolic blood pressure } \\
(\mathrm{mmHg})\end{array}$ & $143.1 \pm 129[66]$ & $143.2 \pm 13.4[47]$ & $143.6 \pm 18.2[41]$ & $0.874^{\mathrm{d}}$ & $0.917^{1}$ \\
\hline $\begin{array}{l}\text { Diastolic blood pressure } \\
(\mathrm{mmHg})\end{array}$ & $81.2 \pm 8.7[66]$ & $80.7 \pm 9.5[47]$ & $80.4 \pm 10.1[41]$ & $0.688^{d}$ & $0.884^{d}$ \\
\hline \multicolumn{6}{|l|}{$\%$ diaberic complications } \\
\hline neuropathy & $47[68]$ & $52[48]$ & 49 & $0.843^{\circ}$ & $0.759^{\mathrm{e}}$ \\
\hline nephroparhy & $53[68]$ & $58[48]$ & 40 & $0.187^{\mathrm{e}}$ & $0.081^{\mathrm{C}}$ \\
\hline coronary heart disease & $41[68]$ & $44[48]$ & 57 & $0.086^{\circ}$ & $0.1182^{\circ}$ \\
\hline $\begin{array}{l}\text { peripheral vascular } \\
\text { disease }\end{array}$ & $16 \llbracket 69]$ & $20[49]$ & 11 & $0.416^{7}$ & $0.188^{\circ}$ \\
\hline terinoparhy & $36[66]$ & $43[47]$ & 45 & $0.373^{e}$ & $0.835^{\mathrm{t}}$ \\
\hline
\end{tabular}

Inumber of patients for which data are used in case data were nor available for all parients]: agures are means $t$ sd unless stated otherwise, ${ }^{b}$ significance level of test between intervention group and control group; significance level of test between intervention subgroup and control group; hood-rario chi square test

Changes between means of $\mathrm{HbA}_{1 \mathrm{c}}$ level in the intervention subgroup were statistically significant, with last three means being smaller than first two. In the control group changes between means of $\mathrm{HbA}_{\mathrm{lc}}$ were also statistically significant. Between groups the differences in mean $\mathrm{HbA}_{1 \mathrm{c}}$ levels increased towards the end of the study. The 


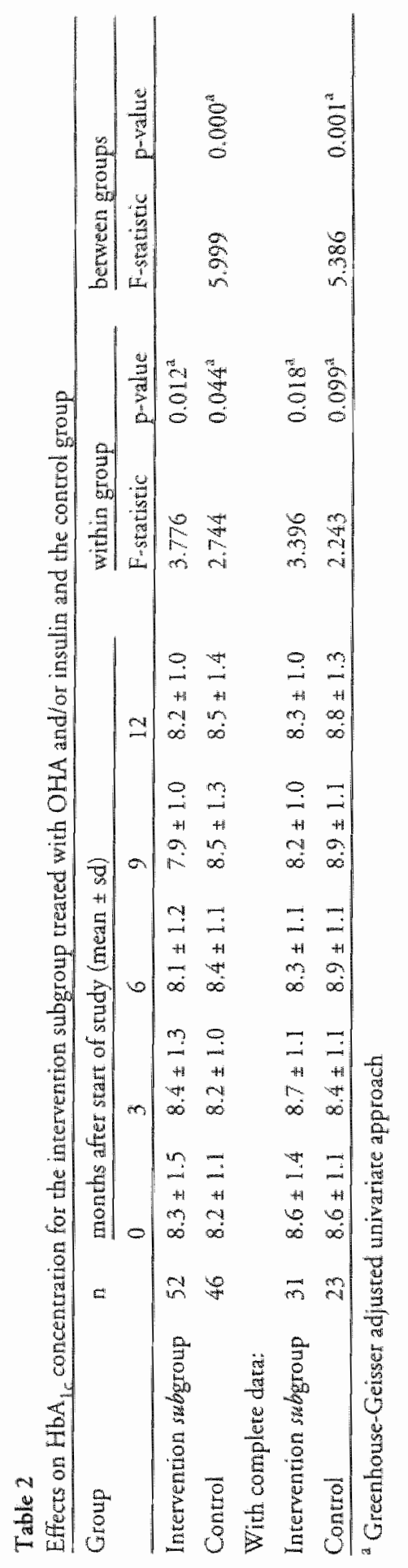


differences berween groups in repeated mean $\mathrm{HbA}_{10}$ levels were statistically significant. When limiting groups to patients with complete data almost the same picture emerged except that the differences between means in the control group were not statistically significant. Between groups the differences in repeated mean $\mathrm{Hb}_{16}$ levels were statistically significant.

Within the intervention subgroup mean total cholesterol declined by $0.5 \mathrm{mmol} / \mathrm{l}$ and mean HDL-cholesterol increased by $0.1 \mathrm{mmol} / \mathrm{l}$. Borh changes were statistically significant. For triglycerides no differences were seen in the intervention subgroup as was the case for all lipids in the control group. Between groups no differences were found in mean concentration of lipids. Restriction to patients with complete dara also showed a decline of $0.5 \mathrm{mmol} / \mathrm{I}$ in total cholesterol within the intervention subgroup.

With regard to BMI no statistically significant changes occurred within or between groups. The changes between mean values of SBP in both groups were statisrically significant. Mean SBP in the intervention group increased by $3.6 \mathrm{mmHg}$, while mean SBP in the control group decreased by $3.0 \mathrm{mmHg}$. Between groups no changes were found in mean SBP. For DBP no changes were seen between or within groups.

With regard to the COOP/WONCA charts fairly, steady mean values were found for all scales in both groups (Table 3). None of the changes within or between groups was found to be statistically significant. On the VAS for quality of life amongst patients, no staristically significant changes were found within or between groups. With means under or around the middle of possible values, the VAS reflected poor quality of life amongst patients.

The improvement in self-regulation by patients in the intervention subgroup was statistically significant (Table 4). Improvement here means more frequent performance. Within the control group or between groups no statistically significant changes were found. Data required to assess overall scores in self-care behaviour -scores on all sub-scales at all measurements-could only be obtained for 18 patients in the intervention subgroup and for 13 patients in the control group. The mean level of knowledge of diabetes of patients was found to be moderate and the changes within or berween groups were not statistically significant. The reliability of the knowledge test proved to be satisfactory $(\alpha=0.80)$.

Mean satisfaction marks for patients in both intervention subgroup $(7.8 \pm 1.4$; $\mathrm{n}=29)$ and control group $(8.1 \pm 1.0 ; \mathrm{n}=21)$ were high. No statistically significant changes were found within or berween groups. At baseline, the response of $86 \%$ of patients in the intervention subgroup $(n=28)$ was to recommend traditional care to others. After having received care according to the substitution model, the response of $89 \%$ patients at both T6 and T12 was to recommend care with a nurse in the central care role. For each of the three measurements in the control group $(n=21), 95 \%$ recommended using traditional care. When patients were asked if they would make use of care in the future, at $" \mathrm{~T} 096 \%$ of patients in the intervention subgroup said they 


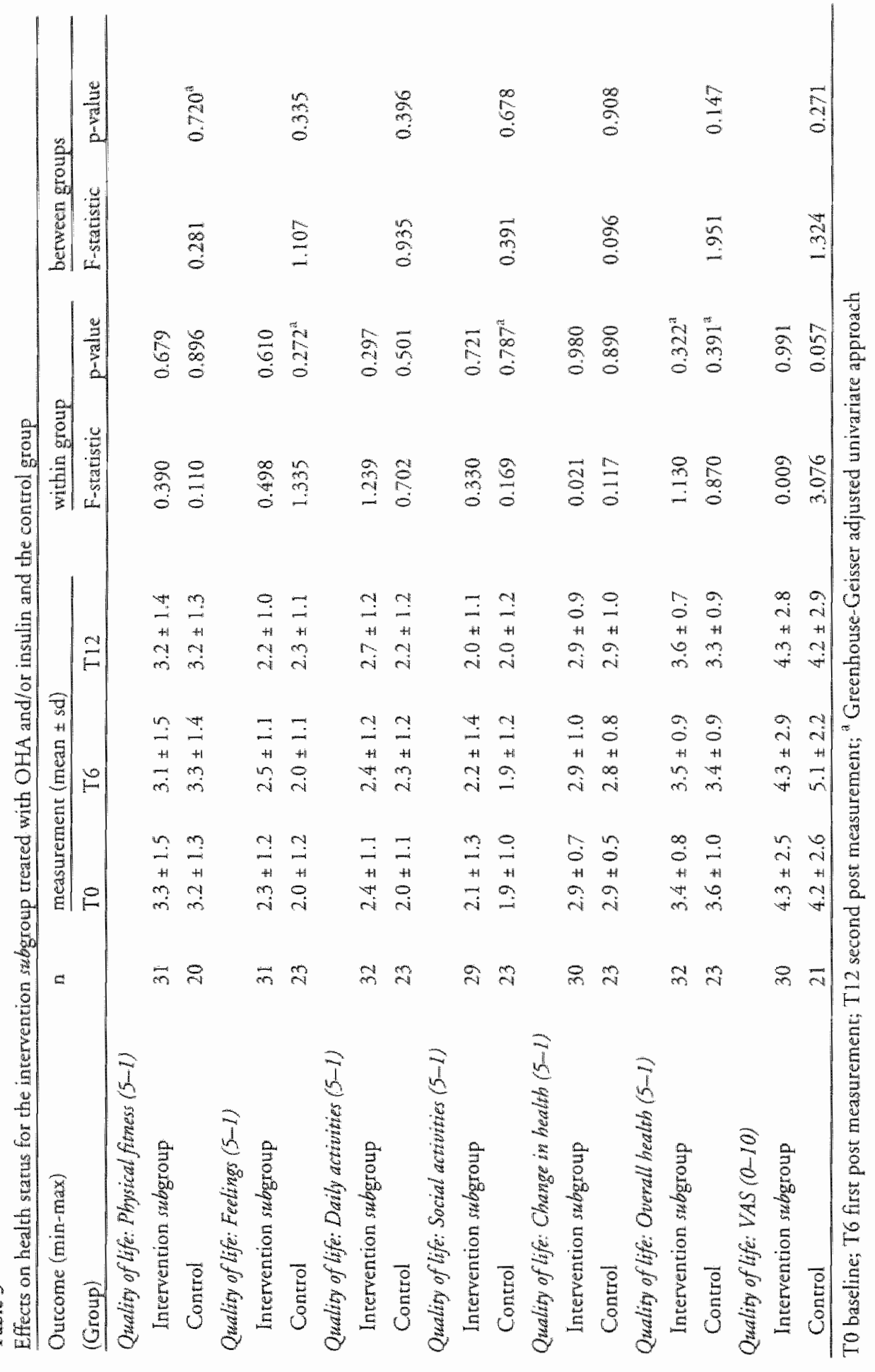




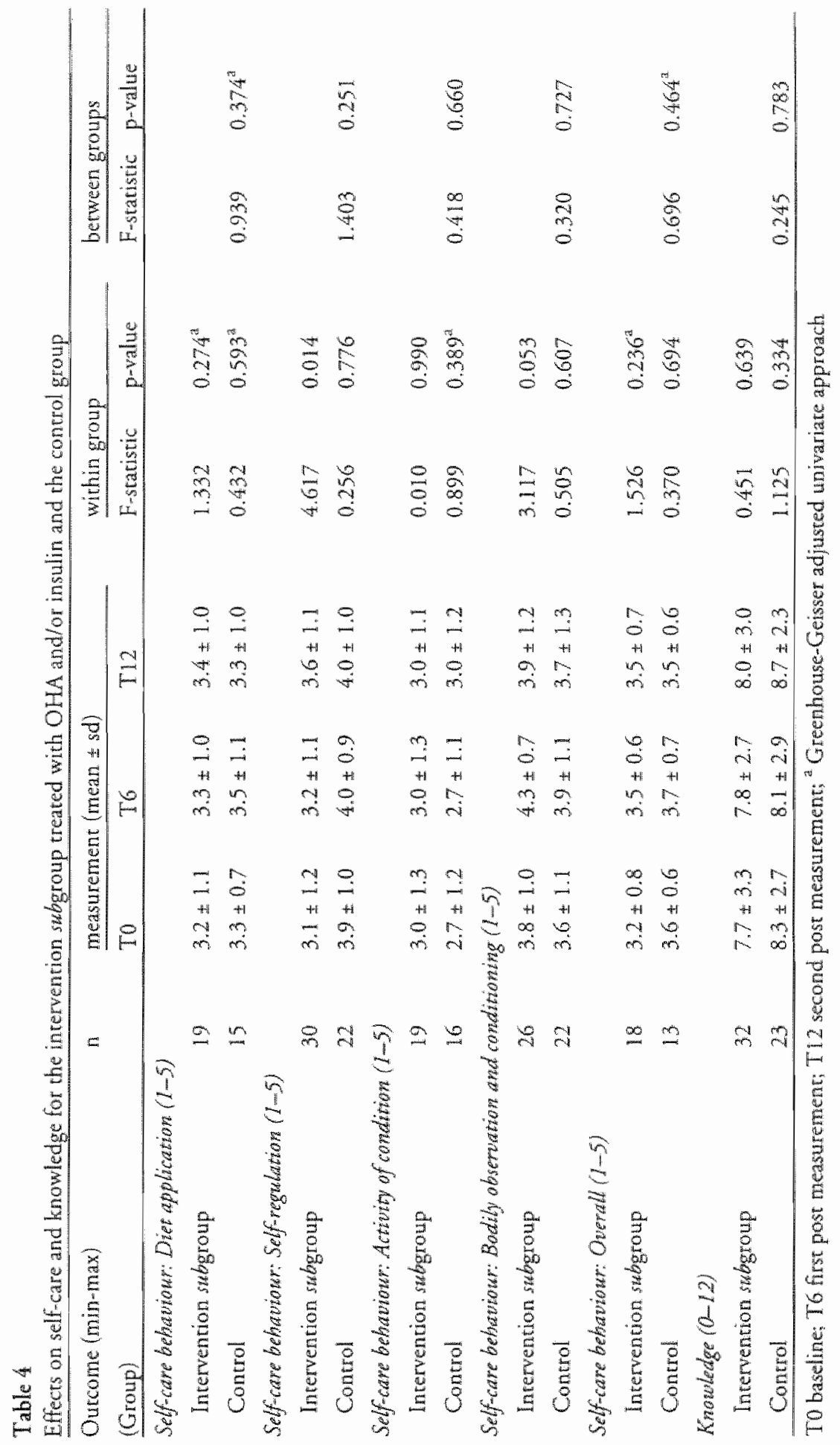




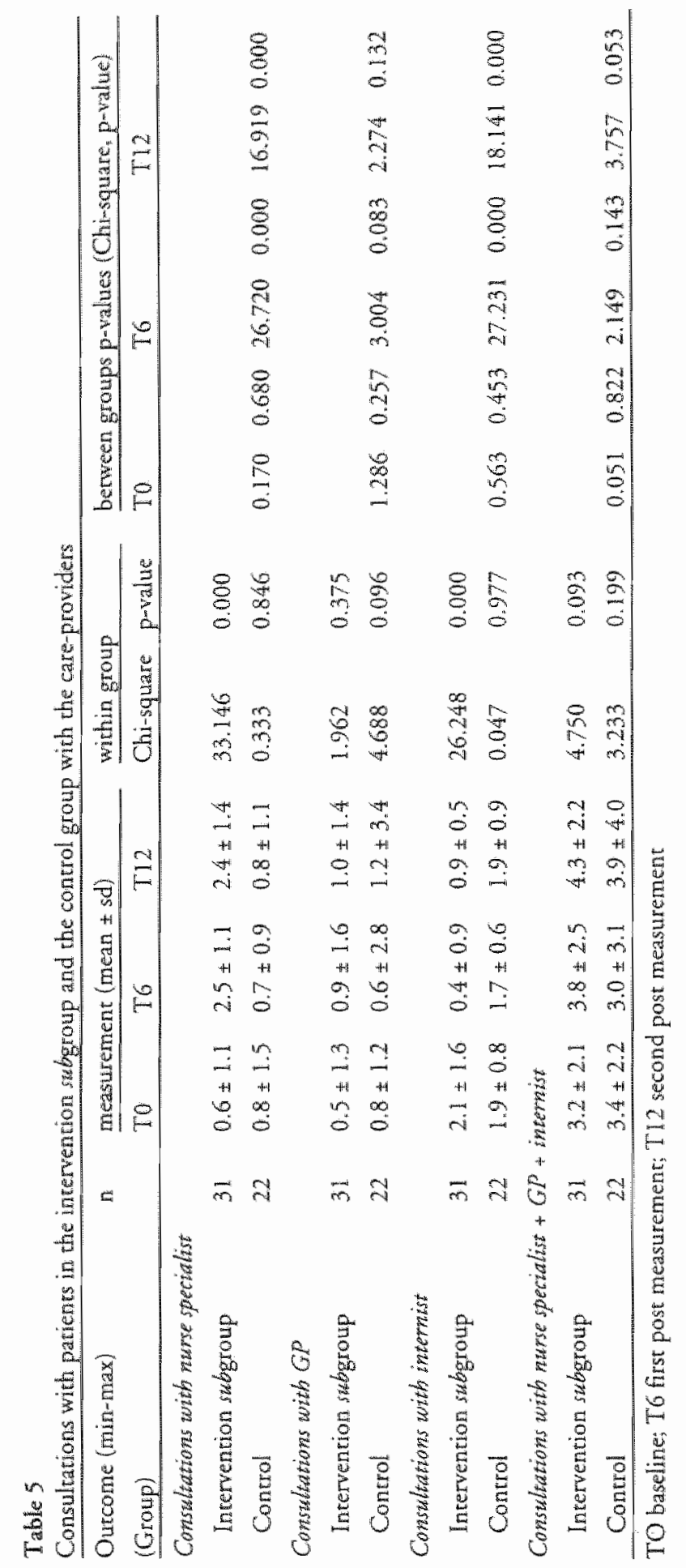


would use traditional care. After having received care with the nurse as central care-provider, both at T6 and T12,89\% of patients said they would make use of the substiturion model in the future, while $4 \%$ of patients showed no parcicular preference between traditional care and substiturion model. For all measurements the entire control group said that it would make use of traditional care in the future.

Within the interwention group statistically significant changes for consultations of care-providers were found (Table 5). During the study the mean number of consultations with the nurse specialist multiplied by four to 2.4 consultations at T12, while the mean number of consultations with the internist decreased from 2.1 at T0 to 0.9 at T12. Changes in the total number of consultations with care-providers were not statistically significant. Within the control group no statistically significant changes were found in mean number of consultations wirh individual nor with all care-providers rogether. The differences between groups in mean number of consultations with the nurse specialist (higher in the intervention group) and mean number of consultations with the internist (higher in the control group), were statistically significant.

\section{DISCUSSION}

Can the transfer of (medical) rasks from an internist to a nurse specialist be justified for the care of stable diabetic outpatients? The arguments contained with this evaluation into the effects on quality of care would seem to suggest that this can be answered affirmatively. It was found that the traditional care model and the nurse specialist model achieved equal patient outcomes in terms of lipid spectrum, BMI, BP, quality of life, self-care behaviour, knowledge of diabetes, patient satisfaction, and overall number of consultations with care-providers, while the glycaemic control of parients in the nurse specialist model is somewhat better than for patients receiving traditional care. So, from this study preliminary evidence was obtained, proving that the nurse specialist model may replace the traditional outpatient model effectively.

Several methodological limitations of this study should be acknowledged. The optimal design to tackle the issue of causal inference is the randomised controlled trial (Oakley, 1998). Under less optimal circumstances, quasi-experimental evaluation may be considered to provide evidence or 'proof of effect' (Van Weel \& Knottnerus, 1999). The requirements for GPs to participate in this study did not allow random allocation. GPs who participate in the substitution model may have a special interest in innovations with respect to (diabetes) care. To support the credibility of results, comparable groups were analysed. For this patients being rreated with OHA only were excluded from the intervention group. Response rates and completion rates were common for longitudinal studies with the chronically ill. 
Patients with missing data from questionnaires had better mean glycaemic control. With improved glycaemic control found in both intervention subgroup of patients with complete data as in entire intervention subgroup (with + wirhout complete data), one can have reasonable confidence in this effect. Good glycaemic control can delay onset and slow down progression of diabetic complications for patients with type 2 diaberes (UKPDS, 1998).

The nurse specialist model targets type 2 diabetic outpatients with stable metabolic control. During inclusion of patients the cut-off value for $\mathrm{HbA}_{\mathbb{I c}}$ was increased with $1.5 \%$-point. This resulted in an expansion of the study population by about $20 \%$ with means of $\mathrm{HbA} A_{1 c}$ in borh intervention group and control group in the order of the entire outpatient population as assessed before (Wolffenbuttel, 1991). General instruments were used to enable assessment of effects of the substitution model more generally. Together with a research period of one year, this might have resulted in not finding existing effects in outcomes.

A review of the literature showed improvements in self-care, quality of life, patient sarisfaction and increased consumption of medical care depending on the way in which tasks were divided between care-providers (Vrijhoef et al., 2000). Improved glycaemic control was found in two trials with the nurse specialist making follow-up telephone calls (Kirkman er al., 1994; Aubert et al., 1998). Expected improvements in knowledge and self-care in this study were not evident. In usual outpatient care the nurse is already involved in the more traditional way.

Two issues need to be addressed in further research. Improved glycaemic control might result from life-style changes and/ or therapy (Fisher et al. 1997). In this study no correlations were found berween change in $\mathrm{HbA}_{1 \mathrm{c}}$ and change in dose of medication or change in self-care behaviour. However, stable diabetic parients, already familiar with a nurse specialist, are transposed into restricted ranges of both level of $\mathrm{HbA}_{\mathrm{Ic}}$ and self-care behaviour. Secondly, although substitution of care-providers occurred, no evidence was provided about the model's cost-effectiveness. The quantity of consultations consumed, does not reflect costs.

In conclusion, this evaluation revealed that consistent follow-up care using nurse specialists who follow protocols and who are the primary interface with the parient, is an appropriate solution for managing the care of stable diabetic outpatients. The transfer of (medical) tasks from the internist to the nurse specialist and, simultaneously, from ourparient to primary care in the care for stable type 2 diabetic patients resulted in at least equal outcomes as traditional diabetic outpatient care.

Rarher than just adding a new care-provider, more responsive models of care are developed that have the potential to improve the delivery of care and patient outcomes (Vrijhoef et al., 2001). With nurse specialists taking on roles and tasks beyond those traditionally regarded as their remit as well as new ones, more equitable and less hierarchical models of multi-professional team working in the care for chronically ill become 
available. For parients with diaberes promising results were found from a model where the nurse specialist plays a central rolle.

\section{ACKNOWLEDGEMENTS}

This study was supported by a grant from Stimuleringsprogramma Gezondheidsonderzoek [Incentive Programme Health Research] and Nationale Commissie Chronisch Zieken [National Committee Chronically III]. The authors gratefully acknowledge the help of E. van den Akker, E. Denis, W. Ellenbroek, M. Frederix, and B. Jöbses for their assistance with data processing.

\section{REFERENCES}

Aubert RE, Herman WH, Waters J, Moore W, Sutton D, Peterson BL, Bailey CM, Koplan JP (1998). Nurse case management to insprove glycemic control in diabetic patients in a health maintenance organization. Annals of Internal Medicine 129:605-12.

Cockroft A, Bagnall P, Heslop A, Andersson N, Heaton R, Batstone J, Allen J, Spencer P, Guz A (1987). Controlled trial of respiratory health worker visining patients with chronic respiratory disabiliry. Bricish Medical Journal 294:225-7.

Couk TD \& Campbell DT (1979) Quasi-experimentation. Design \& analysis issues for field settings. Rand McNally College Publishing Company, Chicago.

Donabedian A. (1980). Explorations in quality assessment and monitoring (Volume 1). The definition of quality and approaches to its assessment. Health Administracion Press, Ann Arbor, Michigan.

Donabedian A (1992). The role of outcomes in quality assessment and assurance. Quality Review Bulletin $18: 356-60$.

Driessen S, Casparie AF, Van den Bos GAM (1994). Uitkomstindicatoren voor kwaliteitsbewaking en-bevordering in de zorg voor chronisch zieken [Outcome indicators for qualiry assurance and improvement in the care for chronically ill]. Study 4 from Rescarch programme Quality of Care. Durch Organisation for Scientific Research [NWO]. The Hague.

Fisher EB, Arfken CL, Heins JM, Houston CA, Jeffe DB, Sykes RK (1997). Acceptance of diabetes regimes in adulss. In Handbook of Behaviour Research. Part II: Prowider cleterminants (Gockman D.S. eds). Plenum press, New York, 189-212.

Grampian Asthma Study of Integrated Care [GRASSIC] (1994). Integrated care for asthma: a clinical, social, and economic evaluation. British Medical Journal 308:559-63.

Institute For The Future (2000). Health \& Health Care 2010; the forecast, the challenge. IFTF, California.

Kirkman MS, Weinberget M, Landsman PB, Samsa GP, Shordife EA, Simel DL, Feussner JR (1994). A telephone-delivered intervention for patienrs wirh NIDDM. Diabetes Care 17:840-6.

Lengacher CA. Mabe PR, Heinemann D, VanCorr ML, Kent K, Swymer S (1997). Collaborationin research: resting the PIPC model on dimical and nonclinical outcomes. Nursing Connections 10:17-30

Long AF, Dixon P, Hall R, Carr-Hill RA, Sheldon TA (1993). The outcomes agenda: contribution of the UK dearing home on health outcomes. Quality in Health Care 2:49-52. 
Maxwell C (1978). Sensirivity and accuracy of the visual analogue scale: a psycho-physical classroom experiment. Briesh foumal Clinical Pharmacology 6:15-24.

MoGillis Hall L. (1997). Staff mix models: complementary or substitution roles for nurses. Nursing Administration Quartedy $21: 31-9$.

Mooy JM, Yondeling H (1996). Diabetes Mellius Type II: epidemiologie en kosten (Diabetes Mellitus Type II: epidemiology and cosis I. DIMS 22:4-7.

Nelson EC, Wasson], Kirk J, Keller A, Clark D, Zubkoff M (1987). Assessment of function in rourine clincal practice description of the COOP hart method and preliminary findings. Journal or Chronic Diseases 40(Suppl 1) $) 55 \$-645$.

Oakley A (1998). Experimentation and social intervertions: a forgotten but important history. Bricish Medical Journal $317: 1239-42$.

Pennings - van der Eerden, L.JM (1992). Self-care behaviour in the reatmenc of diaberes mellicus. Theory, assesment and dererminants of self-care behaviour and diabetes education (dissertation). Uniwersiteit Urache, Ureche.

Ripken ThM], Pennings-van der Eerden LIM, Schrijwers AJP (1990). Diabereseducatie in Eindhoven. Type II diabetespatienten voor her voetichr [Diabeteseducation in Eindhoven, Type II diaberes patients before the footlights]. Medisch Contact 3:88-90.

Spreeuwenberg C (1994). (Nat) Werken woor Chronisch Zieken-inaugurele rede [Nerworking for chronically ill-inaugural lecture]. Universiteit Maastricht, Maastriche.

Temmink D, Francke AI., Hutten JBE, Van der Zee J. Hujer Abu-Saad H (2000). Inmovations in the nursing care of the chronically ill: a literature revew from an international perspective Journal of Advanced Nursing $31: 1449-58$.

UK Prospective Diabetes Study Rescarch group [UKPDS] (1998). Intensive blood-glucose control with suphonylureas or insulin compared with conwentional treatment and risk of complications in patienrs with type 2 diabetes (UKPDS 33). The Lancer $352: 837-53$.

Viihtoef HJM, Diederiks JPM, Spreeuwenberg C (2000). Effecrs on qualiry of care for parients with NIDDM or COPD when the specialised nurse has a central role: a literature review. Patient Educathon and Counseling $41: 243-50$.

Vijhoef HJM, Sprecuwenberg C, Eijkelberg IMJG, Wolfenbuttel BHR, Van Merode GG (2001). Adoption of disease management model for diaberes in regron of Maastricht. British Medical. Joumall $323: 983-5$

Van Weel C (1993). Functional status in primary care: COOP/WONCA charts. Disability and rehabilitation 15:96-101.

Van Wed C, Knotmerus JA (1999). Exidence-based incerventions and comprehensive treatment. The Lancet 353:916-8.

Wolfenbutel BHAR (1991). Type 2 diabetes mellitus. Pathology and treatment (disseration). Unuversieit Manstricht, Masstricht.

World Heath Organisation/ International Diaberes Federanion Europe [WHO/IDF] (1990). Diabetes care and research in Europe the Sant Wincent Decharan. Diabetic Medicine 7:360.

World Health Organisation [WHOJ (1997). The world health repon 1997: conquering suffering,enriching humaniry. WHO, Geneva. 


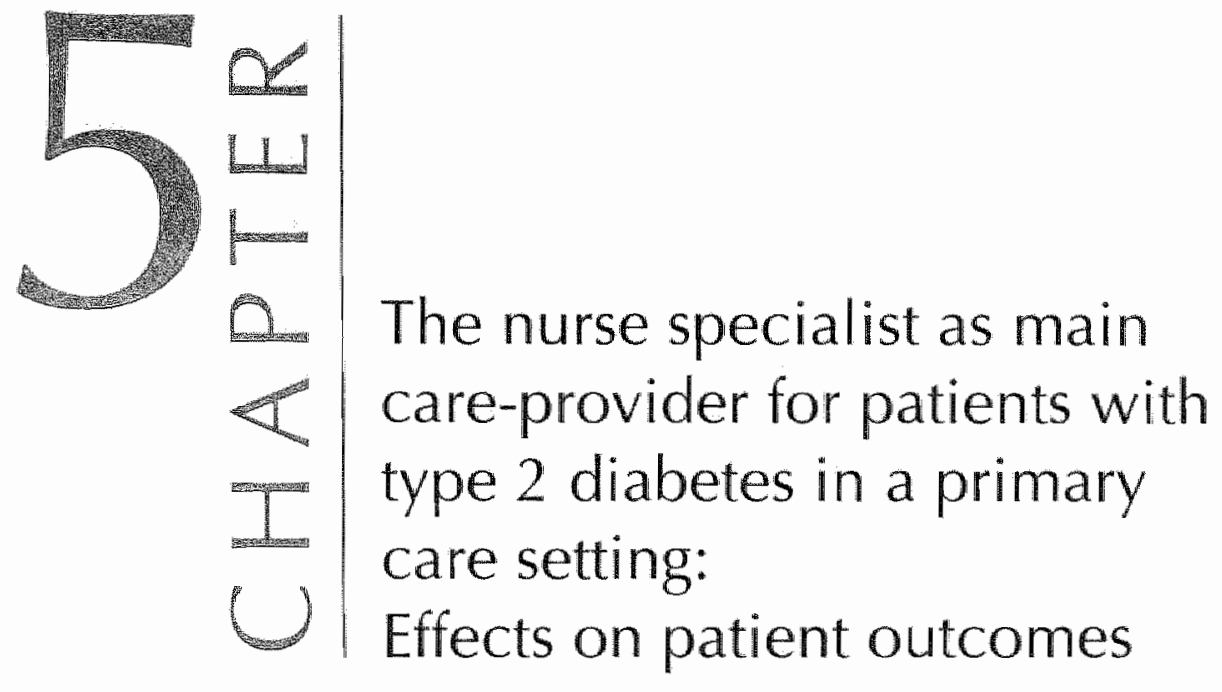

by Vrijhoef HIM, Diederiks IPM, Spreeumenberg C, Wolffenbuttel BHR, Van Wilderen LJGP.

Based on paper published in International Journal of Nursing Studies $2002 ; 39: 441-51$ 
A solution to safeguard high qualiry diaberes care may be to allocate care to the nurse specialist. By using a one group pretest-postrest design with additional comparsons, this study evaluated effects on parient outcomes of a shared care model with the diaberes nurse as main care-provider for patients with type 2 diabetes in a primary care setting. The shared care model resulted in improved glycamic control, additional consultations and other ourcomes being equivalent to diabetes care before introduction, with the general practitioner as main care-provider. Assignment of care for patients with type 2 diabetes to nurse specialists seems to be justified.

\section{INTRODUCTION}

As health care delivery is being reconfigured, so is the future role of care-providers. Diabetes care has gradually moved from the more traditional hospiral clinic to care shared between secondary and primary care-providers (Hampson er al., 1996). However, because most patients with type 2 diaberes are being treated in primary care (De Sonnaville, 1997), because there is an increasing prevalence rate (Ruwaard et al., 1993), and because general practitioners (GPs) are facing a heavy and increasing workload (Van Duijn and Mentink, 1998), a solution to safeguard high-quality diaberes care in the Nerherlands may be to transfer the work carried out by physicians to other health care professionals.

Substitution of care can be divided into horizontal and vertical substitution. Horizontal substitution refers to the transfer of tasks between care-providers with comparable levels of expertise. This means that tasks can be transferred from specialist to generalist or from inside the hospital to outside the hospital. Vertical substitution refers to the transfer of tasks between care-providers across different levels of expertise. Substiturion does not auromatically imply a complete transfer, but it can also mean that professionals share tasks and responsibilities to bridge deficiencies in care (Spreetwenberg, 1994).

Following the US and the UK, the Nerherlands too have seen nurses in a particular area of care expand their specialist skills into areas perhaps more traditionally seen as the activity of medicine (Barton et al., 1999). Despite the popularity of nurse specialists performing a new role in chronic care that challenges established professional boundaries, ewaluation studies regarding outcome and/or process variables are limited mainly due to the -as yet- underdeveloped nature of this field of study (McGillis Hall, 1997; Lengacher et al., 1997; Temmink et al., 2000; Vrijhoef et al., 2000).

In five general practices (11 GPs) in the region of Venlo a pilot project was introduced in which a diabetes nurse performs the role as main care-provider within a 
shared care model for patients with type 2 diaberes. The jointly formulated objectives of this shared care model were: (1) the improvement of glycaemic control of patients, (2) the efficient provision of diabetes care for patients, (3) the improvement of quality of life of patients as well as (4) their levels of satisfaction with respect to diabetes care.

In order to assess if the model is justified, evidence about the realisation of objectives (1), (3) and (4) as well as about effects on other relevant patient outcomes were provided by this study. For this purpose sellected patient outcomes were evaluated within a 12-monch pretest-posttest design, while the subgroup of parients treated with oral hypoglycaemic agents (OHA) and/or insulin was compared with a group from another study directed at outpatients with stable type 2 diaberes (Vrijhoef et all, 2001). An indication for the efficiency of care delivered by the model was based on data from this study as well as from another study on the costs generated by this model (Keijzer, 1999).

\section{PATIENTS AND METHODS}

\section{Patients and setting}

Patients were recruited from the populations of five general practices (11 GPs) in the region of Venlo between September 1997 and April 1998. Patients with previously documented type 2 diabetes attending the general practice were invited by their GP to participate in the study. Patients were provided with a written description of the study and those who supplied written informed consent were enrolled. After enrolment patients were followed for a period of 12 months. The study was approved by the local scientific and ethical committee.

\section{Study design and procedures}

To assess outcomes of care in the new shared care model, a quasi-experimental pretest-posttest design was used (Cook and Campbell, 1979). Before the shared care model was introduced, eligible patients were treated for their diabetes by the GP as main care-provider and some additionally by the endocrinologist, while consultations with other care-providers were organised via the GP.

In the shared diaberes care model, the GP refers parients with type 2 diabetes to the specialised nurse from whom they receive regular consultations at the GP's practice. The annual number of consultations depends on the health status of the patient. If necessary, the nurse refers patients to other care-providers involved in diabetes care: the dietician, the diabetes community nurse, the podiatrist, the ophthalmologist and the endocrinologist. The diabetes nurse co-operates closely with orher involved 
care-providers. The guidelines of the Dutch Colleges of GPs on the management of type 2 diabetes mellitus (Rutren et al., 1999), which have been drawn up in accordance with international guidelines, were used as a reference for the joindly formulated protocol in which tasks, activities and responsibilities of all care-providers inwolved as well as their interrelations were laid down.

Tasks (activities) of the diabetes nutse comprised the following: direct patient care (medical history, physical examination, interpretation of laboratory results, administration of findings); co-ordination and organisation of care (identification of shortcomings in care, referral to and communicating with other care-providers); consultation (advice to patients and other care-providers); and advancement of expertise (education of patients, themselves and other care-providers). The diabetes nurse has the highest qualification level for nursing care and is seen as a nurse specialist who is focused on diabetes care and who possesses quire distinctive skills in this area of practice (Barton et al., 1999). The role of the GP in the new model of diabetes care is confined to performing one annual consultation, controlling the management of the diabetes of patients, being available on demand for the diaberes nurse in case of irregularities, and having final responsibility for the diabetes care. The endocrinologist is a consultant in diabetes care for the diabetes nurse and the GP.

For practical reasons it was not possible to form a control group for assessing the outcomes of the shared diabetes care model in comparison with usual diaberes care. However, the simultaneous start of a study carried out by the university hospital Maastricht, whose aim was to assess effects on patient outcomes when tasks of diabetes care are transferred from endocrinologist to diabetes nurse and also from outpatient to primary care, made it possible to exrend the study design to an untreated comparison group design with pretest and posttest (Cook and Campbell, 1979) (Figure 1). In this way an artempt was made, in addition to suggesting hypotheses for further research, to assess and interpret more conclusively the outcomes of the shared diabetes care model.

In the Mastricht study outpatients with stable type 2 diabetes receiving usual diabetes outpatient care were compared with patients who were mainly treated by specialised nurses in general pracrices (Vrijhoef et al, 2001). In the Maastricht study patients had stable type 2 diabetes when the concentration of glycated haemoglobin $\left(\mathrm{Hb} \mathrm{A}_{\mathrm{I}}\right)$ was $10.5 \%$ or less for the preceding six months at least, and were free of active diabetes-related complications and free of other diseases not related to diabetes for which care from a medical specialist is received. The control group of the Maastricht study, referred to as outpatient group, was used for making comparisons. Usual outpatient care for patients with stable type 2 diabetes consists of regular consultations by the endocrinologist in the hospital. With usual outpatient care for patients with stable type 2 diabetes being substitured both horizontally and vertically, the outpatient group was considered suitable for comparing outcomes of care. 
Group

$\mathrm{TO}(0)$

T16)
$12(12)$

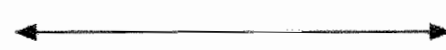

subgraup stiared care reated with OHA and/or insulin (region of Venlo)

ourparient group (region of Maastriche)

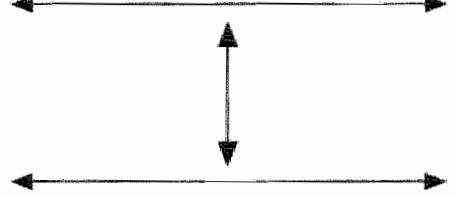

20

23

All patients from the outpatient group were treated with OHA and/or insulin. With diet, OHA, and insulin being successive steps in glycaemic regulation and thus indicators for the severity of diabetes, the subgroup of parients receiving shared care and also being treated with OHA and/or insulin at baseline was compared with the outpatient group.

\section{Outcome meastires}

The outcomes identified for this study were derived from the distinctions made by Donabedian (1992), Long et al. (1993) and Driessen et al. (1994), who seem to agree on patient outcomes for evaluation when the goal is to assess the effects of an intervention concerning quality of chronic care. As indicators of effectiveness, clinical parameters, patient satisfaction, quality of life, self-care behaviour and disease specific knowledge were measured, while consultarions with care-providers were used as an indicator of efficiency.

Clinical parameters. The main outcome measure was the change in glycaemic control, defined as the change in glycated haemoglobin level $\left(\% \mathrm{HbA}_{10}\right)$ and measured using standard laboratory measures. For all parients, first and last assessment of $\mathrm{HbA}_{\mathrm{ic}}$ within the study period were evaluated as were the proportions of patients with good $\left(\mathrm{HbA} \mathrm{I}_{\mathrm{c}}<7.0 \%\right)$, moderate $\left(7.0 \% \geq \mathrm{HbA}_{1 \mathrm{c}}<8.5 \%\right)$ or bad glycaemic control $\left(H b A_{1 c} \geq 8.5 \%\right)$. 
Clinical starus was also determined by systolic blood pressure, diastolic blood pressure, total cholesterol concentration, high density lipoprotein cholesterol concentration, and triglyceride concentration.

Patient satisfaction. Patient satisfaction was measured by asking patients to grade the received care with a report mark (between I for 'low quality of care' and 10 for 'high quality of care'); whether they would recommend the received care to other patients ("yes' or 'no'); and whether they intended to continue using the experienced care in future ('yes, " no,' 'no preference). These items are derived from industrial marketing management and were applied earlier in the same area of research (Cockroft et all, 1987; Grassic, 1994).

Quality of life. Quality of life was defined as health status of parients and measured with the COOP/WONCA charts and a Visual Analogue Scale (VAS), both having proved to be valid instruments (Maxwell, 1978; Nelson et al., 1987; Van Weel, 1993). The charts consist of six single-item measures: physical fitness, feelings, daily activities, social activities, change in health and overall health. Each chart represents a distinct domain, refers to a two-week period, and has a five-point Likert scale where five indicates the worst level. The VAS was used as single-item measure of quality of life. It consists of a 10-centimerre long horizontal line with 'low quality of life' at the left end of the line and 'high quality of life' at the right. For borh instruments Dutch versions were used.

Disease-specific knowledge of patients and self-care behaviour. In addition to the stated objectives of the shared care model, two more classic outcomes related to the murse's interpersonal competence were assessed. Disease-specific knowledge of patients was measured using a Dutch diaberes-specific instrument. This instrument contains 12-multiple choice questions. Each correct answer yields one point and the total score is achieved by summing the correct answers. No data about the reliability of this instrument has been published (Ripken et al., 1990). Reliability analysis on the data of this study yielded a Cronbach's alpha of 0.80 .

Self-care behaviour of patients was measured with a Dutch diaberes-specific instrument, the Self-Care Behaviour Checklist (SCBC). The SCBC consists of four factors (18 inems): self-regulation (three items); bodily observation and conditioning (three items); recording activity of condition (four items); and diet application and commitment (eight items). Every item consists of a five-point Likert scale ranging from 'never' to 'always. 'Scores for each factor were computed (sum divided by range) and also the toral score (sum divided by range). The $S C B C$ was found to be a valid instrument to measure self-care behaviour of diabetes parients (Pennings-van der Eerden, 1992). 
Improvements in both self-care behaviour and knowledge about diabetes were expected to occur.

Consultations with care-providers. As an indicator of efficiency diaberes-related consultations of patients with care-providers were measured. Patienrs were asked to record the number of consultations received from diabetes nurse, GP, and/or endocrinologist.

Co-variables. Diabetes treatment and duration of diabetes served as co-variables. Trearment was specified as diet only, diet with OHA, diet with OHA and insulin, and diet with insulin. A switch berween these treatment regimes was considered as at change in diabetes treatment.

Clinical data were collected when patients attended the general practice for consulration for a period of 12 months after enrolment of patients. Data regarding orher indicators of qualiry of care were collected with questionnaires immediately prior to introduction of the shared care model (TO), after six months (T1) and after 12 months (T2). Questionnaires were mailed with an explanatory letrer to patients in postage-free envelopes. In the Maastricht study identical instruments and moments of measurements were used.

\section{Statistical analysis}

Differences between baseline characteristics were tested using chi-square test and Student's t-test for independent samples. To assess differences in clinical parameters within groups Student's r-test for paired data was used. Analysis of covariance (ANCOVA) was performed for between groups comparisons of change in $\mathrm{HbA}_{1 \mathrm{c}}$ with baseline measurement and duration of diabetes as co-variates. Proportions of patients with good, moderate, or bad glycaemic control were compared between first and last measurement with chi-square rest.

One factor repeared-measures analysis of variance was used for satisfaction rate, VAS, COOP/WONCA charts, Jknowledge and self-care behaviour of patients in the shared care group with complete data and within groups treated wirh OHA and/or insulin. For analysing differences in these outcomes between groups treated with OHA and/or insulin, ANCOVA was used with baseline measurement as co-variate. Comparison of the number of consultations with care-providers within group was performed with Friedman test, while Kruskal-Wallis one-way analysis of variance was used for comparisons berween groups treated with OHA and/or insulin.

All data were analysed on the basis of intention to treat: missing responses were estimated using the last observed response (carry forward). A significance level, $\mathrm{p}=0.05$ (two tailed), was used. Data processing and analyses were conducted with SPSS (Windows Release 9.0). 


\section{Patients}

Of the 325 eligible patients identified by the GPs, 150 (46.2\%) did not participare. Reasons for non-participation were lack of interest (7.7\%), too much rouble (3.4\%), several low prevalence reasons $(6.5 \%$, made up of: mobility problems $(0.9 \%)$, feeling too old $(0.6 \%)$, private reasons $(1.5 \%)$, admitted to hospital $(2.2 \%)$, and unwilling to change care-provider $(1.2 \%))$ or unknown $(28.6 \%)$. Data from consultations were available for all 175 participants. Data from questionnaires were available for 155 patients $(88.6 \%)$ at $\mathrm{T} 0$, for 122 parients $(69.7 \%)$ at $\mathrm{T} 1$, and for 103 patients $(58.9 \%)$ at T2. Main reasons for not returning the questionnaires were loss of interest and antipathy to completing them.

The basic characteristics for patients of whom complete data were available were compared with patienrs for whom data from questionnaires at $\mathrm{T} 0, \mathrm{~T} 1$ and/or $\mathrm{T} 2$ were missing (Table 1). Patients with missing data from questionnaires had suffered from diaberes on average four years longer, had worse glycaemic control, and were less often married than patients with complere data. The basic characteristics for patients from the shared care subgroup with complete data were also compared with patients from the outpatient group with complete data.

Outpatients were on average 5.4 years older than patients from the shared care subgroup. Parients from the outpatient group with complete data differed from outpatients without complete data by having worse glycaemic control (no data given).

\section{Clinical parameters}

Mean $\mathrm{HbA}_{1 \mathrm{c}}$ of patients from the shared care group improved statistically significandly by $0.3 \%$ to $7.7 \%$ (Table 2). Improvement of mean $\mathrm{HbA}_{1 \mathrm{c}}$ was found in the group of parients with missing dara $(0.3 \%)$ and in the group of patients in whom diaberes therapy was unchanged $(0.2 \%)$. Between subgroups no statistically significant differences in change in $\mathrm{HbA}_{1 \mathrm{c}}$ were found. The proportion of badly regulated patients $\left(\mathrm{HbA}_{\mathrm{Ic}}>8.5 \%\right.$ ) decreased by $6.3 \%$ to $20.3 \%$ in the shared care group, by $13.1 \%$ (to $30.4 \%$ ) and $5.2 \%$ (to $18.5 \%$ ) in the group of patients with changed and unchanged diabetes therapy respectively, by $7.9 \%$ (to $42.1 \%$ ) in the shared care group treated with OHA and/or insulin, while in the ourpatient group an increase of $10.9 \%$ (to $52.2 \%$ ) appeared. In all (sub)groups the distribution of patients according to level of diabetes control changed statistically significantly between first and last measurement favourably except for the outpatient group in which after one year follow-up fewer people showed good or moderate glycaemic control. 


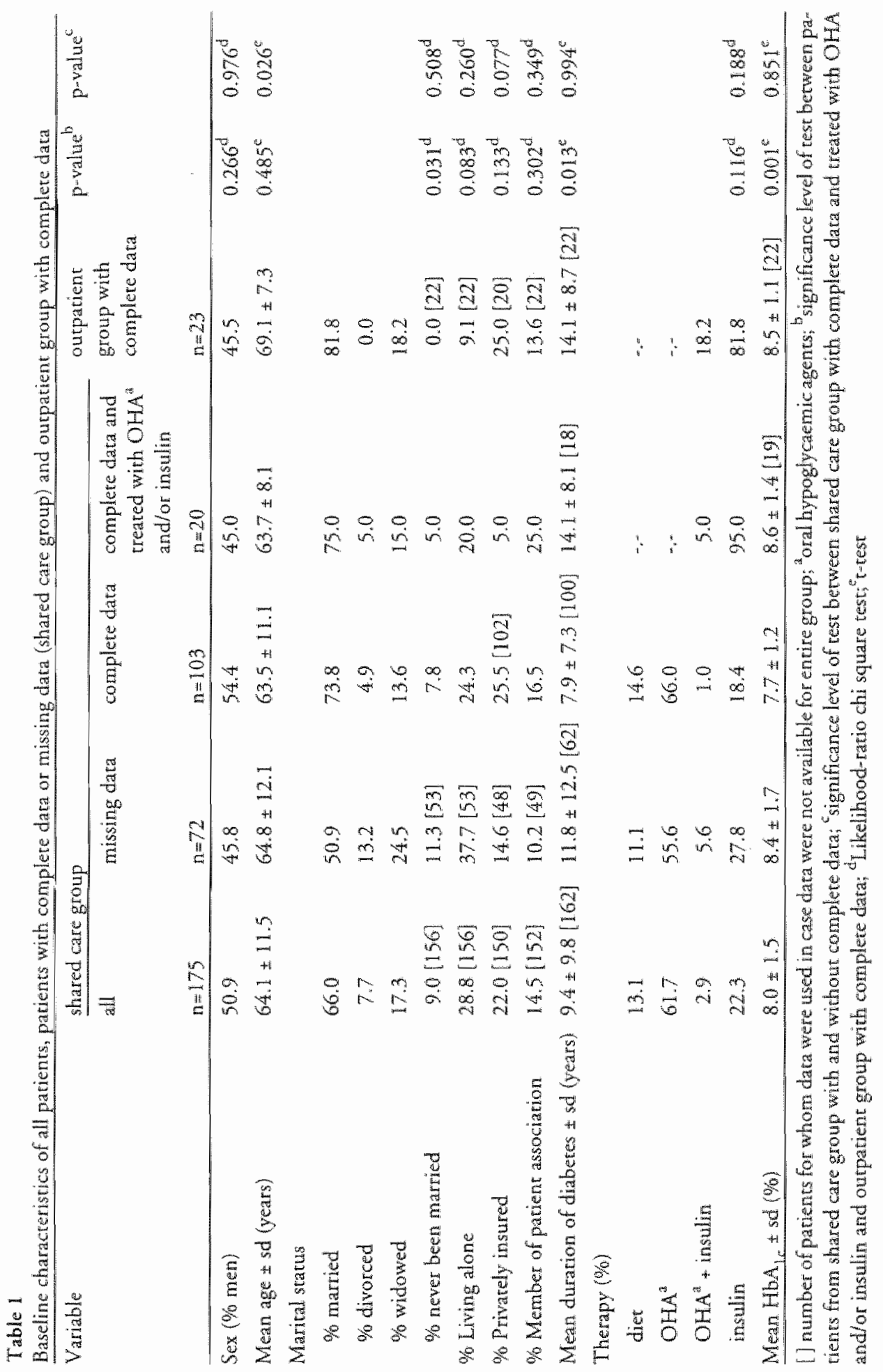


Table 2

Effects in glycaemic control $(\% \mathrm{HbA})$

\begin{tabular}{|c|c|c|c|c|c|c|}
\hline Group of patients & $\mathrm{n}$ & $\begin{array}{l}\text { Grst } \\
\text { measurement } \\
\text { (mean } \pm \mathrm{sd} \text { ) }\end{array}$ & $\begin{array}{l}\text { last } \\
\text { measurement } \\
\text { (mean } \pm \text { sd) }\end{array}$ & $\begin{array}{l}\text { P-value } \\
\text { within } \\
\text { group }\end{array}$ & $\begin{array}{l}\text { last-first } \\
\text { measutement } \\
\text { (mean } \pm \mathrm{sd} \text { ) }\end{array}$ & $\begin{array}{l}\text { p-value } \\
\text { between } \\
\text { groups }\end{array}$ \\
\hline shared care & 158 & $8.0 \pm 1.5$ & $7.7 \pm 1.3$ & 0.001 & $-0.3 \pm 1.0$ & * \\
\hline complete data & 98 & $7.6 \pm 1.2$ & $7.4 \pm 1.0$ & 0.069 & $-0.2 \pm 0.1$ & \\
\hline missing data & 60 & $8.3=1.6$ & $8.0 \pm 1.4$ & 0.004 & $-0.3 \pm 0.8$ & $0.5 \pi 1$ \\
\hline changed therapy & 23 & $8.7 \pm 1.6$ & $8.2 \pm 1.5$ & 0.081 & $-0.5 \pm \mathbb{1} .3$ & \\
\hline unchanged therapy & 135 & $7.7 \pm 1.3$ & $7.6 \pm 1.1$ & 0.010 & $-0.2 \pm 0.8$ & 0.851 \\
\hline $\begin{array}{l}\text { shared care } \\
\text { (OHA/insulin) }\end{array}$ & 38 & $8.8 \pm 1.4$ & $8.4 \pm 1.3$ & 0.008 & $-0.4 \pm 1.0$ & \\
\hline outparienr care & 46 & $8.2 \pm 1.1$ & $8.5 \pm 1.3$ & 0.005 & $+0.3 \pm 0.8$ & 0.001 \\
\hline
\end{tabular}

${ }^{3}$ corrected for baseline wallue of $\mathrm{HbA}_{1 c}$ and duration of diaberes.

Table 3

Outcomes within shated care group

\begin{tabular}{lll} 
Outcome (min-max) & $\frac{\text { measurement (mean } \pm \mathrm{sd})}{\mathrm{T}^{\mathrm{a}}} \mathrm{T1^{ \textrm {b } }} \mathrm{T}^{\mathrm{c}}$ & $\mathrm{p}$-value F-sratistic \\
\hline
\end{tabular}

Sittiffaction

Satisfaction rate $(0-10)$

$95 \quad 8.0 \pm 1.3 \quad 8.2 \pm 1.0 \quad 8.1 \pm 1.0 \quad 0.308^{d} \quad 1.175$

Quality of life

VAS $(0-10)$

Physical fincess $(5-1)$

Feelings $(5-1)$

Daily activities $(5-1)$

Social activities $(5-1)$

Charge in health $(5-1)$

$\begin{array}{llllll}100 & 5.4 \pm 2.5 & 5.3 \pm 2.5 & 5.7 \pm 2.4 & 0.249 & 1.401\end{array}$

$\begin{array}{llllll}98 & 2.6 * 1.3 & 2.5 \pm 1.3 & 2.7 \pm 1.3 & 0.598 & 0.516\end{array}$

$101 \quad 2.2 \pm 1.2 \quad 2.1 \pm 1.0 \quad 2.2 \pm 1.2 \quad 0.502^{d} \quad 0.673$

$\begin{array}{lllllll}101 & 2.0 \pm 1.1 & 2.1 \pm 1.1 & 2.1 & 1.0 & 0.569 & 0.565\end{array}$

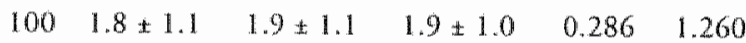

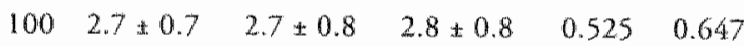

Overall health $(5-1)$

Knowledge and selfoure bebanow

Knowledge (0-12)

$\begin{array}{lllllll}102 & 3.1 & \pm 0.9 & 3.2 \pm 1.0 & 3.2 \pm 1.0 & 0.671 & 0.399\end{array}$

Diet application $(1-5)$

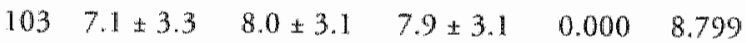

$\begin{array}{lllllll}73 & 3.5 \pm 1.0 & 3.5 \pm 0.9 & 3.4 \pm 0.9 & 0.766 & 0.267\end{array}$

Selfregulation $(1-5)$

Activity of condicion (1-5)

$\begin{array}{llllll}47 & 3.4 \pm 1.2 & 3.9 \pm 1.1 & 3.9 \pm 1.2 & 0.012 & 4.619\end{array}$

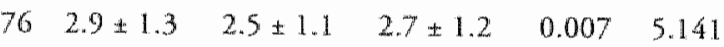

Bodily observation and conditioning (1-5)

$81 \quad 3.3 \pm 1.3 \quad 3.5 \pm 1.3 \quad 3.8 \pm 1.2 \quad 0.000 \quad 8.092$

Overall self-care behaviour (1-5)

$\begin{array}{llllll}21 & 3.4 \pm 0.7 & 3.4 \pm 0.8 & 3.4 \pm 0.6 & 0.851 & 0.162\end{array}$

"To baseline; "T1 firse post measurement; $\mathrm{T} 2$ second post measurement; ${ }^{\text {"C }}$ Creenhouse-Geisser adjusted univariate approach 
The mean $\mathrm{HbA}_{1 \mathrm{c}}$ of patients treated with OHA and/or insulin and receiving shared care showed a statistically significant improvement of $0.4 \%$ to $8.4 \%$, while in the group of outpatients the mean $\mathrm{Hb}_{1 \mathrm{c}}$ deteriorated statistically significantly by $0.3 \%$ to $8.5 \%$. This difference in change was found to be statistically significant when corrected for baseline $\mathrm{HbA}_{1 \mathrm{c}}$ and duration of diabetes.

In the shared care group improvements were found in mean diastolic blood pressure, by $4.0 \mathrm{mmHg}$ to $80.6 \mathrm{mmHg}(\mathrm{n}=124 ; \mathrm{p}=.000)$, in total cholesterol concentration, by $0.1 \mathrm{mmol} / 1$ to $5.6 \mathrm{mmol} / \mathrm{l}(\mathrm{n}=130 ; \mathrm{p}=.048)$, and in the concentration of triglyceride, by $0.2 \mathrm{mmol} / \mathrm{l}$ to $1.8 \mathrm{mmol} / \mathrm{l}(\mathrm{n}=128 ; \mathrm{p}=.005)$. A statistically significant difference ( $\mathrm{p}=.016$ ) was found berween groups for change in systolic blood pressure: an improvement of $5.1 \mathrm{mmHg}$ was found in the group with complete data $(\mathrm{n}=80)$, while a deterioration of $4.5 \mathrm{mmHg}$ was found in the group with missing data $(\mathrm{n}=31)$. Due to insufficient data abour blood pressures and lipids of ourpatients, no analyses between the shared care group and outpatient group could be performed for these clinical parameters.

\section{Patient satisfaction}

Mean satisfaction rates of patients receiving shared care were high and fairly stable (Table 3). The mean rate at T0 reflects satisfaction of patients with traditional care, while mean rates at $T 1$ and $T 2$ reflect patient satisfaction with the shared care model. The comparison of the subgroup treated with OHA and/or insulin with the outpatient group also showed mean satisfaction rates around the value of eight for all measurements, indicating high mean satisfaction of patients with received care. No statistically significant changes were found either within or between groups.

At baseline $96 \%$ of patients ( $n=95$ ) stated they would recommend traditional care to others. After having received shared care, $97 \%$ of patients at both $\mathrm{T} 1$ and $\mathrm{T} 2$ would recommend shared care. When patients ( $n=98$ ) were asked if hey would make use of care in the furure, at T0 $97 \%$ said they would use traditional care. After having received shared care, at 'T1 $64 \%$ of patients said they would use shared care in the future, whille $33 \%$ of patients showed no particular preference berween traditional care and shared care. At T2 these percentages were $76 \%$ and $12 \%$ respecrively.

As for recommending care to others when the subgroup treated with $\mathrm{OHA}$ and/or insulin $(n=19)$ was compared with outpatients $(n=21), 95 \%$ or more of patients in both groups for all moments of measurement said they would do so. As for making future use of traditional care for all measurements the entire outpatient group $(n=21)$ said they would. The same was seen at baseline in the shared care group $(n=20)$, while at T1 60\% said they would make use of shared care in the future and $35 \%$ showed no preference. Ar T2 these percentages were $75 \%$ and $10 \%$ respectively. 


\section{Quality of life}

On the VAS for quality of life amongst parients, no statistically significant changes were found in the shared care group (Table 3). Means were slightly above the middle of possible values. The subgroup of patients treated with OHA and/or insulin showed mean scores under the middle of possible values for all measurements. Within and between the subgroup treared with OHA and/or insulin and the outpatient group, no statistically significant differences were found.

With regard to the COOP/WONCA charts, fairly steady mean values were found for all scales in the shared care group (Table 3). None of the changes found was staristically significant. Patients treated with $\mathrm{OHA}$ and/ or insulin showed mean scores that were fairly similar to entire shared care group on all charts. Wirhin the subgroup receiving shared care and treated with $\mathrm{OHA}$ and/or insulin, a statistically significant deterioration was found in change in health $(F=4.065 ; \mathrm{p}=0.026)$. Within the outpatient group no changes were found. No changes were found between the groups treated with diabetes medication.

\section{Disease-specific knowledge of patients and self-care bebaviour}

Patients receiving shared care showed a statistically significant improvement in their mean level of knowledge about diabetes during the study (Table 3). Means with respect to the diabetes knowledge of patients treated with $\mathrm{OHA}$ and/or insulin were higher than for the entire shared care group. When the subgroup of patients receiving shared care and treated with OHA and/or insulin was compared with outpatients no statistically significant changes within or between groups were found.

With regard to self-care behaviour in the shared care group, statistically significant improvements were seen in means for self-regulation and for bodily observation and conditioning, while a statistically significant deterioration was seen in activity of condition (Table 3). Activity of condition deteriorated between baseline and first post measurement, but improved towards the end of the study. Improvement here means more frequent performance, while deterioration means less frequent performance. Data required to assess overall scores in self-care behaviour could only be obtained for 21 patients. No change was seen in overall score. When the subgroup of patients receiving shared care and treated with OHA and/or insulin was compared with the outpatient group for self-care behaviour, higher means were shown at baseline for self-regulation and bodily observation than for the entire shared care group. No statistically significant changes were found within or between groups. 
Table 4

Consultations of parients with care-providers

\begin{tabular}{|c|c|c|c|c|c|c|}
\hline \multirow[t]{2}{*}{ Outcome } & \multirow[t]{2}{*}{$n$} & \multicolumn{3}{|c|}{ measurement (mean $\& \mathrm{sd})$} & \multirow[t]{2}{*}{ chi-square } & \multirow[t]{2}{*}{ p-value } \\
\hline & & $70^{\mathrm{a}}$ & $\mathrm{T}^{\mathrm{b}}$ & $\mathrm{T} 2^{\circ}$ & & \\
\hline \multicolumn{7}{|l|}{ Consultations with care-providers } \\
\hline Consultations with diaberes nurse & 87 & $0.6 \pm 1.3$ & $2.0 \pm 1.2$ & $1.7 \pm 1.7$ & 60.316 & 0.000 \\
\hline $\begin{array}{l}\text { Consultations with general practi- } \\
\text { tioner }(G P)\end{array}$ & 90 & $1.3 \pm 1.3$ & $1.7 \pm 1.6$ & $1.2 \pm 1.1$ & 7.977 & 0.019 \\
\hline Consultations with endocrinologist & 93 & $0.2 \pm 0.6$ & $0.2 \pm 0.6$ & $0.2 \pm 0.6$ & 1.914 & 0.384 \\
\hline $\begin{array}{l}\text { Consullations wich diaberes nurse * } \\
\text { GP + endocrinologist }\end{array}$ & 85 & $1.9 \pm 1.9$ & $4.0 \pm 2.8$ & $3.1 \pm 2.3$ & 45.452 & 0.000 \\
\hline
\end{tabular}

${ }^{a}$ To baseline; ${ }^{b}$ Tr first post measurement; ${ }^{\text {T }}$ 2 second post measurement

\section{Consultations with care-providers}

The partern of consultations of patients in the shared care group showed a statistically significant increase in mean number of consultations with the diabetes nurse, with fairly stable means for number of consultations with the endocrinologist (Table 4). The number of consultations with the GP increased from baseline to $\mathrm{T} \mathbb{1}$ and decreased back to baseline level at $\mathrm{T} 2$. Overall mean number of consultations increased from baseline to $T \rrbracket$ and remained statistically significantly higher.

When the subgroup of patients receiving shared care treated with insulin and OHA was compared with the outpatient group, a statistically significant difference was found in the mean number of consultations with the diabetes nurse between groups, with an increase in the shared care group. The groups also differed for mean number of consultations with the endocrinologist, with higher consumption in the outpatient group. For the number of consultations with all three care-providers, it was found that the statistically significant difference between groups at baseline, with a smaller mean consumption in the shared care group, disappeared at $\mathrm{T} 2$.

\section{DISCUSSTON}

The effectiveness of new models for chronic care has largelly gone untested (Davis et al., 1999). In this study, evidence abour a shared care model for patients with type 2 diabetes was gathered when the diabetes nurse is the main care-provider in a primary care setting. Applying a quasi-experimental design, it was found that the glycaemic control, diastolic blood pressure, and the concentration of toral cholesterol and triglyceride of patients receiving shared care improved, while qualiry of life and satisfaction of these patients remained equal when compared with the situation before the 
shared care model was introduced. Furthermore, improvements were found in knowledge, self-regulation, and bodily observation and conditioning, while activity of condition increased towards the end after having decreased between start and first post measurement. Overall self-care remained unchanged. Patients reported consulting the diaberes nurse in addition to the GP. Comparisons of the subgroup treated with OHA and/or insulin with an outpatient group - except for blood pressures and lipids showed better glycaemic control and more consultations with the diabetes nurse as remaining affects.

A review of the literature about care models with the nurse specialist in the central role showed improvements in self-care, quality of life, patient satisfaction and increase in medical consumption depending on the division of tasks berween care-providers (Vrijhoef et al., 2000). Improved glycaemic control was found in two trials with the diabetes nurse making follow-up telephone calls (Kirkman et al., 1994; Aubert et al., 1998). The Maastricht study, from which the control group was used, evaluated effects of borh horizontal and vertical substitution and showed equal patients ourcomes in all except glycaemic control (Vrijhoef et al., 2001). The glycaemic control of patients treated by the diabetes nurse as main care-provider was found somewhat better than that in patients receiving usual outpatient care.

This study has several limitations, the first of which concerns the study popularion. All patients with type 2 diabetes from the participating GPs received shared care with the nurse as main care-provider. Not all of these patients participated in this study nor provided complete data. The response rate $(54 \%)$ and completion rate $(59 \%)$ of the shared care group were rather low, yer not uncommon in current longitudinal studies with the chronically ill. With sponsorship of the questionnaire by the GPs, an explanatory letter, postage-free envelope, as well as reminders, several steps to help increase the response rate were taken. The considerable length of the questionnaire could have put off respondents. The study findings may have been biased, because patients with incomplete data suffered on average longer from diabetes and had worse mean glycaemic control. In addition to estimating the missing tesponses by impuring the last observed response, reanalyses were performed for the variables with most missing values: patient satisfaction rate, quality of life, knowledge, self-care behaviour, and consultations (data not shown). Missing responses at baseline were replaced by the mean of the group and subsequently carried forward. Reanalyses were performed on the data of 155 patients at three measurements and largely confirmed the research findings. With regard to quality of life a statistically significant deterioration in social activities for the shared care group was found, while between subgroups treated with OHA and/or insulin a statistically significant difference was found for change in health. With regard to self-care behaviour statistical significant improvements were found within the shared care group for activity of condition and bodily observation and conditioning, while a difference was found for the overall score in self-care behav- 
iour between the groups of patients treated with OHA and/or insulin. The subgroup of patients receiving shared care showed an improvement in overall score in self-care behaviour, while the outparient group showed a deterionation. The applicability of our findings to all patients with (type 2) diabetes being treated in primary care requires furrther study.

A second limitation is the applied study design. With regard to research about the effecriveness of complex interventions like the shared care model assessed here, the randomised controlled trial as ideal design could not be met. To strengthen the evidence of the outcomes of the shared care model under real life conditions, Van Weel and Knotnerus (1999) proposed the use of alternative designs. Within the restrictions we met, use was made of a rwelve-month one-group pretest-posttest design with additional comparisons for the subgroup of patients treated with oral hypoglycaemic agents and/or insulin with patients from the control group of a study directed at outpatients with stable type 2 diabetes. Treatment with insulin is the last step in glycaemic control and, as advised by the guideline (Rutten et al., 1999), GPs often make use of secondary care when therapy with insulin is appropriate. This explains the relatively small size of the subgroup of patients treated with OHA and/or insulin in the primary care setting considered in this study. Notwithstanding the size of groups compared and thus the difficulty for assessing effects, not performing the comparison would certainly leave the findings of the pretest-posttest design hard to interpret.

Since data about glycated haemoglobin were available for all patients who responded, one can have reasonable confidence in the improved glycaemic control found in the entire shared care group as well as in the subgroup treated with OHA and/or insulin. Improved glycaemic control can be obtained by life-style changes and/or through therapy (Fisher et al., 1997). With no difference in the effect on $\mathrm{HbA} \mathrm{A}_{1 \mathrm{c}}$ between patients with unchanged and changed diabetes therapy, the effects may most probably be ascribed to life-style changes recommended and/or reinforced by the main care-provider, the diaberes nurse. This supposition seems reasonable with the improvements in knowledge, self-regulation, and bodily observation and conditioning found in the shared care group. These improvements did not remain in the subgroup treated with OHA and/or insulin, but were more difficult to find because of the small group size. Moreover, baseline means for knowledge and self-care behaviour of patients treated with diabetes medication were more or less equal to that of the entire shared care group at final measurement. Changed diabetes therapy in this study means a transition between the existing modes of therapy. When receiving diabetes medication, a change in dose is the most accurate measurement for change in therapy. No statistically significant correlation between change in $\mathrm{HbA}_{1 c}$ and change in doses of OHA and/or units of insulin was found in the groups treated with diabetes medication. 
Although the exact dinical magnirude of the improved glycaemic control in patients as found in this study is hard to express, any improvement in glycaemic control across the diabetic range is likely to reduce the risk of diabetic complications. Moreover, the lower the glycaemia the lower the risk of complications (Stratton et al., 2000). Furthermore, when patients suffer less from diabetic complications, their quality of life scores are expected to improve as well. Future research should address this relation as well.

Without data about blood pressures and lipids from the outpatient group, the differences found in these clinical parameters in patients receiving shared care are hard to interpret. In the earlier mentioned trials with the diabetes nurse making follow-up telephone-calls no differences in blood pressures or lipids were found berween groups (Kirkman et al., 1994; Aubert et al., 1998). The application of electronic patient records might result in a more complete clinical data set and enable statistical analysis.

The instrument applied to assess self-care behaviour of patients also limits the results of this study. The overall score could only be assessed for a minority of the parients because sub-scales were not administered completely. The SCBC has recently been simplified but its psychometric qualities remain unknown (Van den Arend et al., 2000). More research should be initiated into psychometric characteristics of existing instruments to measure self-care behaviour of (Durch) diabetes patients or perhaps even into the development of new instruments.

A fifth limitation of the study is related to the measurement of consultations of patients with care-providers. Some patients appeared to consult the diabetes nurse at baseline, so before the introduction of the new shared care model. The most reasonable explanation is confusion among patients about the role performed by the nurse. With the same person working as practice nurse before introduction of the new model and as diaberes nurse after, it was at least at baseline unclear for patients that the same person performed different roles in care. In a study about the direct medical costs of this shared care model the time-span of consultations as well as time-prices were assessed (Keijzer, 1999). Keijzer (1999) reported that there was no difference in direct medical costs between traditional diabetes primary care and new shared care. The consultations of patients with GPs in the shared care model seem to be shorter than before introduction. With only data about medical consumption and direct medical costs, a well-founded basis for assessing the cost effectiveness of the shared care model is lacking. This issue also needs to be addressed in future research.

In the evaluated model the diabetes nurse is taking on roles and tasks beyond those traditionally performed by physicians. By allocating tasks and responsibilities the relationship berween the GP and the diabetes nurse is one of partnership. Patient ourcomes were equal to or better than pre-existing care arrangements. There is no single diaberes management model to be applied everywhere, but this study clarifies that the substiturion of rasks from physician to diabetes nurse seems to be justified in 
terms of patient outcomes and can be part of such a model. Nevertheless, for (broader) implementation of the nurse specialist in diabetes care, several difficulties like educational preparation for undertaking the role of nurse specialist, appropriate salary, professional collaboration, and evaluation and quality control need to be addressed.

The evidence from this study seems to justify continuation of a model of shared diabetes care with the diaberes nurse as main care-provider for patients with rype 2 diabetes in a primary care serting. High quality care was safeguarded, while future research should provide evidence about the cost-effectiveness. With the continuous rise in the need for chronic disease management the pressure will increase on nurses to deliver that care. When non-physicians are assigned the responsibilities for chronic care, their roles extend, and new models of multi-professional team-working which meet the needs of the growing number of chronically ill people become available.

\section{ACKNOWLEDGEMENTS}

This study was supported by a grant from Stimuleringsprogramma Gezondheidsonderzoek [Incentive Programme for Health Care Research] and Health Insurer VGZ [Zorgverzekeraar VGZ]. The authors gratefully acknowledge the help of H. van Dam, H. Geven, A. Seegers ( $\dagger$ ), M. Vorstermans, and M. van Wilderen-Smeets in providing care in its broadest meaning and $T$. Vullings for her help with data-entry.

\section{REFERENCES}

Aubert RE, Herman WH, Waters J, Moore W, Sutton D, Peterson BL, Bailey CM, Koplan JP (1998). Nurse case management to improve glycemic control in diabetic patients in a health maintenance organization. A randomized, controlled trial. Annals of Internal Medicine 129(8):605-12.

Barton TD, Thome R, Hopstroff M (1999). The nurse practicioner: redefining occupational boundaries? International Journal of Nursing Srudies 36(1):57-63.

Cockroft A, Bagnall P, Heslop A, Andersson N, Heaton R, Batstone J, Allen J, Spencer P, Guz A (1987). Controlled trial of respiratory health worker visiting patients with chtonic respivatory disability. British Medical Journal 294(6566):225-7.

Cook TD, Campbell DT (1979). Quasi-experimentation. Design \& analysis issues for field settings. Rand McNally College Publishing Company, Chicago.

Dawis RM, Wagner EH, Growes T (1999). Managing chronic disease. British Medical Journal 318(7191): 1090-1.

De Sonnaville JJJ, Bouma M, Colly LP, Devillé W, Wi,kel D, Heine RJ (1997). Sustained good glycaemic control in NIDDM patients by implementation of strucrured care in general practice: 2-year follow-up study. Diabetologia 40, $1334-40$.

Donabedian A (1992). The role of outcomes in quality assessment and assurance, Quality Review Bulletin 18(11):356-60.

Driessen S, Casparie AF, Van den Bos GAM (1994). Uitkomstindicaroren voor kwaliteitsbewaking en-bevordering in de zorg woor chronisch zieken lOutcome indicators for qualiry assurance and 
improvement in the care for chronically ill]. Sudy 4 from Research programme Quality of Care: Dutch Organisation for Scicntific Research (NWO), The Hague.

Fisher EB, Arfken CL, Heins IM, Houston CA, Jeffe DB, Sykes RK (1997). Acceprance of diabetes regimes in adulrs. In Gochman, D.S., ed. Handbook of Behaviour Research. Part Il: Provider determinants. Pllenum Press, New York.

Grampian Asthma Study of Integrated Care [GRASSIC] (1994). Integrated care for asthma: a clinical, social, and economic evaluation. British Medical Journal 308(6928):559-564.

Hampson JP. Roberts RI, Morgan DA (1996). Shared care: a review of the literature Journal of Family Pinctice 13(3):264-79.

Keijzer FB (1999). De kontenvergelijking wan de reguliere en transmurale diabetes mellinus rype 2 zorg. Een toepassing van a $\mathrm{ABC}$-methode (docroraalscriptic). [The comparison of costs betwen ustal rype 2 diaberes care and shared type 2 diabetes care. An application of the A.BC method (masters thesis)]. Universiteit Mastricht, Maastricht.

Kirkman MS, Weinberger M, Landsman PB, Samas GP, Shortlife EA, Simel DL, Feussner JR (1994). A relephone-delivered intervention for patients with NIDDM. Diaberes Care 17(8):840-6.

Lengacher CA. Mabe PR, Hememann D, VanCotr ML, Kent K, Swymer S (1997). Collaboration in. research: resting the $P I P C$ model on clinical and nonclinical ourcomes. Nursing Connections $10(1): 17-30$

Long AF, Dixon P, Hall R, Carr-Hill RA, Sheldow TA (1993). The ouccomes agenda: contriburion of the UK clearing home on heal hith ourcomes. Qualiry in Health Care 2:49-52.

Maxwell C (1978). Sensitivity and accuracy of the visual analogue scalle a psycho-physical classroom experiment. Brisish Jounal Clinical Pharmacology 6(1) 15-24.

McGillis Hall L (1997). Staff mix models: complementary or substitution roles for nurses. Nursing Administration Quarterly 21(2):31-9.

Nelson EC, Warson K, Kirk J, Keller A, Clark D, Zubkoff M (1.987). Assessment of function in routine clinical practice: description of the COOP chart method and preliminary findings. Journal of Chronic Diseases 40 (Suppl 1) $555-64$ S.

Pennings-Eerden van der LJM (1992). Self-care behaviour in the rrearment of diaberes mellitus. Theory, assessments and dererminants of self-care behaviour and diabetes education [dissertation]. Universireir Utrecht, Utrecht.

Ripken ThMJ, Pennings-Eerden van der LJM, Schrijvers AJP (1990). Diabeteseducatie in Eindhoven, type II diabetespatiënten voor het voetlicht [Diabetes education in Eindhoven, type II diaberes patients before the footlights]. Medisch Conracr 45(3):88-90.

Rurten GEHM, Verhoeven S, Heine RJ, De Graww WJC. Cromme PVM, Reenders K, Van Ballegooie E, Wiersma Tj (1999). NHGm-Standard Diabetes Mellirus Type 2, eerste herzening [NHG-Standard Diaberes Mellirus Type 2, first rexision]. Huisarts en Wetenschap 42 (2):67-84.

Ruward D, Hoogenween RT, Verkleij H, Kromhout D, Casparie AF, Van der Veen EA (1993). Forecasting the number of diabetic patients in the Netherlands in 2005. American Journal of Public Health 83:989-95.

Sprecuwenberg C (1994). (Net)werken voor chronisch wieken-inatigurele rede [Networking for rhe chronically ill-inaugural lecture]. Universireir Maastricht. Maastricht.

Strarron IM, Adler Al, Neil AW, Marthews DR, Manley SE, Cull CA, Hadden D, Turner RC, Holman RR on behalf of the UK Prospective Diaberes Srudy Group (2000). Association of glycaemia with macrovascular and microvascular complications of type 2 diabetes (UKPDS 35): prospective observa. tional study. Brivish Medical Journal 321 (7258):405-12.

Temmink D, francke AL, Kerkstra A. Huyer Abu-Saad H (2000). Dutch transmural nurse clinics for chronic parients: a descriptive study. Patient Education and Counseling $39(2-3): 177-84$.

Van den Arend IJM, Stollk RP, Rurten GEHM, Schrijwers GJP (2000). Education integrated into structured general practice for Type 2 diabetic parients results in sustained improvement of disease knowledge and self-care. Diabetic Medicine 17(3):190-7. 
Yan Duijn NP, Mentink S (1998). We moeten langzamerhand wel erg veel. . Ower het activf controleren wan chronisch zieken (commentaar) (Gradualy we teally have to do al lor... Alout active inspection of chronically ill (commentary)]. Huisarns en Wetenschap $41(12) 228-560$.

Van Weel C (1993). Functional status in primary care: COOP/WONCA charts. Disability and rehabilitation $15(2): 96-101$.

Van Weel $C$, Knotmerus JA (1999). Evidence-based interventions and comprehensive treatment. The Lancer 353:916-8.

Vrijhoef HIM, Diederiks JPM, Sprecuwenberg C (2000). Efects an quality of care for parients with NIDDM or COPD when the specialised nurse has a central role: a literature review. Patient Education and Counseling $41(3): 243-50$.

Veijhoef HIM, Diederiks JPM, Spreeuwenberg C. Wolfenburtel BHR (2001j. Substirution model with central role for nurse specialist is justified in the care for stable type 2 diabetic outpatients, Journal of Advanced Nursing 36(4):546-556. 


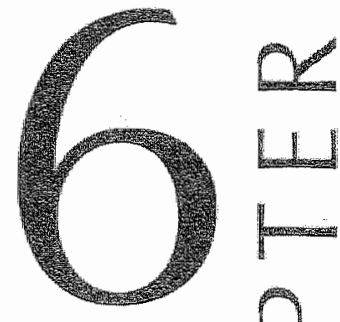

mans

Transfer of care for outpatients with stable Chronic Obstructive Pulmonary Disease (COPD) from pulmonologist to nurse specialist:

$\cup$ A randomised controlled study

by Vrijhoef HIM, Van den Bergh IHAM, Diederiks JPM, Weemhoff I, Spreeuwenberg C Based on paper submitted for publication. 
Objective. To assess effects on patient outcomes when care for patients with stable COPD is transferred from pulmonologist to nurse specialist.

Design. Randomised controlled rrial.

Setting. Respiratory outparient clinic of a general and teaching hospital in Alkmaar, the Netherlands.

Subjects. Of 720 patients, 187 were eligible for randomisation and gave informed consent; 93 patients received care from the nurse specialist and 87 received usual care. Clinical data were analysed for 91 patients in intervention group and for 83 patients in the control group, data from questionnaires for 84 patients receiving care from the nurse and for 75 patients receiving usual care.

Main ouscome meastures. Clinical parameters, health status, self-care behaviour (including knowledge), patient satisfaction, consultarions with main care-prowiders. Results. The nurse specialist reported more consultations than the pulmonologist (mean (SD)): number of consultations $3.1(0.7)$ by nurse and $2.0(0.9)$ by pulmonologist. Patients cared for by the nurse showed worsening in mean forced vital capacity $(-5.5 \%(13.3 \%)$ vs $+2.9 \%(18.2 \%)$ with pulmonologist $)$, indifference in self-assessed condition $(0.0(1.6)$ vs $+0.6(1.6)$ with pulmonologist), while improvements were found for subjective knowledge $(+2.3(4.0)$ vs $+0.6(3.7)$ with pulmonologist), self-assessed rate for coping with COPD $(+0.3(1.3)$ vs $-0.1(1.4)$ with pulmonologist), overall satisfaction $(+0.5(1.5)$ vs $-0.1(1.2)$ with pulmonologist $)$, and for the majority of individual indicators of satisfaction. Groups were indifferent for $\mathrm{FEV}_{1}, \mathrm{BMI}$, smoking status, health starus, objective knowledge, other items of self-care behaviour, and consultations with main care-providers.

Conclusions. Assignment of care for outpatients with stable COPD to the nurse specialist, working under a protocol, seems to be justified in terms of patient outcomes.

\section{INTRODUCTION}

Chronic obstructive pulmonary disease (COPD) is one of the leading causes of morbidity and mortality world-wide and will rise in the rankings of both measures in the future (Lopez \& Muray, 1998). COPD is characterised by the progressive development of airflow limitation that is not fully teversible (Barnes, 2000). COPD is stable when the parient is either symptom-free or has symptoms without substantial fluctuation (Madison \& Irwin, 1998). The aims of the management of stable COPD are to improve symptoms and quality of life, to reduce the decline of lung function, to prevent and treat complications, to increase survival with maintained quality of life, and to avoid or minimise adverse effects of treatment (Siafakas et al., 1995). 
In the care of chronically ill patients, the role of nurse specialists is growing in importance. Nurse specialists receive master's level training in single specialties, while they have the authority to practice independently under supervision from a physician. As one of the first hospitals in the Netherlands, Medisch Centrum Alkmaar placed the nurse specialist in a central role in the management of the growing number of patients with stable COPD. In this role the nurse specialist is taking on tasks and roles traditionally regarded as the remit of the pulmonologist, allowing physicians to shift the balance of their activities towards managing patients with the most 'serious' health problems. This transfer of care is a case of vertical substitution: a transfer of tasks berween care-providers across different levels of expertise (Spreeuwenberg, 1994). Despite the popularity of nurse specialists performing a new role in chronic care, evaluation studies regarding outcome and/or process variables are limited due to the as yet- underdeveloped nature of this field of study (Wilson-Barnett \& Beech, 1994; McGillis Hall, 1997; Temmink et al., 2000; Vrijhoefer al., 2000; Laurant et al., 2002; Loveman et al., 2002).

This study was performed to assess effects on quality of care in terms of patient outcomes, when care for patients with stable COPD is transferred from the pulmonologist to the nurse specialist. It was hypothesised that the nurse specialist, working under a protocol, can achieve patient outcomes at least equivalent to those achieved by the pulmonologist providing usual respiratory care.

\section{METHODS}

\section{Patients and setting}

This study was performed in the respiratory outparient clinic of Medisch Centrum Alkmaar, a general and teaching hospital in an urban district with about 240,000 residents. Patients were recruited between January and July 1999 and, if eligible, followed for nine months.

Patients with previously documented COPD attending the respiratory outpatient dinic were invited by their pulmonologist to participate in the study when they had a forced expiratory wolume in one second $\left(\mathrm{FEV}_{1}\right)$ berween $40 \%$ and $80 \%$ of predicted value (postbronchodilator). Patients were not eligible if they were known to have had more than three exacerbations in the 12 months preceding the study, if they were using oxygen, if they were suffering from another disease not related to COPD for which they were receiving care from a medical specialist, if they had a known arterial carbon dioxide tension $\left(\mathrm{PaCO}_{2}\right)$ of $6.7 \mathrm{kPa}$ or higher, or if they lacked sufficient mastery of the Dutch language. Eligibility was assessed by the pulmonologist when patients attended the outpatient clinic for scheduled consultation. 
Considering the multiple and diverse airns of the management of stable COPD (Siafakas et al., 1995) as well as the nature of the intervention, i.e. a complete transfer of care, no primary outcome measure was selected for the purpose of a power calculation. Patients were provided with a written description of the study and those who supplied written informed consent were enrolled. The study was approved by the local ethics committee.

\section{Study design and procedures}

Eligible patients were randomised by means of a computer-generated list of random numbers immediately after consenting to participate in the study. Neither the patient nor the members of the study team were aware of the treatment assignment until after randomisation. The study treatment consisted of outpatient appointments with the nurse specialist as main caregiver, while patients assigned to the usual care group received routine respiratory outpatient care provided by the pulmonologist. When allocated to the intervention group, formal transfer of the patient from pulmonologist to nurse specialist took place.

The nurse specialist was trained to perform routine consultations. Tasks (activities) of the nurse specialist were:

- direct patient care (medical history taking, physical examination, interpretation of tests, administration and assimilation of findings);

- organisation and co-ordination of care for individual parients (identification of shortcomings in care, referral to and communication with caregivers);

- consultation (providing advice to patients and other caregivers);

- promotion of expertise (education of parients, themselwes and other caregivers).

Patients in the intervention group received quarterly consultations from the nurse specialist in the outpatient clinic. If complications arose, the nurse could consult the pulmonologist. Final responsibility for the care provided remained with the pulmonologist. The delivery of care was negotiated with all parties involved in respiratory care before the study began and strictly formulated in a protocol.

Patients assigned to the usual care group received follow-up consultations from their pulmonologist at the outpatient clinic. The minimum frequency of planned follow-up consultations in usual respiratory outpatient care is annual, while the pulmonologist may plan follow-ups as frequently as quarterly when indicated. Routine management involved the tasks and activities transferred to the nurse specialist and outlined above.

The duration of the consultations differed between the two groups. Initial consultations with the respiratory nurse could last up to 30 minutes, while follow-up consultations lasted 15 minutes. A consultations by the pulmonologist takes 10 minutes. 
Selected indicators of quality of care are considered essential when looking at outcomes in quality of care research for chronically ill (Donabedian, 1992; Long et al., 1993; Driessen et al., 1994). These are clinical paramerers, health status, self-care behaviour (including knowledge), and patient sarisfaction. We added number of consultations with main care-providers. Data about clinical parameters, and number of consultations were obtained from the caregivers' registries.

Dara about other outcomes were gathered via quesrionnaires mailed, together wirh an explanarory letter and a prepaid return envelope, to patienrs. Number of consultations was measured by a separate questionnaire mailed to patients at entry into the study, three, six, and nine months larer. Data about health status, self-care behaviour, and parient satisfaction were measured at entry and six months later. The questionnaire sent at entry included items about socio-demographic characteristics of parients.

Clinical parameters were $\mathrm{FEV}_{1}$, forced vital capacity (FVC), body mass index (BMI), and smoking starus. Airflow limitation was measured by spirometry. The caregiver asked the patient about his/ her smoking status. Body height and weight were measured by the caregiver during consultarion. Baseline values were derived from the pulmonologist's records. For this, values measured during the last consultation before the start of this study were used except if these were older than six months.

Generic health status was measured with the Durch version of the COOP/WONCA charts as generic instrument (Nelson et al., 1987; Van Weel, 1993). These charts assess physical activities, feelings, daily activities, social activities, change in health, and overall health. Each domain is covered by a single question to be answered on a five-point scale and is supported by a pictograph representing the options. The scores are calculated for each chart separately. Disease-specific health status was measured with the St George"s Respiratory Questionnaire (SGRQ) (Jones er al., 1992). The SGRQ consists of 76 items and measures three components: symptoms, activities, and impact. It also yields a total score. Scores range from 0 to 100 , with a score of zero indicating no impairment.

For the measurement of self-care behaviour a Dutch instrument was used (Deenen, 1996). Objective knowledge was measured by means of 22 questions abour COPD (range 0-22, Cronbach's al pha $=0.70$ ). Subjecrive knowledge was measured by means of six questions indicating the estimation patients make of their amount of knowledge (five-point scale ranging from very little to much, Cronbach's alpha $=0.91$ ). Two self-care dimensions were measured: compliance and condition-maintenance. For compliance patients were asked to give a mark $(1-10)$ for the extent to which they think they keep to prescribed medication and for their way of coping with COPD. In addition, they were asked how frequently they used medication according to the prescription, more than prescribed, or less than prescribed (questions have a five-point 
scale ranging from never to always and are expressed as one overall score). Condition-maintenance, the extent to which the patient actively works on maintaining a good physical condirion, was measured with five items. Patients were asked whether they participated in active movement during their free time (five-point scale ranging from never to very often) and whether they participated in sports (yes/no). Furthermore, they were asked about their daily pattern of movement by asking whether they generally sit, stand, walk, carry heavy subjects, and whether they are tired in the evening (questions have a frve-point scale ranging from never to always and are expressed as one overall score). Patients were asked to compare their daily activities with peers (five-point scale ranging from much less difficult to much more difficult) and to give a mark $(1-10)$ for the extent to which they think they maintain their physical condition.

Patient satisfaction was measured using a selection of questions out of a previously validated instrument (Wensing et al., 1996). Because the original instrument was developed for general practice (containing nine dimensions with 51 indicators), dimensions as well as indicators judged as irrelevant for outpatient pulmonary care were not used in this study (the dimensions availability for emergencies, premises, and co-operation). For each dimension the indicators with the highest factor loading were selected. Patients were asked about six dimensions consisting of 20 indicators for quality of care (six-point scale ranging from poor to excellent). Furthermore, patients were asked to grade their satisfaction with a mark $(\mathbb{1}-10)$, if they would recommend the care they had received to orher patients (yes/no), and if they intended to continue making use of received care in the future (yes/no/no preference). These items are derived from industrial marketing management and have been applied earlier in the same area of research (Lirtlejohns et al., 1991; GRASSIC, 1994; Shum et al., 2000).

Number of consultations with main care-providers comprised questions about the number of consultations for COPD at the outpatient clinic - with the pulmonologist or nurse specialist - , with the general practitioner, and with the physiotherapist.

\section{Statistical analyses}

All the analyses presented were based on intention to treat, while missing response was handled by using the last observed response (carry forward procedure) (Hollis \& Campbell, 1999). Groups were compared for baseline characteristics using chi-square test and independent sample $t$-test. Baseline values of clinical parameters were derived from patient records kept by pulmonologists. Student's t-test for independent samples was used to assess differences between groups in FEV, FVC, BMI, COOP/WONCA charts, SGRQ-scales, knowledge, and self-care behaviour scores. For smoking status and indicators of satisfaction proportions were calculated and compared between groups at baseline and at post-measurement with Pearson chi-square. Comparison of 
the number of consultations with main care-providers was performed with Kruskall-Wallis one-way analysis of variance. A significance level, $p=0.05$ (wwo-tailed) was used. Data processing and analyses were conducted with SPSS (Windows Release 10.0).

\section{RESULTS}

\section{Patients flow and follow up}

The study sample was recruited from 720 patients who consulted the pulmonary department for their COPD berween January and July 1999 (figure). A toral of 187 patients met the inclusion criteria as assessed by the pulmonologists and was invited to participate in the study. Ninety-four patients were randomised to treatment by the nurse specialist and 93 patients to treatment by the pulmonologist. Of parients randomised to the nurse specialist $93(99 \%)$ patients received care with $84(90 \%)$ of them returning all questionnaires. Of patients randomised to the pulmonologist, 86 (92\%) parients received usual outpatient care and were followed in this study, with 75 $(87 \%)$ of them returning all questionnaires.

Four patients allocated to the control group and diagnosed with cancer were wrongly assessed for eligibility. Shortly after randomisation one pacient allocated to the control group died and one patient moved away. To the intervention group one patient with asthma was wrongly allocated. Baseline comparisons of groups were performed for the patients including those who withdrew after randomisation or moved away (intervention group $\mathrm{n}=93$, control group $\mathrm{n}=87$ ), but excluding the patients who were lost for other reasons. It seems unlikely that the exclusion of these patients could have affected the study results, because these patients required different care than the care parients with stable COPD receive in daily practice.

Data on clinical parameters were analysed for the patients who received care, excluding those who withdrew their informed consent as well as those for whom recent data on clinical paramerers at baseline were not available (nine patients in the intervention group, two patients in the control group). Of patients followed up in the intervention group one died of cancer. This patient and six other patients of the intervention group and eight patients of the control group did not return all questionnaires. However, except for the patient who died, the orher 14 patients consulted the caregiver allocated to. The two groups did not differ for main characteristics at baseline (Table 1). 
Figure

Trial protile

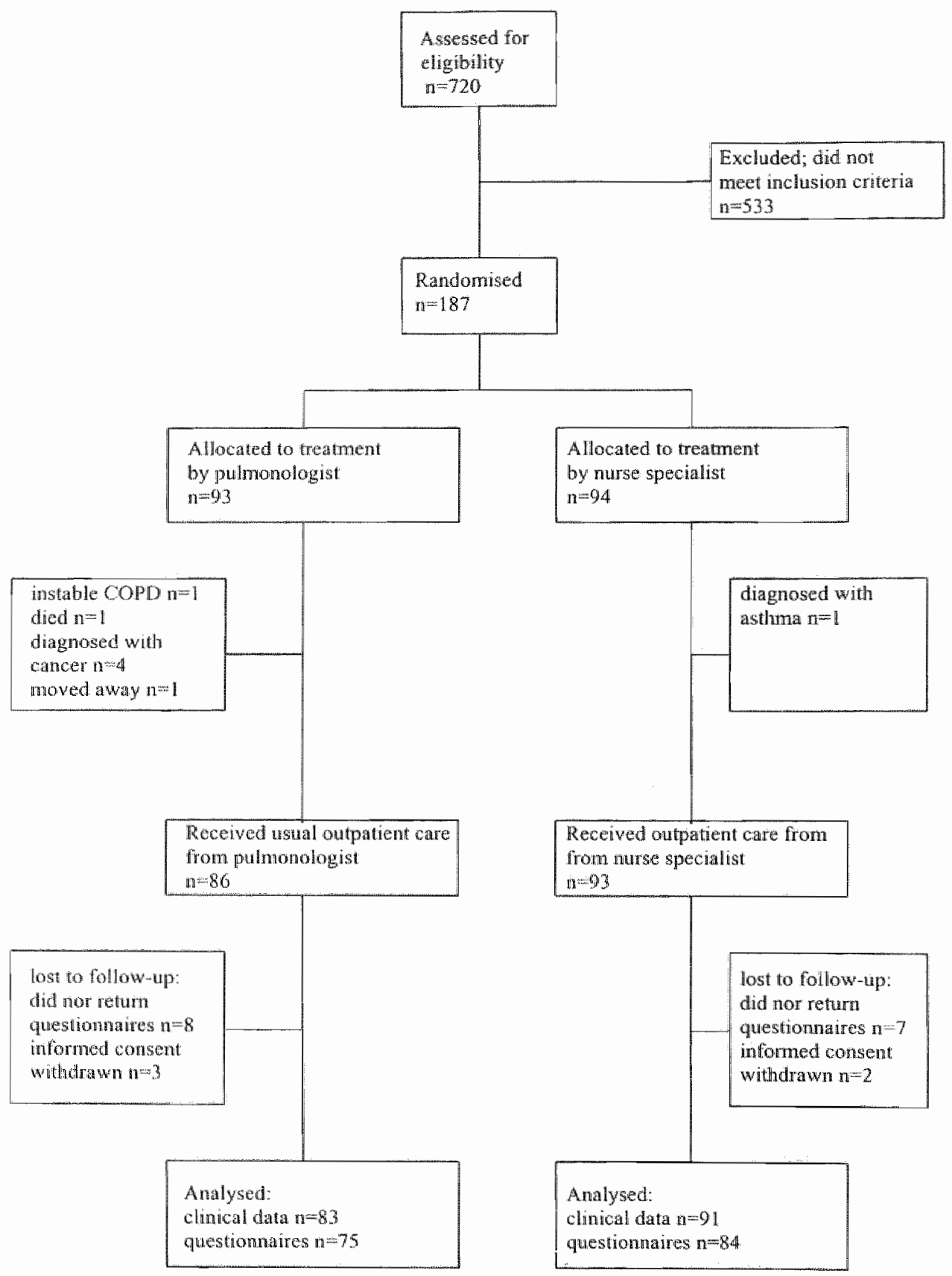


Table 1

Baseline characteristics of patients

\begin{tabular}{|c|c|c|c|c|}
\hline Varable & $\mathrm{n}$ & Control group & $\mathrm{n}$ & Intervention group \\
\hline Femalehale $(\%)$ & 87 & $51.7 / 48.3$ & 93 & $39.8 / 60.2$ \\
\hline Age $(y r s)$ & 87 & $64.4 \pm 10.5$ & 93 & $64.4 \pm 10.2$ \\
\hline Tine since diagnosis COPD (yrs) & 86 & $7.7+6.2$ & 83 & $9.1 \pm 8.2$ \\
\hline Current smoker $(\%)$ & 86 & 24.4 & 84 & 33.3 \\
\hline FEV, $(\%$ predicted value & 84 & $57.7+16.8$ & 84 & $56.8 \div 15.2$ \\
\hline FVC (\% predicted value) & 84 & $84.6 \pm 18.6$ & 84 & $85.0 \pm 17.5$ \\
\hline Body Mass Index $\left(\mathrm{kg} / \mathrm{m}^{2}\right)$ & 82 & 26.1 .5 .4 & 82 & $25.9 \pm 4.0$ \\
\hline Marital status $(\%)$ & 74 & & 89 & \\
\hline Married & & 68.9 & & 70.8 \\
\hline Divorced & & 12.2 & & 9.0 \\
\hline Widowed & & 16.2 & & 13.5 \\
\hline Never been married. & & 2.7 & & 6.7 \\
\hline Liwing allone (\%) & 71 & 21.1 & 87 & 20.7 \\
\hline Privaltely insured $(\%)$ & 73 & 30.1 & 85 & 22.4 \\
\hline Employed $(\%)$ & 72 & 12.5 & 89 & 16.9 \\
\hline Member parient association (\%) & 68 & 8.8 & 82 & 8.5 \\
\hline
\end{tabular}

whilues are mean $t$ standard deviation unless stated orherwise

\section{Patient outcomes}

Of patients in the intervention group who gave informed consent $(n=91)$ on average $3.1 \pm 0.7$ consultations with the nurse were registered, with wo patients consulting the nurse once. The mean number of registered consultations with the pulmonologist by parients who received usual care and who gave informed consent $(n=83)$ was $2.0 \pm 0.9$. Groups differed statistically significantly $(t=8.93 ; p=0.00)$ for the mean frequency of consultations with the main care-provider. Of parients who received usual care, 23 patients consulted the pulmonologist once during the study period. Additional analyses were performed to compare patients who received one consultation with those who received rwo or more consultations on clinical parameters.

Differences were found for $\mathrm{FEV}_{1}$ and $\mathrm{BMI}$, with mean scores in favour of patients with one consultation only $\left(\triangle \mathrm{FEV} V_{\mathbb{1}}=8.3 \% ; \triangle B M I=2.8 \mathrm{~kg} / \mathrm{m} 2\right)$.

Only for patients with at least two consultations were effects on clinical parameters analysed (Table 2). No differences were found between subgroups for $\mathrm{FEV}_{1}, \mathrm{FVC}_{\text {, }}$ or $\mathrm{BMI}$ at baseline, while groups differed for change in FVC. In the intervention group mean FVC deteriorated by $5.5 \%$, compared with an improvement of $1.1 \%$ in the control group. In the intervention group the proportion of patients who reported 
smoking decreased by $4.8 \%$ to $29.3 \%(n=24)$ berween first and last consultation, against an increase in the control group of $1.7 \%$ to $23.3 \%(n=14)$. Groups did not differ statistically significantly for smoking status at baseline nor at post-measurement.

With regard to health status of patients, steady mean walues were found for scales measured with COOP/WONCA charts as well as for scales measured with SGRQ (Table 3). None of the changes berween groups was found to be statistically signifcant.

The questions about patients' knowledge about COPD were incompletely answered by a significant part of both the intervention group (objective knowledge) and the control group (objective and subjective knowledge) (Table 4). No change was seen between groups in objective knowledge of patients about COPD, while means in both groups were slightly higher than half the maximum score. Although parients of both groups reported improvements in subjective knowledge, the improvement for patients cared for by the respiratory nurse was statistically significantly bigger than for patients in the usual care group. Scores for subjective knowledge were slightly above half the maximum score in both groups.

Of indicators measuring self-care behaviour, patients cared for by the nurse showed an improvement in the mark for coping with COPD, while patients cared for by the pulmonologist reported a higher mark for maintaining condition (Table 4). No differences were seen between groups in the changes on the other indicators. For all indicators, groups scored acceptable means.

Although an improvement in the mean rate for satisfaction was found in the incerwention group, patients of both groups were almost equally satisfied with the received care (Table 4). When looking at specific indicators for sarisfaction (Table 5), no differences in satisfaction with the care provided by the pulmonologist were found between groups at baseline. In both groups the proportion of most satisfied patients was highest for the indicators about continuity and stimulating self-help, while in both groups too the proportion of satisfied patients was lowest for supporting patients' relarives. Towards the end of the study, groups differed statistically significantly for 14 of the 20 indicators in fawour of the group cared for by the nurse. No differences between groups were found with regard to recommendation of received care to orhers and furure use of received care (Table 5). In both groups a big majority of patients said they would recommend received care and make furure use of it.

Groups were similar in the mean number of reported consultations with main care-providers (Table 6). Nine months after the start of the study groups differed in mean number of reported consultations with the nurse - intervention group - or with the pulmonologist - control group. Although not statistically significant, the control group reported more consultations with the physiotherapist. In both groups the number of teported consultations with the general practitioner decreased towards the end of the study. This was also found for consultations with all three main 


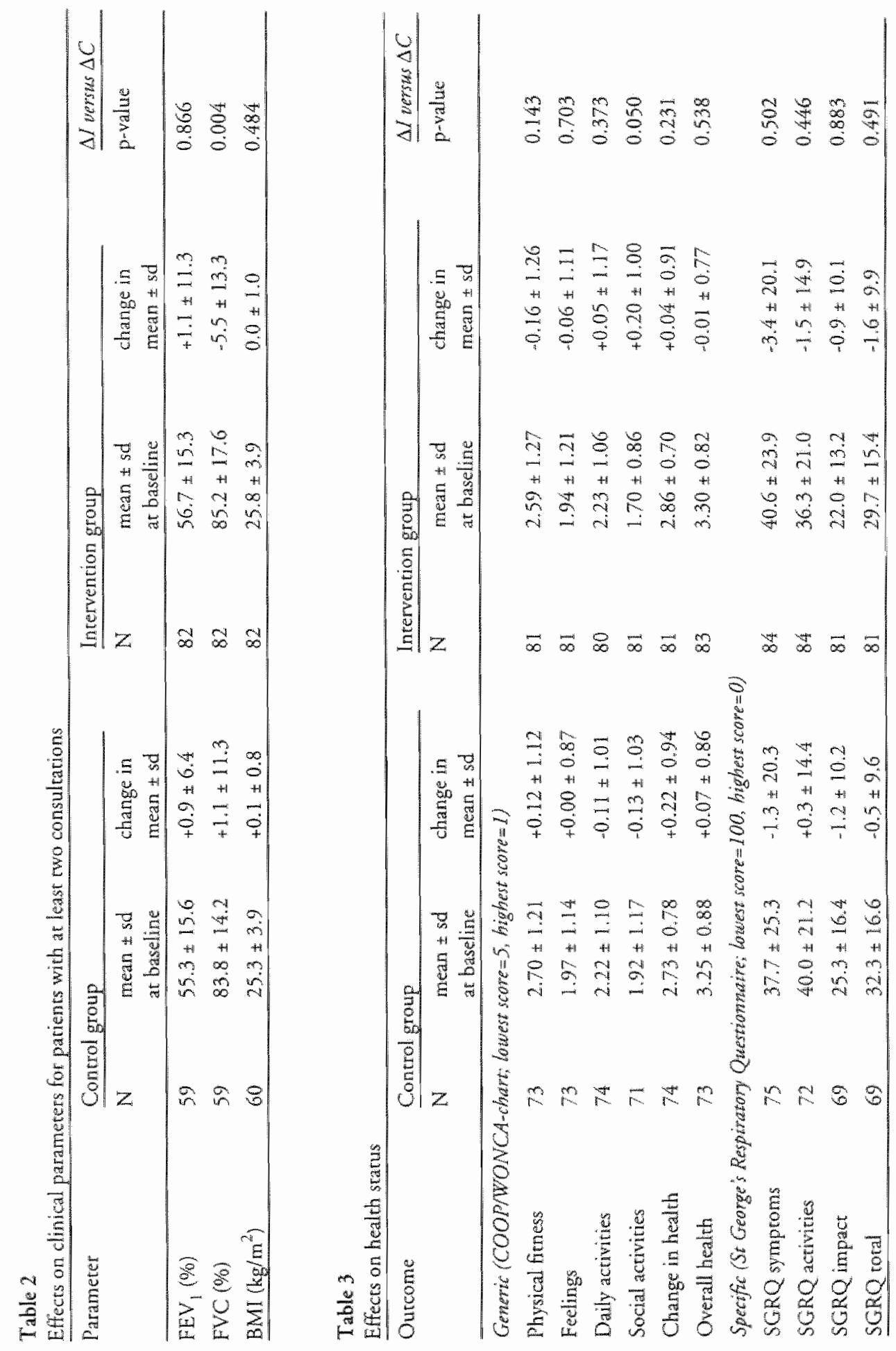




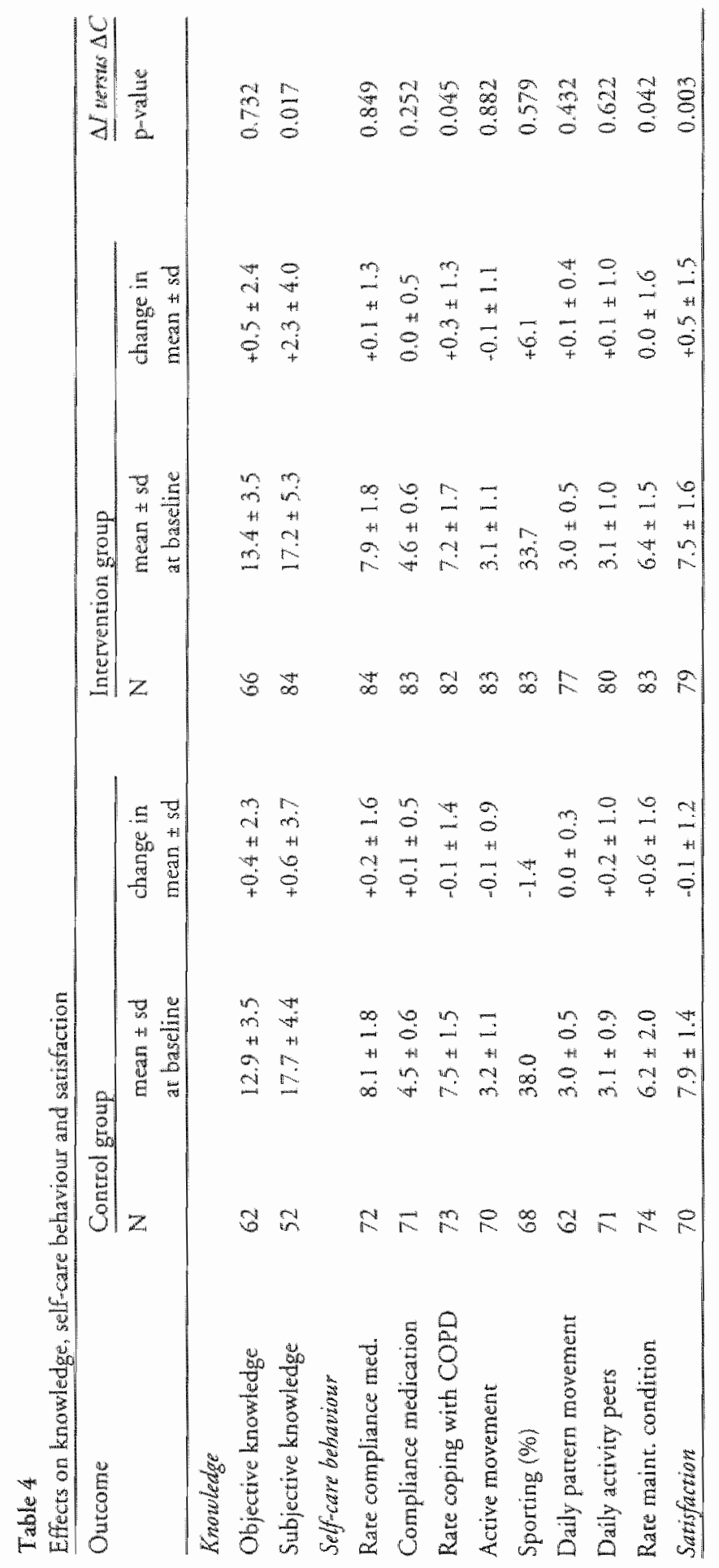


Table 5

Effects on patient satisfaction

\begin{tabular}{|c|c|c|c|c|c|c|c|c|}
\hline \multirow[t]{3}{*}{ Indicator } & \multicolumn{3}{|c|}{ Conrrol group } & \multicolumn{3}{|c|}{ Intervention group } & \multirow{2}{*}{\multicolumn{2}{|c|}{$\frac{16 \text { versus CO }}{p \text {-value }}$}} \\
\hline & \multirow[t]{2}{*}{$\mathbb{N}$} & \multicolumn{2}{|c|}{ proportion (\%) } & \multirow[t]{2}{*}{$N$} & \multicolumn{2}{|c|}{ proportion (Q) } & & \\
\hline & & base & $\mathrm{pm}$ & & base & prn & base & $p m$ \\
\hline \multicolumn{9}{|l|}{ Appointments } \\
\hline$A^{A}$ & 72 & 61.1 & 56.9 & 81 & 49.4 & 74.1 & 0.146 & 0.026 \\
\hline$B$ & 72 & 66.7 & 65.3 & 83 & 68.7 & 66.3 & 0.790 & 0.897 \\
\hline $\mathrm{C}$ & 72 & 48.6 & 47.2 & 83 & 43.4 & 42.2 & 0.514 & 0.528 \\
\hline \multicolumn{9}{|l|}{ Continuity } \\
\hline $\mathrm{D}$ & 70 & 65.7 & 61.4 & 84 & 77.4 & 78.6 & 0.108 & 0.020 \\
\hline $\mathrm{E}$ & 66 & 74.2 & 65.2 & 82 & 80.5 & 86.6 & 0.364 & 0.002 \\
\hline $\mathrm{F}$ & 69 & 73.9 & 68.1 & 82 & 7.4 .4 & 84.1 & 0.947 & 0.020 \\
\hline \multicolumn{9}{|l|}{ Effectuenes of care } \\
\hline$G$ & 68 & 69.1 & 67.6 & 82 & 69.5 & 86.6 & 0.258 & 0.005 \\
\hline $\mathrm{H}$ & 67 & 59.7 & 62.7 & 84 & 61.9 & 60.7 & 0.783 & 0.804 \\
\hline I & 67 & 52.2 & 52.2 & 82 & 61.0 & 56.1 & 0.284 & 0.638 \\
\hline \multicolumn{9}{|l|}{ Hwnaneness } \\
\hline J & 67 & 62.7 & 59.7 & 82 & 58.5 & 85.4 & 0.606 & 0.000 \\
\hline \multicolumn{9}{|c|}{ Exploring patients needs } \\
\hline $\mathrm{K}$ & 67 & 62.7 & 61.2 & 83 & 51.8 & 78.3 & 0.181 & 0.022 \\
\hline L. & 67 & 65.7 & 61.2 & 84 & 57.1 & 78.6 & 0.286 & 0.020 \\
\hline $\mathbb{M}$ & 66 & 53.0 & 48.5 & 83 & 39.8 & 74.7 & 0.106 & 0.001 \\
\hline \multicolumn{9}{|c|}{ Motolwement in decisions } \\
\hline $\mathbb{N}$ & 66 & 60.6 & 59.1 & 81 & 56.8 & 75.3 & 0.640 & 0.036 \\
\hline \multicolumn{9}{|l|}{ Drformativentess } \\
\hline 0 & 67 & 62.7 & 53.7 & 82 & 59.8 & 72.0 & 0.715 & 0.021 \\
\hline $\mathbb{P}$ & 66 & 63.6 & 59.1 & 83 & 54.2 & 78.3 & 0.247 & 0.011 \\
\hline \multicolumn{9}{|l|}{ Samulating self-belp } \\
\hline $\mathrm{Q}$ & 66 & 75.8 & 69.7 & 84 & 75.8 & 81.0 & 0.664 & 0.109 \\
\hline \multicolumn{9}{|l|}{ Connseling } \\
\hline $\mathbb{R}$ & 69 & 44,9 & 40.6 & 83 & 37.3 & 73.5 & 0.344 & 0.000 \\
\hline$S$ & 67 & 40.3 & 38.8 & 83 & 33.7 & 71.1 & 0.407 & 0.000 \\
\hline \multicolumn{9}{|c|}{ Supporting patienus" relatives } \\
\hline $\mathrm{T}$ & 65 & 21.5 & 20.0 & 81 & 22.2 & 34.6 & 0.921 & 0.052 \\
\hline Recommend to others & 67 & 97.0 & 95.5 & 78 & 91.0 & 94.9 & 0.136 & 0.84 \\
\hline Futhere wase & 69 & 100.0 & 100.0 & 78 & 97.4 & 98.7 & 0.180 & 0.345 \\
\hline
\end{tabular}

A Claricy of information; B Telephone accessibility for making an appointment; C Possibilitics for getring an appoinment quickly; D Possibilites for seeing the same care provider; $\mathbb{E}$ Care provider knows which symproms have been discussed before; F Patient is asked to come back regularly for monitoring; Ga Care provider tries to reduce symptoms; H Care provider's treatment helps to reduce complaints I Care pro* wider's treatment helps the patient to feel better for a longer period of time; ] Care prowider shows personal interest; K Care provider helps to clarify symptoms; L Care provider shows (s) he understand whar patient rells; M Care provider involves the parient in looking for an explanation of symptoms; N Care prowider discusses treatment oprions with the patient; O Care prowider tells clarly what (s) he is up to; P Care provider gives understandable explanation of the treatment; QCare provider convinced the parient of following adwice; $R$ Care provider helps the patient in dealing with the disease; $S$ Care provider has attention for the consequences of the disease in daily life; T" Care prowider involves patients' relatives in treatment 


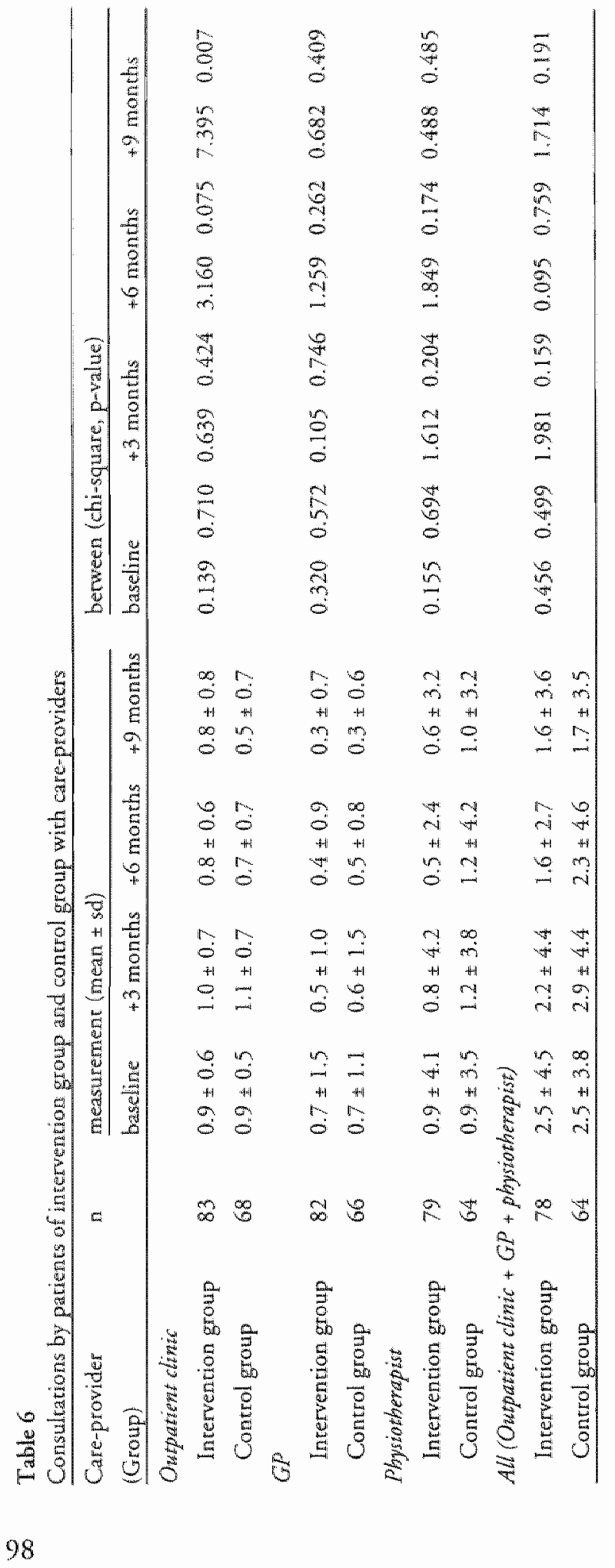


care-providers together. In the control group fewer visits to the pulmonologist were reported rowards the end of the study.

\section{DISCUSSION}

This study assessed effects on quality of care when care for outpatients with stable COPD is transferred from pulmonologist to nurse specialist. Compared with patients cared for by the pulmonologist, patients receiving outpatient care from the nurse specialist showed a deteriorated mean FVC, did not report an improved physical condition, but did show improvement in subjective knowledge and satisfacrion. Groups were found to be comparable for FEV 1 , BMI, smoking status, health status, objective knowledge, and compliance. Based on the consultations reported by primary care-providers, parients cared for by the nurse consumed more consultations whereas no differences in number of consultations were found from questionnaires filled out by patients.

Comparable intervenrions, evaluated with the randomised controlled trial as study design, were compared in a recent literature review (Vrijhoef et al., 2000). Although seven studies were aimed at patients with respiratory diseases and fulfilled the inclusion criteria of the review, the intervention studied by Littlejohns et al. (1991) mostly resembles this study when considering the tasks performed by the central care-provider. An important difference with the intervention evaluated by Littlejoluns et al. (1991) is that in the current study a complete transfer of patients from pulmonologist to nurse specialist took place; in the study by Littlejohns et al. (1991) patients in the intervention group continued with their routine ourpatient appointments, while care by a respiratory health worker was provided as well. Comparison of the findings by Littlejohns et al. (1991) with those in this study is hampered by the differing study groups with regard to their pulmonary function as well as by some of the instruments used. Littlejohns et al. (1991) expected reductions in respiratory impairment, disability, and experienced handicap when cared for by a respiratory health worker, while higher survival, more number of consultations, improved quality of life and equity for expected ourcomes was found. Patients assessed the nurse specialist working in the substitution based model as more satisfactory than the pulmonologist, while in the complementary model no difference in patient satisfaction was found (Littlejohns et al., 1991). The study by Littlejohns et al. (1991) showed a "useful" complementary model for frail parients, while the current study shows that the substiturion based model is a justified alternarive for patients with stable COPD.

From the registration of care-providers it was found that for the number of consultations performed, the nurse worked closely to the protocol. The pulmonologists performed on average less consultations, with one consultation for patients in a rela- 
tively more stable phase. Reasoned deviation from the protocol seems to be justified, while more research is needed to define the optimal number of consultations for individual patients. Differences exist between the number of consultations registered by care-providers and by patients. A possible explanation for this is the moment when patients completed the questionnaires. Although not recorded, it was experienced that not all patients returned the questionnaire within the offered time frame. This might have influenced the findings in the first three months. From the questionnaires administered by patients, differences berween groups in the number of consultations with outpatient care-provider seem to be present towards the end of the study. Future research should address the cost-effectiveness of the intervention evaluated here.

No explanation can be given for the statistically significant, but clinical irrelevant difference between groups in FVC. With comparable outcomes for FEV 1 , BMI, smoking status and health status one can have reasonable confidence in the clinical. safery of the nurse as main care-provider to patients with stable COPD. Although acknowledging the meaning of exacerbations of COPD as an indicator for the quality of care, this outcome was not assessed because of the absence of a valid and reliable reporting system for exacerbations experienced by patients. Considering the group of patients in this study - stable COPD - one might wonder about the relevance of this parameter here. Moreover, this seems to be confirmed by the comparability of groups in FEV $1, \mathrm{BMI}$, smoking status, health status, objective knowledge, and consultations with care-providers.

Questions about knowledge might have been too difficult for patients with stable COPD in this study. Because of missing answers, no total score could be computed for 30 and 22 patients of the intervention and the control groups respectively. Moreover, of patients who answered all questions about objective knowledge, the mean score was just slightly above half the maximum score. Six months might be too short to measure an increase with instrument used for objecrive knowledge, because patients cared for by the nurse estimated their knowledge better at the start than patienrs in the control group. Higher response on the knowledge questionnaires might be reached when the nurse gathers the answers of patients on the questions during consultation, while after assessment of these data it would enable the nurse to provide the patients with an intervention tuned to the individual parient. With means for subjective knowledge in both groups just above half the maximum score, improving of the knowledge of parients about COPD seems to be a goal in respiratory care.

Assessment of the effects on self-care behaviour was limited by using instruments for just two dimensions. However, internationally valid and reliable instruments to measure self-care behaviour of patients with COPD seem to be lacking. Some changes occurred on indicators of self-care, but groups were fairly comparable at the end of the study with regard to self-care behaviour. 
Patients in the intervention groups showed better ourcomes for the grade for satisfacrion and for the majority of indicators of satisfaction compared with patients in the control group. This ourcome seems to make the difference berween care with the nurse in a central role and usual outparient care. While a relationship between length of consultation and patient satisfaction exists, Shum et al. (2000) found that differences in patient satisfaction with nurses and general practitioners remained significant when this was accounted for. Research to the factors leading to this difference as well as to the influence of sarisfaction on other outcomes is needed.

In conclusion, this study shows that transfer of care for patients with stable COPD to the nurse specialist is justifiable in terms of patient outcomes. For patients it is acceptable to consult the nurse specialist instead of the pulmonologist. The substitution-based model evaluated is a justified alternative for traditional outpatient care of patients with stable COPD.

\section{REFERENCES}

Bames PJ (2000). Chronic obstrucrive pumonary disease. New England Jounal of Medicine $343(4): 269-80$.

Deenen ThAM (1996). Patient health-education and self-management: a medical-psychological intervention study on severe asthma and COPD in a high alricude dinic. Thesis. Universiry of Croningen.

Donabedian A (1992). The role of outcomes in qualicy assessment and assurance. Quality Review Bulletin $356-60$.

Driessen S, Casparie AF, Van den Bos GAM (1994). Uirkomstindicatoren voor de kwaliteitsbewaking en -bevordering in de zorg woor chronisch zieken [Ontcome indicators for quality assurance and improvement in the care for chronically ill]. Study 4 from Research programme Qualiry of Care. Dutch Organisarion for Scientific Research (NWO). The Hague.

GRASSIC: Grampian Asthma Study of Integrated Care (1994). Integrated care for asthma: a climical, social, and economic evaluation. British Medical Journal 308:559-64.

Hollis $\$$, Campbell $\mathrm{F}(1999)$. What is mean by intention to treat analysis? Survey of publistred randomised controlled trials. British Medical Journal 319:670-4.

Jones PW, Quirk FH, Baveystock CM, Litdejohns P (1992). A self-complete measure of health stafus for chronic airflow limitation: the St. George Respiratory Questionnaire. American Review of Respinttory Diseases 145:1321-7.

Laurant M, Sergison M, Sibbald B (2002). Substitution of doctors by nurses in primary care (Protocol for a Cochrane Review). In: The Cochrane Library, Issuc 2. Oxford: Update Sofrware.

Lirtejohns P, Baveystock CM. Parnell H. Jones PW (1991). Randomised controlled trial of the effectiveness of a respiratory health worker in reducing impairment, disability, and handicap due to chronic airflow limication. Thorax $46.559-64$.

Long AF, Dixon P, Hall R, Carr-Hill RA. Sheldon TA (1993). The outcomes agenda: contriburion of the UK clearing home on health ourcomes. Quality in Health Care 2:49-52.

Lopez AD, Muray CC (1998). The global burden of disease, 1990-2020. Nat Medicine 4:1241-3.

Loveman E, Royle P, Wagh N (2002). Specialist nurses in diaberes mellirus (Protocol for a Cochrane Review). In: The Cochrane Library, Issue 1. Oxford: Update Software.

Madison JM, Irwin RS (1998). Chronic obstructiwe pulmonary disease. Lancer 352:467-73. 
MoGills Hall L (1997). Staff mix models: complementary or substicution roles for murses. Nursing Administution Quarterly $21: 31-9$.

Nelson EC, Wasion J. Kirk J, Kaller A, Clark D, Zubkoff M (1987). Assessment of funccion in routine dinical practice: description of the COOP chart method and preliminary findings. Joumal of Chronic Discases 40:558.64S.

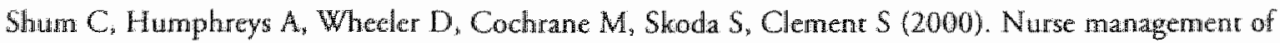
patients with minor illiness in general practice: muluicentre, randomised controlled trial. British Medical Journal 320:1038-43.

Siafakas NM, Vermeire P, Pride NB, Padeti P, Gibson J, Howard P. Yernaule IC Decramer M, Higenbortam "T, Postma DS, Rees J, on behalf of the Task Force (1995): Optimal assessment and management of chronic obstructive pulmonary disease (COPD). A consensus statement of the European Respiratory Sociery (ERS). European Respiratory Journal 8: 1398-1420.

Spreeuwenberg $\mathrm{C}$. (Net) werken woor chronisch zieken-inaugurele rede $N$ Nerworking for chronically illinaugural leciure]. Uniwersiteir Maastricht, 1994.

Temmink $\mathrm{D}$, Francke $\mathbb{A L}$, Kerkstra $\mathrm{A}$. Hujęr Abu-Saad $\mathrm{H}(2000)$. Dutch transmural nurse clinics for chronic patients: a descriptive study. Parient Education \& Counseling 39:177-84.

Van Weel C (1993). Funcrional status in primary care: COOP/WONCA charrs. Disability Rehabilitarion $15: 96-101$.

Vrijhoef HJM, Diederiks JPM, Spreeuwenberg C (2000). Effects on qualiry of care for patients with NIDDM or COPD when the specialised nurse has a central role: a literature review. Patiene Education \& Counseling $41: 243-50$.

Wensing M, Grol R, Van Montfort P, Smirs A (1996). Indicators of the quality of general practice care of patients with chronic illness: a step rowards the real involvement of patients in we assessment of the quality of care. Quality Health Care 5:73-80.

Wilson-Barnetr J. Beech S (1994). Ewaluating the clinical nurse specialist. A review, International Journal of Nursing Studies 31:561-71. 


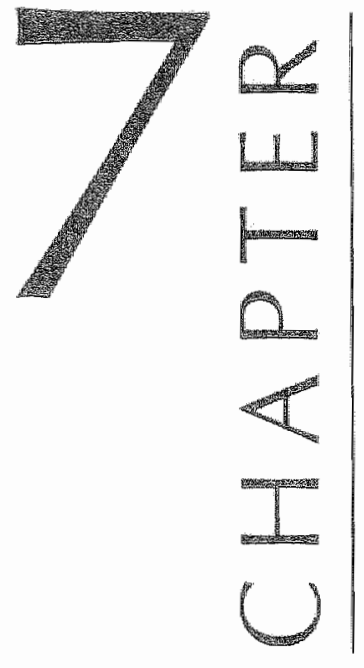

Undiagnosed patients and patients at risk for COPD in primary health care:

Early detection with the support of non-physicians

by Vrijhoef HIM, Diederiks JPM, Wesseling GIl, Van Schayck CP, Spreeuwenberg $C$.

Based on paper accepted by Journal of Clinical Nursing 
Given the increasingly heavy workload in the primary health care sector, the option of allocating activities involving the management of chromic diseases to non-physicians has recently come under scrutiny. The purpose of this study was to assess the feasibility of the support prowided by non-physicians to general practitioners in the early detection of COPD. A convenience sample consisting of two hundred and thircy-one parients ( $40-70$ years; $>10$ pack years) from eight general practices in the Maastricht region in the southern Netherlands, who consulted their general practitioner for reasons unrelated to respiratory diseases, were assessed for their respiratory function. Prior to the first assessment, patients were interviewed about their medical history and symptoms. By taking the results of the lung function measurement as the starting point, the predictive value of medical history and symptoms in the identification of patients at risk for airflow obstruction or of COPD was assessed and compared with findings in literature.

Seventeen patients (7.4\%) were diagnosed with COPD, 11 patients $(4.8 \%)$ with asthma. In addition to age and moderate smoking history, breathlessness and a history of heavy smoking were identified as risk factors for airflow limitation and COPD. Early detection of COPD in primary health care by non-physicians is feasible and should be considered for middle aged, moderate and heavy smokers experiencing breathlessness.

\section{INTRODUCTION}

The shift from secondary to primary care in Western countries coupled with falling medical manpower has increased the burden and stress on general practitioners (GPs) (Hodgkin, 1998). The refocusing of activicies in primary health care towards, for example, the management of chronic diseases, has increased the workload in the primary care sector even more (Richards et al., 2000). Wirh chronic obstructive pulmonary disease (COPD) as one of the leading causes of death and disability in Western countries (Siafakas et al., 1995) - with prevalence and mortaliry rares still rising - in conjunction with current levels and distribution of the workload in general practice related to this, consideration has been given to allocaring some or part of this work to orher care-providers, including non-physicians. Patients with COPD ofren seek treatment too late in the course of the disease and reliable evidence suggests underdiagnosis in the general population, with only $25 \%$ of cases being diagnosed (Siafakas et al., 1995).

Early detection and treatment of patients with COPD is important (Postma \& Sluiter, 1989). Dompeling er al. (1992) concluded that early detection of patients at 
risk can be performed easily and effectively by GPs by monitoring and making use of ventilatory funcrion indices, while others have shown the predicrive value of findings like decreased expiratory breath sounds, shortness of breath or wheezing (Van Schayck et al., 1991; Badgett et al., 1993; Den Otrer et al., 1997; Den Otter et al., 1998; Nihlén et al., 1999). Some studies even suggest to diagnose airflow limitation by risk factors alone (Van Schayck et al. 1991; Badgett et al. 1993).

To detect COPD in general practice, spirometry can be used and, if necessary, allocated to non-physicians (Quanjer et al., 1993; Geijer er al., 1997). In spite of the heavy workload, this solution has not until now been included in daily practice (Richards et al., 2000). Recently, nurse practitioners have been introduced into primary health care, tasked with treating COPD.

In the Maastricht region, a pilot programme was launched in which nurse practitioners, supported by undergraduates, routinely performed early detecrion and provided treatment to parients with previously unknown airflow obstruction. The guidelines of Dutch GPs, which have been drawn up in accordance with recenty published international guidelines (Geijer et al., 1997), were used as a point of reference around which the activities of the non-physicians were organised.

The research question dealt with by this study concerns the extent to which the support offered by undergraduates and nurse practirioners to GPs in the early derection of patients with COPD is effective. This was measured in terms of the number of patients identified with COPD as well as by assessing the credibility of offered early derection. Ideally, subsequent to the early detection performed by non-physicians, patients should undergo the same investigation by physicians. In order to minimise the burden on patients and physicians, and taking into account the restricted resources, it was decided to assess the credibility of early detection provided in an alternative way. It should be possible to differentiate patients with airflow obstruction or COPD from patients withour, on the basis of known risk factors. Thus to enable comparison with predictors found in other studies, the results of the lung function measurement were taken as the starting point to assess the predictive value of symptoms and medical history in the identification of patients at risk from airflow obstruction or COPD.

\section{METHODS}

\section{Recruitment of participants}

Berween September 1998 and July 1999 the programme was offered to patients in eight practices of 12 GPs. These GPs belong to a group of practices parricipating in a project in which nurse practitioners perform a central role in the care of patients with 
COPD. Half of these practices are run by single $\mathrm{GP}_{s_{s}}$ half by two partners. Although the nurses were already otherwise active in these practices, their involvement in the detection of COPD represented a new undertaking.

The practice assistant asked patients, visiting the general pracrice for reasons not related to a respiratory disease and aged between 40 and 70 years, if they were former or current smokers. If so, the GP assessed exclusion criteria. Patients who were already receiving lung medication, with a known diagnosis of asthma, COPD or chronic bronchitis or suffering from important concomitant morbidity (severe cardio-problems, cor pulmonale, active malignancies), were excluded from the study. After having given informed consent, patients were scheduled for assessment of their respiratory function according to the guidelines of Durch GPs on COPD and asthma in adults (Geijer er al., 1997). In this way a convenience sample was obtained.

Programme and study were approved by the ethical commirtee of the university hospital Maastricht.

\section{Protocol}

Patients were examined according to the protocol as illustrated in figure $\mathbb{1}$. The protocol was separated in a screening and a diagnostic part. Initial lung function testing was performed by four medical undergraduates, who had received full day training in a university lung function laboratory. Moreover, during the first day their testing was supervised by a respiratory nurse practitioner. The medical undergraduates recorded the forced expiratory volume in one second $\left(F E V_{1}\right)$ and the ratio of $F E V_{1}$ to forced vital capaciry (FVC) using spirometry (Vitalograph 2120; spirometer without the facility of printing a curve). Patients with an $\mathrm{FEV}_{1}$ less than $50 \%$ of the predicted value were eliminated from the study and referred to a pulmonologist. If the $\mathrm{FEV}_{1}$ of patients was less than $84 \%$ of the predicted value or when the $\mathrm{FEV} / \mathrm{FVC}$ ratio (both as percentage of the predicted value) did not exceed 65\%, airflow limitation was assumed. For these patients reversibility of the airflow limitation was assessed by measuring the $\mathrm{FEV}_{1} 15$ minutes after inhalation of $500 \mu \mathrm{g}$ terbutaline. The FEV $/$ /FVC ratio is also referred to as Tiffenau index (Siafakas er al., 1995).

In accordance with the guidelines, asthma was diagnosed if the $\mathrm{FEV}_{\mathbb{1}}$ before and after using terbutaline differed by more than 9\% (Geijer et al., 1997). On the basis of these findings, trearment was started by the GP. These measurements were only used for initial screening. In case of irreversible aiflow limitation, COPD was suspected and parients were invited for further diagnostic testing by one of two experienced respiratory nurse practitioners. If irreversibility was confirmed, the FEV 1 of parients was measured (Microlab 3300; spirometer with the facility for printing a curve) after which they were given $30 \mathrm{mg}$ prednisone daily for 14 days. If the difference between the FEV 1 measured before the second reversibility test and after the steroid-test was 
smaller than $9 \%$, COPD was diagnosed. If this reversibility was $9 \%$ or more, asthma was diagnosed (Geijer et al., 1997). If patients were diagnosed as having COPD, nurse practitioners started treatment in accordance with the GP.

Both medical undergraduates and respirarory nurse practitioners performed lung function tests according to European Respiratory Sociery (ERS) guidelines (Quanjer er al., 1993).

\section{Symptoms and medical bistory}

After inclusion bur before first assessment of airflow limitation, parients were interviewed by undergraduares if a) ever asthma, emphysema, chronic bronchitis or allergy had been diagnosed, b) if these diagnoses were present in family, c) if they suffered from asthma or bronchiris during childhood, and d) if they suffered from cough in the morning, production of sputum, and breathlessness during exercise. Based on the results of first lung function measurement the sample was divided in a group of patients with and a group of parients without airflow limitation. The predictive value of symptoms and medical history for airflow limitation was then assessed. The predic tors of COPD were identified according to the same method, using the results of the diagnostic test to divide the sample.

\section{Analyses}

Variables measured at the start of the study were used as predictors of airflow limitation and COPD in a logistic regression analysis. These involve: age, sex, body mass index (BMI), pack years (number of packs of cigarettes smoked per day multiplied by the number of years the individual has smoked), former diagnosis of asthma, emphysema, chronic bronchitis or allergy; presence of these diseases in family of the patient; presence of asthma or bronchitis during childhood; and the symptoms morning cough, spurum production, and breathlessness during exercise. For this purpose all variables were dichotomised. For age, BMI and pack years the mean value of patients with airflow limitation of COPD was used as cut-off value $(\leq$ mean value $>$ mean value). Differences in the prevalences of variables were tested with Pearson chi-square. The odds ratios (OR) with their 95\% confidence intervals (CO) and the statistical significance were derermined for all predictors both separately (univariate analysis) and in combination (multivariate analysis). The goodness-of-fit test according to Hosmer and Lemeshow was used (Hosmer \& Lemeshow, 1989). The predictive power of the models was tested by Receiver Operator Characteristic (ROC) Curves (Van der Schouw et al., 1992). Finally, in a ROC-analysis, data from logistic regressions were evaluated at different cut-off values to determine the maximum sum of sensirivity and specificity as the optimum cut-off value and the positive and negative 
predictive values. As significance level, $\alpha=.05$ (two tailed) was used. Data processing and analyses were conducted with SPSS (Windows Release 9.0).

\section{RESULTS}

\section{Patients and basic characteristics}

The sample included a total of 231 patients from the eight practices. The mean age of all parients is 53.5 years, about half $(48.5 \%)$ were male. About $62 \%$ are current smokers with a mean number of 31.2 pack years. Furthermore the group showed on average normal FEV $(3015 \pm 82 \mathrm{~mL})$ and $F V C(4112 \pm 105 \mathrm{~mL})$. Of 205 patients, complete data were available from lung function tests and interview.

\section{Early detection of COPD}

After the first lung function test, two patients were referred to a pulmonologist. Airflow limitation was assumed to be present in 44 patients (19.0\%), while in 185 patients $(80.0 \%)$ a normal lung function was measured. One patient with an $\mathrm{FEV}_{1}$ as percentage of predicted value above $84 \%$ had a Tiffenau index below 0.65 and was also administered terbutaline.

After the first administration of terbutaline, the $\mathrm{FEV}_{1}$ as percentage of predicted value of 38 patients was less than $84 \%$ and for two patients the difference in FEV before and after using terburaline was less than $9 \%$. In five parients asthma was diagnosed and treatment was started by the GP.

The subsequent diagnostic test was performed on 40 patients (Figure 1). Afrer repeated spiromerry, 12 patients had an FEV 1 as percentage of predicted value of $84 \%$ or more. In 28 patients with an $\mathrm{FEV}_{1}$ as percentage of predicted value below $84 \%$, reversibility was tested. After the administration of terbutaline $\mathrm{FEV}_{1}$ as percentage of predicted value increased over $84 \%$ in two patients.

All 26 patients whose irreversibility was assessed at two different measurements were invited to participare in the steroid test. One patient was unable to perform the steroid test because of too poor command of Dutch language, while two patients refused to undergo the test. Seventeen patients were diagnosed as having COPD and six as having asthma.

\section{Diagnoses of airflow linitation and COPD by patient's history and symptoms}

Of 43 patients with airflow limitation and of 162 patients without airflow limitation, data were available from lung function tests and interview. The odds ratios for all 
Figure 1

Flow char early derection of COPD.

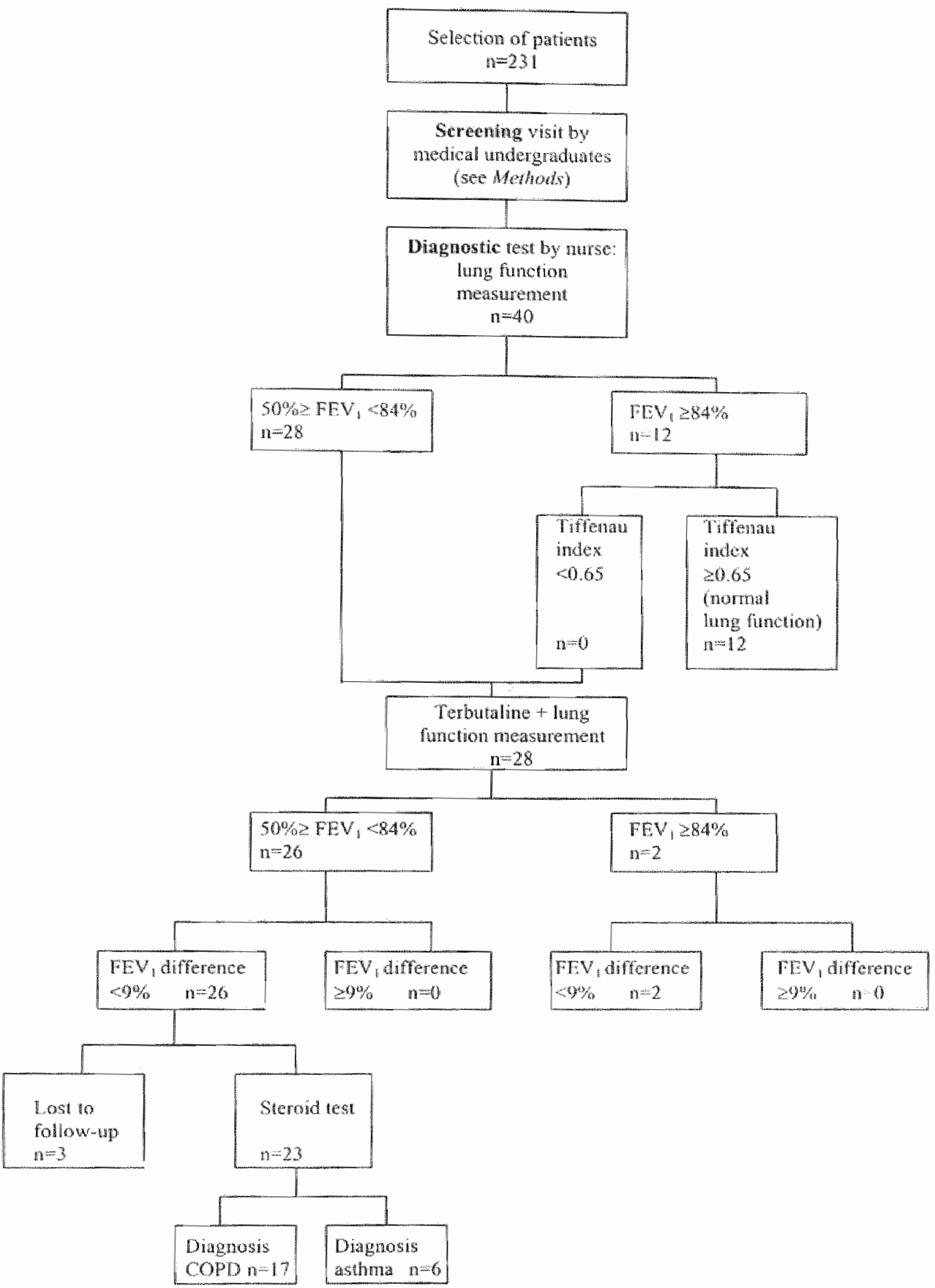




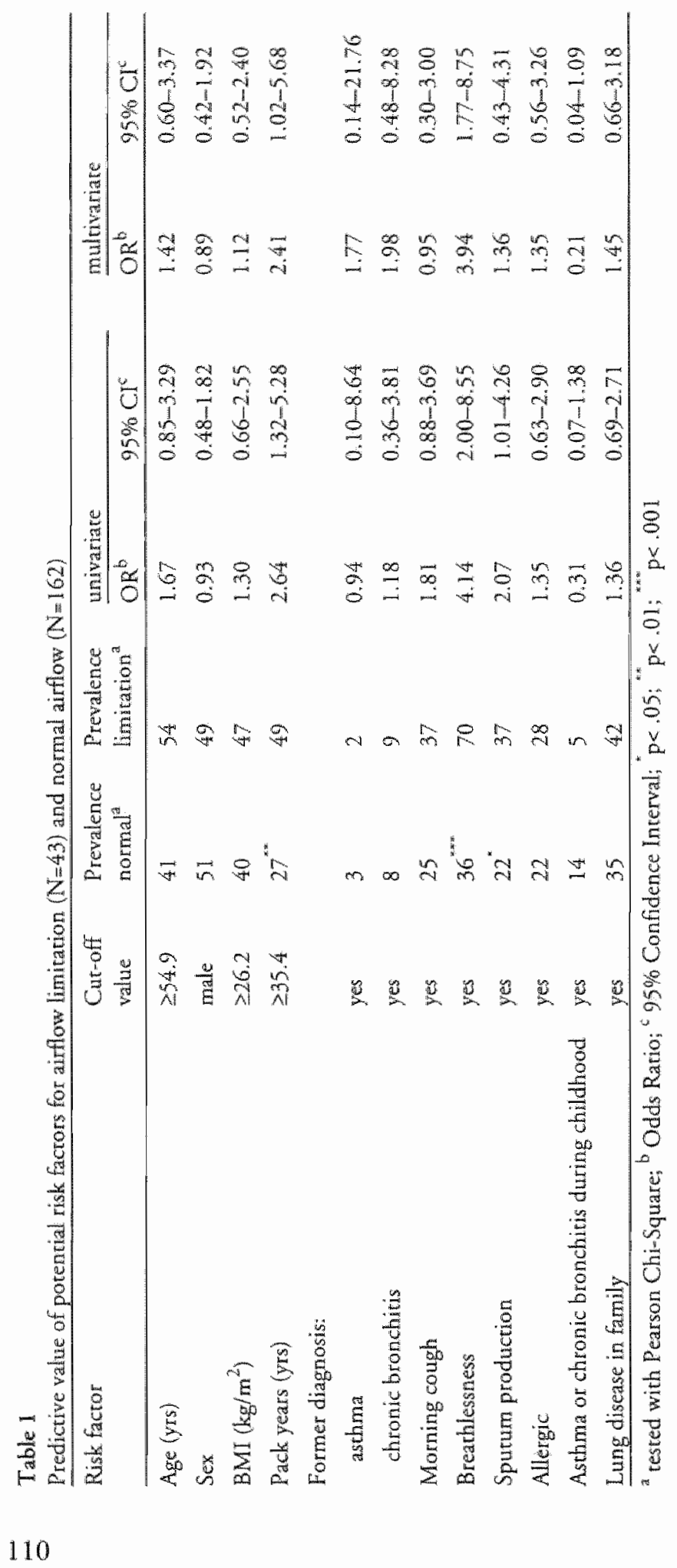


potential risk factors for aiflow limitation are presented in table 1 . Because lung emphysema was not reported by parients this variable was left our of this analysis. Univariate analyses showed that pack years, breathlessness and sputum production were statistically significant predictors of airflow limitation with respectively 2.6, 4.1, and 2.0 times higher risk. In the multivariate logistic regression, breathlessness and pack years retained as risk faccors for airflow limitation.

From the Hosmer and Lemeshow test it appeared that the model fits the data reasonably well $(\mathrm{p}=0.69)$. Furthermore, with an area under the ROC curve of 0.75 , the model distinguishes between patients with airflow limitation and those without. The statistically optimum cut-off value, was found to be 0.29 or 0.30 . Both values showed the highest sumscore $(142 \%)$. Thus, when patients with a predictive probability of 0.29 or grearer are classified as having COPD, $84 \%$ of patients with COPD according to lung function measurement are identified on the basis of the risk factor model and $58 \%$ of patients withour COPD according to lung funcrion measurement, are classified as parients without COPD on the basis of the model.

Because of the reclassification of 12 out of 40 patients after the first measurement by the nurse practitioner, we also looked for predictors of airflow limiration defined by the nurse. Statistically significant differences in prevalence were found for pack years and breathlessness. Both predictors of aiflow limitation retained after univariate and multivariate analyses, with equal odds ratios. In addition the model now fitted the data reasonably well (Hosmer and Lemeshow test with $p=0.76$ and area under curve of 0.75), while the statistically optimum cut-off value was found to be 0.19 (sumscore $=145 \%$ ).

Of 16 patients with COPD and of 189 patients withour COPD data were avalable from lung function cests and interview. The findings of the analyses of the predictive values of potential risk factors for COPD are presented in table 2. Male sex, pack years, breathlessness and spurum production were statistically significant predictors of COPD, of respectively $4.7,6.8,4.5$, and 3.3 times higher risk. Because patients did not report the presence of asthma or emphysema, these two variables were kept out of the model. After multivariate analyses sex, pack years and breathlessness retained as statistically significant predictors of COPD. The Hosmer and Lemeshow test showed a $\mathrm{p}$-value of 0.68 , and the area under the ROC curve was 0.87 . Like the airflow model the COPD model differentiates between observed and predicted values and discriminates between patients with and without COPD. The cut-off value of 0.08 was found to be the statistically optimum cut-off value (sensitivity $=88 \%$, specificity $=80 \%$, sumscore $=168 \%$ ). 


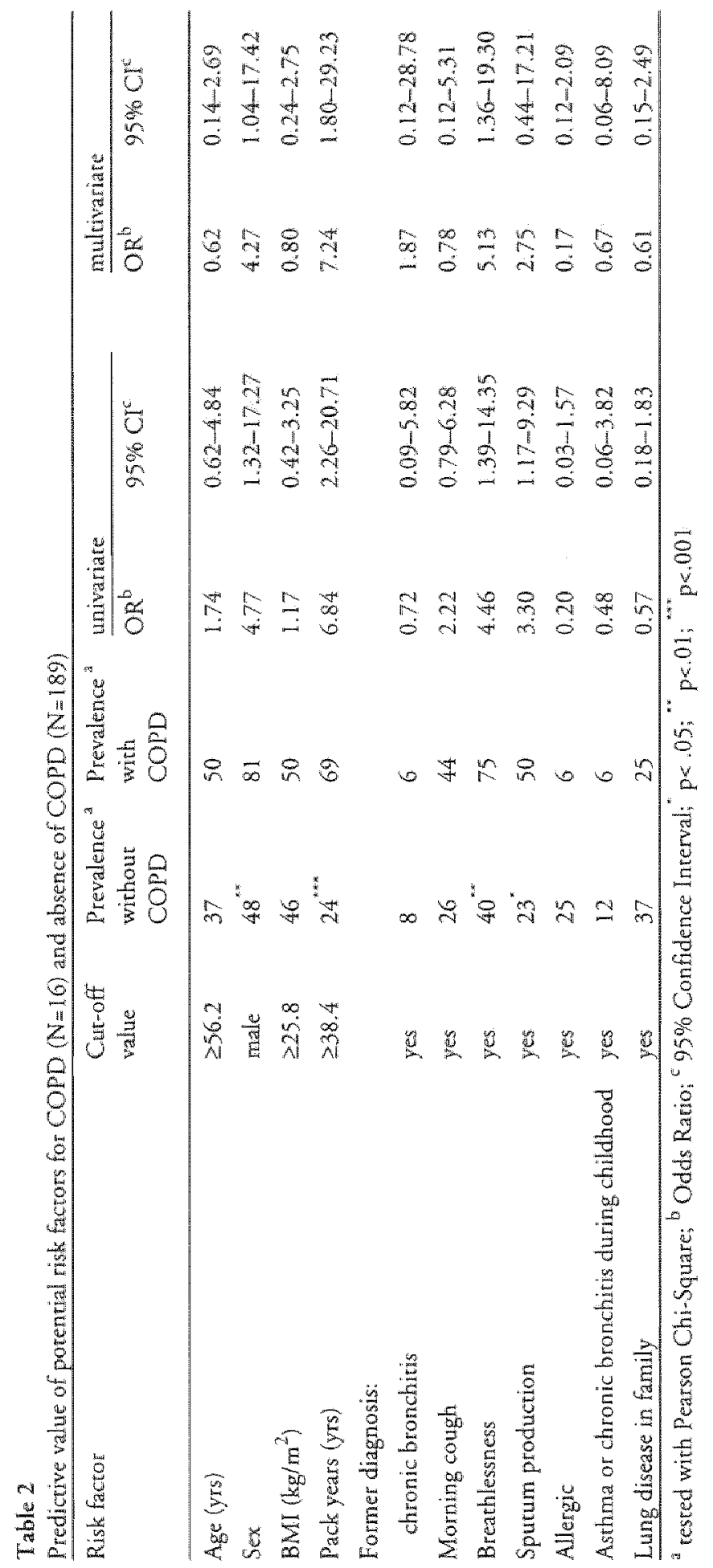


In this study the feasibility of a pilot programme based on current guidelines for Dutch GPs for early detection of COPD performed by non-physicians was assessed. Applying the programme to middle aged patients ( $\mathrm{n}=231$ ) at risk from COPD, who visited the GP for reasons not related to respiratory diseases, resulted in the identification of 17 patients with COPD $(7.4 \%)$ and 11 patients with asthma (4.8\%). Nihlén et al. (1999) reported a detection rate for COPD of $9.2 \%$ when corrected for known earlier diagnoses, which is fairly comparable with the rate found here. Nevertheless, selection bias might have accurred because of the nature of the sample.

Of the 40 patients with airflow limitation reported by the undergraduates, 12 parients (30\%) were reclassified by the nurses. Inquiry revealed undergraduates experiencing difficulies with the instruction of patients to perform a good lung function test during the carly stages of the programme. Adequare rraining can overcome this accurrence. In the setting of this study medical undergraduates were available, while it is imaginable that in a different setting pracrice assistants or practice nurses, if adequately trained, can perform lung function tests. Future research needs to be initiared here.

Furthermore, early detection of COPD with the support of undergraduates and nurses showed acceprable credibility. Withour having the disposal of a golden standard, the predicrive value of symptoms and medical history in identifying patients at risk from airflow obstruction or COPD was used as indication for the credibility of early detection. Logistic regression analyses showed the predictive value of pack years and breathlessness for both airflow limitation and COPD and also of sex for COPD. The predictive power of the models was acceptable. Positive and negative predictive values (not presented) as well as sensitivity and specificity of models also appeared to be acceptable at optimum cut-off values.

Other research reported smoking history, self-reported history of wheezing and wheezes during examination as best predicrors of airflow limitation (Holleman et al., 1993), while diminished breath sounds (Den Otter er al., 1998), heavy smoking history" (Den Otter et al., 1998), breathlessness and wheezing (Den Otter er al.. 1997) were reported as best predicrors of COPD. Physical signs have greater valuc in monitoring the severity of airflow limitation in COPD than in early derection (Badgett et al., 1993). In this study wheezing or physical signs as predictors of COPD were not studied. The finding that breathlessness and pack years are risk factors for COPD corresponds with earlier research. The increasing number of women who smoke, makes it likely that male sex as a risk factor for COPD will (continue to) decrease in the future. This is when sex category can be seen as risk factor, because sex probably just modifies the effect of pack years on COPD and therefore in itselfis not a risk factor. 
Future research should also be initiated to the complex interaction among predictors. In this study predictors were regarded individually and dichotomised or classified by using the mean value. Classification and Regression Trees (Breiman et al., 1984) can be used to study the interactions as well as find less arbitrary cut-off points for predictors.

How should a programme for early detection of COPD be organised? Firstly, detection of patients with early COPD should preferably take place in general practice (Van Schayck et al., 1991). Secondly, the services of non-physicians can be taken advantage of. Lung function measurement requires expertise that will be gained when performed routinely and can be carried out effectively by non-physicians. Nurse practitioners can also play a central role in the treatment of parients, which is subject of current evaluarion. Ideally all listed patients of adult age in general practice should be screened, but if this is not feasible active case finding is recommended (Nihlén et al, 1999). Adult age, moderate or heavy smoking history and shortness of breath should be taken along when considering a more proactive strategy.

This study illustrates the development of the role of the nurse in primary care to one of partnership with the GP. By taking on roles and tasks tradirionally performed by physicians shared decision making and mutual respect have become the new core values in care. Future research needs to address the effects of the allocation of work on patient outcomes, while issues like educational preparation for undertaking the new role, appropriate salary, and quality control also need to be addressed.

\section{ACKNOWLEDGEMENTS}

The authors gratefully acknowledge the help of E. van den Akker (including her help with data-entry), A. Bennaghmouch, J. Evers, E. Knapen, I. Lutgens and G. Vermeulen in measuring patients' lung funcrion, and M. Frederix and V. Zwietering for their commentary and advise during the preparation and execution of the project.

\section{REFERENCES}

Badgett RG, Tanaka DJ, Hun DK, Jelley MI, Feinberg LE, Steiner DF, Petty "TL. (1993). Can moderate chronic obsrrucrive pulmonary disease be diagnosed by historical and physical findings alone? The American Joumal of Medicine $94,188-96$.

Den Otter IJ. Knitel M, Akkermans RPM, Van Schayck CP, Folgering HTM, Van Weel C (1997). Spiromery in general practice: the performance of practice assistants scored by lung function rechnicians. Brivish Journal of General Practice 47, 41-2.

Den Otter J, Van Dijk B, Van Schayck CP, Molema J, Van Weel C (1998). How ro avoid underdiagnosed asthraa chronic obstructive pulmonary disease? Journal of Asthma $35(4), 181-7$. 


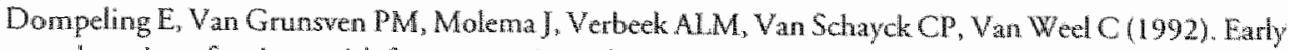
derecion of patients with fast progressive aschma or chronic bronchitis in general practice. Scandinatvian Journal of Primary Health Care 10, 143-50.

Gejjer RMM. Thiadens. HA, Smeele IIM, Van der Zwan AAC, Sachs APE, Botrema BJAM, Van Hensbergen W, Van Schayck CP, Van Weel C, Rosmalen CFH (1997). NHG-standard COPD en astma bi wolwassenen: diagnostiek (Guideline of Dutch general practinoners on COPD and asthma in adults: diagnostics). Huisarts \& Wetenschap 40, $416-29$.

Hodgkin P (1998). Shifting the work. British Journal of General Pracrice 48, 1040-1.

Holleman DR, Simel DL, Goldberg IS (1993). Diagnosis of obstructive airways disease from the clinical examination. Journal of General Intemal Medicine $8,63-8$.

Hosmer DW, Lemeshow S (1989). Assessing the fic of the model. In Applied logistic regression. John Wiley and Sons, New York.

Niblén U. Monenémery P, Lindholm LH, Löfahl C (1999). Detection of chronic obstructive pulmonarys disease (COPD) in primary health care: role of spiromerry and respiratory symptoms. Seandinavian Journal of Primary Health Care 17,232-7.

Posma DS, Sluiter HJ (1989). Prognosis of chronic obstructive pulmonary disease: the Durch experience. American Review of Respiratory Diseases $140,100-5$.

Quanjer PH, Tammeling GJ, Cotes JE, Pedersen OF, Peslin R, Yernatr JC (1993). Lung wolumes and forced ventilatory flows. Report Working Party Standardization of Lung Function rests, European Community for Sted and Coal. Official Statement of the European respiratory Society. European Respiratory Journal 16(Suppl.), 5-40.

Richards A, Carley J, Jenkins-Clarke S, Richards DA (2000). Skill mix between nurses and doctors working in primary care-delegation or allocation: a review of the literature. International Journal of Nursing Studies 37, 185-97.

Siafakas NM, Vermeire P, Pride NB, Paoletti P, Gibson I, Howard P, Yernault IC, Decramer M, Higenbotram 'T, Postma DS, Rees $J$, on behalf of the Task Force (1995). Oprimal assessment and management of chronic abstructive pulmonary disease (COPD). A consensus statement of the European Respiratory Society (ERS). European Respiratory Journal 8, 1398-420.

Van der Schauw YT, Verbeek ALM, Ruys JHJ (1992). ROC curves for the initial assessment of new diagnostic tests. Family Practice 9, 506-11.

Wan Schayck CP, Van Weel C, Harbers HJM, Van Herwaarden CLA (1991). Do physical signs reflect rhe degree of airflow obstruction in patients with asthma or chronic obstructive pulmonary disease? Scandinavian Journal of Primary Health Care 9, 232-8. 


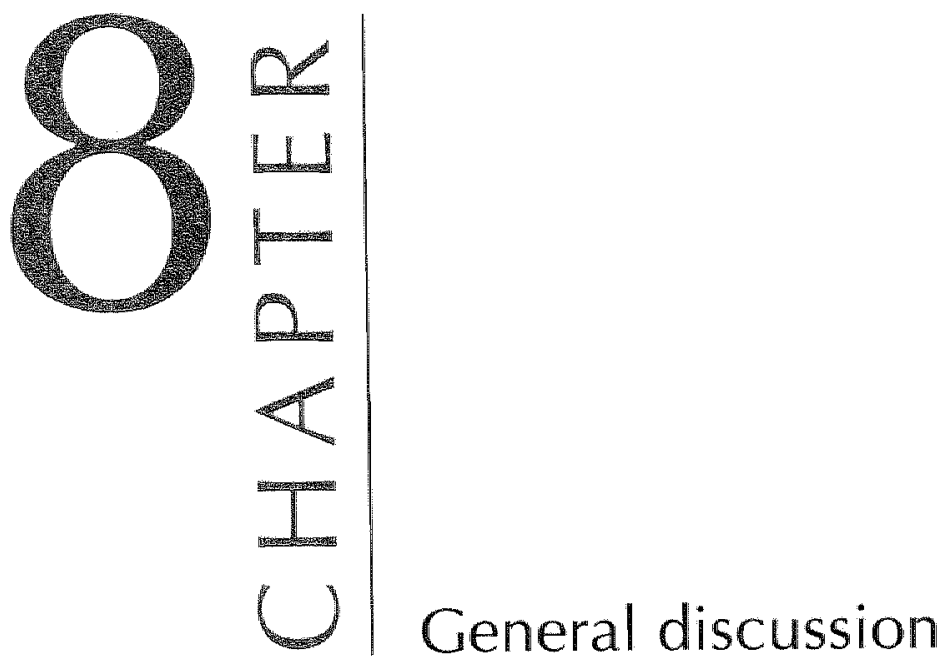


The main goal of this thesis was to obtain more insight into the effects on quality of care for patients with stable type 2 diabetes or COPD when tasks are transferred from physician to nurse specialist. In addition, in the phase of early detection of COPD the feasibility of the support provided by the nurse specialist to the GP was assessed, while for patients with RA low disease activity criteria, using the DAS28, were assessed for their feasibility to measure stability. It was assumed that the care-networks in which the nurse specialist performs a central role influence the outcomes of care.

The findings reported in the individual chapters are briefly summarised below. Subsequently, conclusions derived from the study findings about the role of the nurse specialist in the care for chronically ill persons are given. The methodological strengths and limitations of the research presented in this thesis are discussed, while this chapter ends with recommendarions for further research and implications for health care professionals and policy makers.

\section{SUMMARY OF FINDINGS}

Chapter 2 examines whether the low disease activity criteria using the Disease Activity Score (DAS28) can be applied by nurse specialists to assess the degree of disease stability in patients with rheumatoid arthritis, and whether these criteria are sufficiently reliable to select stable patients out of an outpatient population for enrolment in a care-network. Compared to diabetes and COPD, for RA there is no internationally accepted parameter to assess stability. Patients regularly seen at the theumatology outpatient department of the University Hospital Maastricht were invited for assessment of the srability of their rheumatoid arthritis. Sixty-six (66) patients completed the study - completion rate of $68 \%$ - and underwent three assessments using the DAS28. With almost $40 \%$ of patients classified as stable and a good similarity score, the low disease activity criteria using the DAS 28 criteria were found to be applicable for the selection of patients with stable, low disease activity of rheumatoid arthritis out of a rheumatology outpatient department.

Chapter 3 presents a review of the literature, focusing on a selection of ten trials concerning the effectiveness and efficiency of models of care for patients with type 2 diabetes or COPD where the nurse has a central role. The rrials showed differences in the roles or tasks performed by the nurse and therefore in the outcomes assessed and realised. Survival, clinical parameters, quality of life, self-care, and patient satisfaction are regarded as indicators for effectiveness, and these are related to medical consumption and costs for the assessment of efficiency of the models of chronic care. Furthermore, it was found that clinical parameters did not improve as often as expected. 
Moreover, improvements in quality of life, self-care, and patient satisfaction occurred, while patients had higher medical consumption when they were cared for by the nurse specialist. The review indicated that, depending on the content of the intervention, effective and efficient models of chronic care with the nurse in a central role had been devised. It was noticed that evaluative studies about both the processes and effects of care are needed to gain more insight into how high quality care should be maintained in the near furure.

To enable the reader to compare the main characteristics and findings of the central research questions, presented in chapters 4,5 and 6 , wirh the way the literature was reviewed in chapter 3 , these are summarised in Tables 1 and 2 .

Chapters 4 and 5 present the findings of two care-networks for parients with type 2 diabetes with the nurse specialist in a central role (Table 1). Chapter 4 investigates the effects on quality of care, when care for patients with stable type 2 diabetes is transferred from outpatient department to general practice and from endocrinologist to nurse specialist - diagonal substitution. The nurse specialist, having the highest level of qualification and specialised in diabetes, performed tasks concerning direct patient care, organisation and co-ordination of care for individual patients, consultation, and advancement of expertise. The first three of the recommended quarterly consultations during one year were transferred to the nurse specialist, leaving one consultation for the endocrinologist. The intervention was carefully described in a protocol and agreed by all parties involved. Using a 12 -month non-equivalent control group design, it was found that except for glycaemic control, groups were comparable for health starus, self-care behaviour, knowledge of diabetes, patient satisfaction, and consultations with main care-providers (Table 2). The mean $\mathrm{HbA}_{\mathbb{1}}$ level for outpatients cared for by the nurse specialist in the primary care setting improved (with $-0.3 \%$ to $8.3 \%$; $\mathrm{n}=31$ ), while the mean $\mathrm{HbA}_{1 \mathrm{c}}$ level for patients cared for by the endocrinologist in the outpatient setting showed a statistically significant deterioration (with $+0.2 \%$ ro $8.8 \% ; \mathrm{n}=23, \mathrm{p}$-value between groups $=0.001$ ).

Applying a 12-month one-group pretest-postrest design with additional comparisons using data from the study in the chapter 4 , the transfer of care for parients with stable type 2 diabetes from general practitioner to nurse specialist - vertical substitution - was studied in chapter 5 . With a few minor adjustments, use was made of the protocol formulated in chapter 4. For instance, the number of consultations performed by the nurse was not fixed, while the annual consultation by the general practitioner was. Again statistically significant improvements in glycaemic control were found (with $-0.3 \%$ to $7.7 \% ; n=158$ ), as were improvements in health status, self-care behaviour, knowledge of diabetes, and patient satisfaction. Patients reported a statistically significant increase in the number of consultations with main care-providers. Chapters 4 and 5 show that substitution-based care-networks, with the nurse taking on roles and tasks traditionally performed by the physician, result, in 

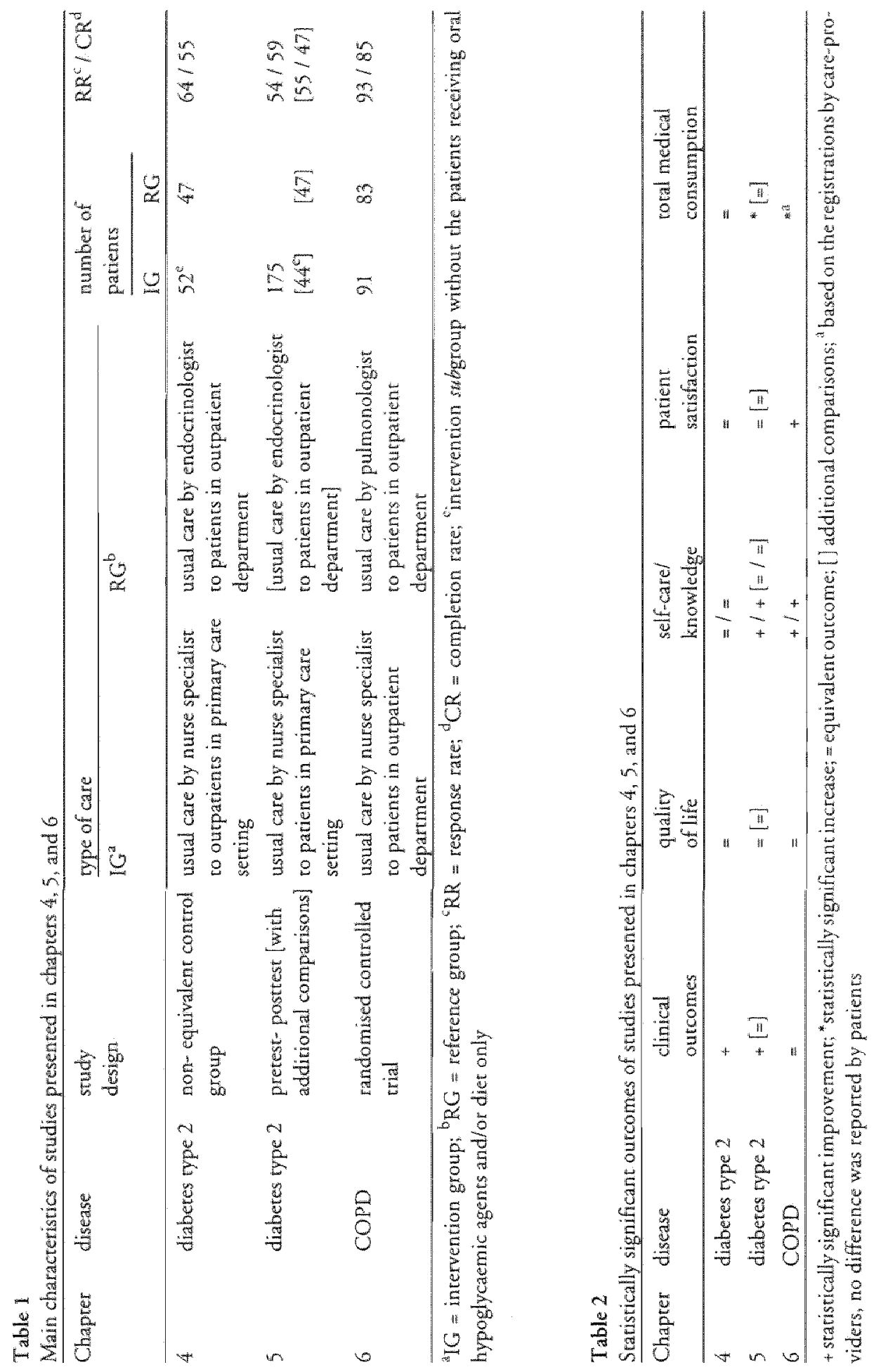
terms of parient outcomes, in equal quality of care with improvements in glycaemic control.

In chapters 6 and 7 interventions with the nurse specialist in a central role in the care for patients with COPD were studied. The effects on quality of care when tasks are transferred from pulmonologist to nurse specialist in the care for outpatients with stable COPD - vertical substitution - were studied in Chapter 6. Care was provided by the nurse specialist, having the highest level of qualification and specialised in COPD, working under a protocol in the outpatient department of a hospital. Using a nine-month randomised controlled trial, it was found that groups (intervention group $n=91$, control group $n=83$ ) were fairly equal for clinical parameters, health status, knowledge of COPD, and self-care behaviour, while patients cared for by the nurse specialist received statistically significantly more consultations and reported statistically significantly higher satisfaction with care. It was concluded that the transfer of care for outparients with stable COPD with the nurse working under a protocol is, in terms of patient outcomes, a justifiable alternative for care delivered by the pulmonologist. Patients, visiting their general practirioner for reasons not related to a respiratory disease, who stated they were former or current smokers had their respiratory function assessed by the nurse specialist in the primary care setting, as reported in Chapter 7. COPD was detecred in $7.4 \%$ of patients at risk $(\mathrm{n}=231)$, while the credibility of the early detection by non-physicians in general practice was confirmed by strong predictive values of pack years and breathlessness in these patients. It was concluded that the services of the nurse specialist are also useful for the early detection of COPD.

\section{CONCLUSIONS}

There are both intrinsic and extrinsic rationales for placing the nurse specialist in at central tole in the care for patients with chronic diseases. Against the background of the growing number of chronically ill people and their unique needs, the reallocation of work according to skills and experience of caregivers and the combination of care with cure has resulted in a new pro-active approach to chronic care with a central role for the nurse specialist. Extrinsic motives are the high workload of physicians and a predicted shortage in their numbers in the near future. Considering the existing arrangements for the delivery of care, it is believed that the nurse specialist can substitute for the physician in the care for patients with a chronic disease in a stable phase as part of an interactive and interdependent network of care delivery.

The review of the literature revealed a paucity of (randomised) controlled trials investigating the effects of the nurse specialist substituting for the physician on quality of care for chronically ill patients. However, from the selected publications it was 
found that giving the nurse specialist a central role in the care for parients with rype 2 diabetes or COPD is justified in terms of patient outcomes. Using three different study designs in various settings for patients with stable type 2 diabetes or COPD, it was found that in terms of effects on parient outcomes the transfer of care from physician to nurse specialist is justified; at least equal outcomes were established. Furthermore, it is concluded that also in the phase of early detection of COPD, nurse specialists can play an important role by independently performing lung function measurements and diagnosing patients. Finally, for RA it was found that, applying the low disease activity criteria based on the DAS28, a substantial proportion of outpatients can be identified as having 'stable' RA. This finding suggests that, like diabetes type 2 and COPD, RA is a relevant and suitable chronic disease to unfold an inter-professional network of care delivery.

\section{METHODOLOGICAL CONSIDERATIONS}

\section{Research design}

Performing research into the effects of an intervention on the quality of care assumes the presence of some model of cause and effect, while assessing effects on the aspect of outcomes of quality brings one directly to quantitative methods of research. However, considering the delivery of health care as an open system, the possibilities of multiple causation and contingent causes create problems in its evaluation (Cook \& Campbell, 1979). In a recently published review, the methodological value of comparative analyses of the individual practice of physicians, nurses, and midwives of evaluations has been questioned (Watts et al., 2001). Because of the occurrence of methodological constraints when evaluating complex, composite interventions in daily practice of health care delivery, Van Weel and Knotmerus (1999) conclude that the randomised controlled trial is very difficult to apply. With the care-network being refined and adjusted in daily practice, standardisation of the intervention is impossible. Desirable elements of methodology for scientific research, like a control group, randomisation, and blinding, are also difficult if not impossible to realise (Steuten et al, submitted). While this might, coupled to the early stage of this field, explain the paucity of (randomised) controlled trials about the effectiveness of the nurse substituting for the physician, the adoption of (potential) effective interventions in the delivery of health care is strongly guided by evidence derived from traditional, quantitative research.

In the studies published in this thesis, concepts of traditional, quantitative research were used to the level permitted by the individual settings to provide insight, together with the forthcoming findings of the process cvaluation, into the effects on quality of care. The application of the low disease activity criteria, as presented in chapter 2 , is a 
pragmatic solution in order to evaluare, in a clinical siruarion, the suitability of RA as a chronic disease where the nurse specialist might play a role in the deliwery of care to a selected group of patients. The DAS28 has not been developed for assessing stability of RA of parients.

Unconventional methods were used in the study presented in chapter 7, where the level of confidence of the early detection of COPD by the nurse specialist was compared with the risk profile of patients. Constraints of the burden on patients and physicians, when using a subsequent assessment by the physician, meant that only known risk factors could be applied as the standard for the credibility of early detection by nurse specialists.

In evaluating the effects on quality of care for patients with stable type 2 diaberes (chapters 4 and 5) or with stable COPD (chapter 6) when the nurse specialist is given a central role in the delivery of care, three different designs were used. Acknowledging the circumstances encountered, use was made of a non-equivalent control group design (chapter 4), a pretest-posttest design with additional comparisons (chapter 5), and a randomised controlled trial (chapter 6). From the findings of these three studies, it was concluded that the nurse specialist can substiture for the physician in the care for patients with stable diabetes type 2 or COPD.

Is a quasi-experimental or observational design then sufficient to evaluate the effectiveness of different models for the delivery of care? "To answer this question, other main factors influencing the methodological quality of findings are discussed. These factors are interventions, outcome measures, popularions (external validity), and statistical analyses (together with design: internal validiry) (CRD, 2001).

\section{Standardisation of care}

For all interventions reported in chapters $2,4,5,6$, and 7 protocols were formulated to standardise the care provided by the nurse specialist. For the studies in chapters 4,5 , and 6 this meant that the complete phase of care delivery was defined in the protocol. For the number of consultations of patients with main care-providers, as administered by patients, a possible bias occurred in the observational study (chapter 5). In this study it seems that parients consulted both the nurse specialist and the general practitioner for their diabetes. As discussed in chapter 5 , this increased consumption was not reflected in a difference in direct medical costs. Blinding of study-participants was impossible. Findings derived from the process evaluation will shed more light on the occurrence of performance bias. As for the stability of the intervention, a learning effect from the nurse specialist might occur.

For the assessment of stabiliry of RA in patients (chapter 2), it is very unlikely that potential changes in care, as provided by the rheumatologists, were reflected in the assessments performed within a period of six months. Performance bias with regard to 
the early detection of COPD, thus the performance of a lung function assessment, did occur. Patients with airflow limiration as reported by the undergraduates were reclassifred by the nurses. This was due to difficulties with the instruction of patients to perform a good lung function test during the early stages of the programme. While this only results in false positive findings, a better training programme can overcome this occurrence.

\section{Outcome variables and instruments}

The ser of outcomes used in the studies presented in chapters 4,5 , and 6 was based on accepted objectives in the care for chronically ill people and covers all relevant outcomes (Driessen et al., 1994). Internationally accepted clinical outcomes were assessed for diabetes type 2 and COPD. When comparing the presence of data from clinical parameters between groups, it was seen that for patients cared for by the nurse specialist data are more complete than for patients cared for by the physician, a finding made clear by the experimental designs (chapters 4 and 6). Firstly, this indicates that the nurse specialist works more closely to the protocol. With respect to the quality of the care delivery ir is unclear what this difference exactly means. From chapter 6 it was found that pulmonologists provide fewer consultations to patients in a relatively more stable phase of COPD. Although this might suggest that nurse specialists are stronger initiators in care, without evidence about the optimal frequency of consultations for chronically ill patients this remains controversial. Secondly, this might indicate that patients cared for by the nurse specialist have more consultations than patients receiving usual care. Although this is confirmed by the results from the experimental studies (chapters 4 and 6 ), the numbers of consultations with the nurse specialist were in accordance with the protocol. The differing presence of clinical outcomes did not prevent performing analyses, but did influence the applicability of statistical analyses. Repeated measures analyses were performed in chapter 4 , while in chapters 6 independent sample t-tests were performed.

For the measurement of quality of life, the Visual Analogue Scale (Maxwell, 1978) and COOP/WONCA charts were chosen to enable more general conclusions to be drawn (Nelson et al., 1987). It should be emphasised that no direct effect from the nurse specialist on quality of life was expected, but rather an indirect effect with clinical outcomes, knowledge and/or self-care as intermediate factors, was regarded as possible. The Visual Analogue Scale was replaced by a disease-specific instrument in the study for patients with COPD for two reasons (chapter 6). Firstly, whilst showing better glycaemic control but no change in quality of life, the generic instruments to measure quality of life might not be sensitive enough to measure a possible change. The second reason was that quality of life as outcome parameter has a more specific meaning in the treatment of COPD and thus requires a disease-specific instrument. 
For patients with COPD, the COOP/WONCA charts and the St George's Respiratory Questionnaire (Jones et al., 1992) were used. Without finding differences for quality of life within or between groups, as measured with generic and specific instruments, the conclusion that with the nurse specialist as main care-provider equality in quality of life is achieved, seems to be rather robust. Measuring quality of life over a longer period of time should be undertaken to shed more light on this topic.

Self-care behaviour and disease-specific knowledge of patients are important outcomes when redesigning care-delivery towards a model in which the patient has more responsibility. Both outcomes were measured with disease-specific instruments developed in the Netherlands (Deenen, 1996; Pennings-van der Eerden, 1992; Ripken et al., 1990). Among all outcomes, lowest completion rates were scored for these instruments, which might be translated as the instruments being too difficult for some patients to complete, or as too confrontational for some patients. Higher response rates might be achieved when the assessment of self-care behaviour and knowledge are assessed during consultation, offering the addirional possibility for care-providers to make instant use of this information. The instruments should be evaluated for this function. Notwithstanding the imperfect completion rates, indications exist that the nurse specialist improves the level of self-care behaviour and knowledge of patients, after being introduced as the main care-provider (chapters 5 and 6). In chapter 4 the nurse specialist, although not as main care-provider, was already active on this area before the start of the study - as reflected in high scores at baselinewhich might explain the absence of further improvements in the setting in question.

Patient satisfaction was assessed by instruments derived from industrial marketing management, which have been applied in the same area of research before (Cockroft et al., 1987; GRASSIC, 1994; Littlejohns et al., 1991; Sum et al., 2000). These instruments also served as the basis for a recently developed instrument for satisfaction with health care delivery (Wensing, 1997). Using the 'markering-instruments' made clear that the care-network with the nurse specialist in the central role is well accepted by patients (chapters 4, 5, and 6). Only when patients are asked to grade their satisfaction for specific aspects of care-delivery, is it possible to make an inventory of the aspects in need for improvement. From chapter 6, ir was clearly seen that higher proportions of patients cared for by the nurse were sarisfied with care received than of patients receiving usual care. In other words, the room for improvement in usual care is bigger than in the care with the nurse specialist in the central role. A finding confirmed by the results of a focus group interview under patients with diabetes type 2 or COPD in the region of Maastricht (Koppers, 2000). While a relationship between length of consultation and patient satisfaction exists, in another study it has been found that differences remained statistically significant when this was accounted for (Sum et al., 2000).

Consultations with main care-providers were measured by means of a self-developed booklet in the studies presented in chapters 4 and 5 , while in chapter 6 the regis- 
trations of care-providers were also used as data-source. With respecr to the bookllets, it was found that not all patients filled in the booklets for the intended time period when compared with the data derived from the registranions of care-providers (chapter 6). However, when considering the data for the entire study-period, it is unlikely that this inaccuracy has resulted in invalid conclusions. Similar consideration applies to the other data gathered by questionnaire, although for these outcomes a possible inaccuracy is of less significance. Again, combining consultations with the collection of data might be a solution for this bias.

One variable of highly relevance was not measured in the studies presented in this thesis. With the focus on the aspect of effectiveness, outcomes were not related to their inputs. Considering the limited resources of this effect evaluation, it was decided to evaluate the effectiveness first. However, the question "how efficient is the care-nerwork?' has even become more relevant and should be addressed in the near future.

In chapter 2 the low disease activity criteria using the DAS28 were applied to assess stability in patients with RA, while these criteria have not been developed for this purpose. Without the existence of a gold standard to assess stability in RA, the findings cannot always be interpreted unambiguously but nevertheless they yielded conclusions in which one can have confidence. Moreover, in the absence of a gold standard, the credibility of early detection of COPD by the nurse specialist was assessed by making use of known risk factors (chapter 7). By combining the lung function measurement and the gathering of data on risk factors of patients, this strategy proved to be acceptable.

\section{Power considerations and populations}

No power calculation was performed for the quasi-experimental study presented in chapter 4 . Here, as in the study presented in chapter 5 , the sample size was defined by the local circumstances, i.e. the number of participating general practitioners, the criteria for stability, and the willingness of patients to participate. For the randomised controlled trial (chapter 6) a power calculation was performed, taking patient satisfaction as primary outcome. Moreover, based on the GRASSIC study (1994), it was calculated that, to find a difference in satisfaction rate of 0.7 on a scale between 1 and 10 , a number of 75 patients per group was needed.

Allocation of patients to groups took place on level of participarion of general practitioners in the study presented in chapter 4 , while patients were allocated at random in chapter 6. Differences between comparison groups at baseline were found in chapter 4. With no patients in the control group being treated by oral hypoglycaemic agents alone, analyses were performed between patients receiving oral hypoglycaemic agents and/or insulin. If this affecred the study results, then it would certainly not be 
advantageous for the nurse specialist. With only modest response rates and completion rates in the studies with type 2 patients, the drop-out of patients is even more precarious with poorer controlled people not finishing the studies. As discussed in chapters 4 and 5 , this might have influenced the results, but did not affect the conclusions. A possible explanation for the relatively high response rate and completion rate in the study for patients with stable COPD (chapter 6) might be the non-academic setting with patients not being tired of the umpteenth scientific research.

The loss of one third of the group of parients with RA (chapter 2) allso needs attention. It was conceivable that the patients with missing data had more often non-stable RA. Moreover, if data had been available for these non-stable parients, the test-rerest reliability of the low disease activity criteria using the DAS28 would have been smaller. However, it is unlikely that the missing data would have affected the proportion of patients with stable RA. Also in the study about the early detection of COPD, a small number of patients $(n=26)$ dropped out (chapter 7). Apart from the possible influence on the study findings, for these patients there is a danger that, in case of airflow limitation, treatment will start too late and thus is less effective.

\section{Statistical analyses}

Incongruence in the unit of allocation and the unit of analysis occurs in much experimental research about the effectiveness of interventions aimed at improving the quality of diabetes care (Renders, 2001). Moreover, this unit of analysis error increases the apparent precision of estimates (Divine et al., 1992). When the intervention is directed at care-providers, but the outcomes are analysed at the parient level, ideally the clustering of patients within care-providers should be taken into account. The observations made of patients cared for by the same provider are not independent. Standard methods of analysis that ignore the clustering of patients within providers affect the study findings and might even result in incorrect conclusions (Renders, 2001).

For the experimental study reported in chapter 4 this error did occur. In this study patients received diabetes care from one of two nurse specialists, when their general practitioner was willing to participate in the care-network; otherwise patients received usual care by one of five medical specialists. In chapter 6 patients were allocated to the nurse specialist or the pulmonologist, while outcomes were analysed on the patient level.

To protect against systematic differences between comparison groups in terms of non-respondents, intention to treat analysis was applied. Especially for pragmatic trials of effectiveness, intention to treat analysis is suitable (Roland \& Torgerson, 1998). According to a recently suggested method for the handling of missing responses (Holis \& Campbell, 1999), intention to treat analysis was applied by using 
the last observed response (chapters 4 and 6). Based on the primary findings in chapter 5 , it was assumed that unchanged outcomes on the group level could be imputed in terms of the means of outcomes for individuals.

In conclusion, experimental designs are difficult to apply in these settings but, because of the difficulties encountered, offer more insight into the effectiveness of the intervention than observational studies, when conducted appropriately. Experimental designs are preferable, but should not have exclusivity in this area of research because absence of evidence - which should not be confused with evidence of absence (Altman \& Bland, 1995) - should be avoided.

\section{RECOMMENDATIONS}

As recently stated in the Netherlands as well as in other industrialised countries and confirmed in chapter 3 , evidence of the effectiveness of nurse specialists is at present unclear (Laurant et al., 2002; Loveman et al., 2002; Richardson et al., 1998; Temmink, 2000; Van der Linden, 2001). The studies presented in this thesis contribute to a better understanding of the effects of substituting nurse specialists for physicians. The extent to which this thesis will help policy makers and health care professionals to achieve good quality care is outlined below. Finally, topics for further research are identified.

\section{Recommendation for policy}

From the findings presented in this thesis, it is concluded that the central role in the care for patients with stable diabetes type 2 or COPD for the nurse specialist is justified. To make full advantage of the services of the nurse specialist, this profession needs to be institutionalised and legalised. Therefore it should become clear how the role, skills, and responsibilities of the nurse specialist relate to the medical professions as well as to the other non-physician practitioners. Currently, a number of non-physician practitioners are claiming, mostly without a strong evidence base, a rolle in the delivery of care to chronically ill people. Aspects of controversy and conflict should be prewented, as these are only harmful for the patient. Professional and occupational boundary redefinition should take place.

An important element of this redefinition is the education required to fulfil a particular role in care-delivery. In the Netherlands, only since April 2001 has an accredited course been launched for nurses willing and able to specialise in diabetes mellitus, while for specialities like COPD or RA still no officially recognised courses exist. For non-physician practitioners other than the nurse specialist, no accredited educational programmes exist either. Although 'learn by doing' and ultimately being 
able to provide jusrified care has worked so far, it is undesirable for wise and wide implementacion. In the construction of these educational programmes the current single-professional approach has to be changed in an inter-professional focus.

The change in tasks and activities as well as the related responsibilities should be converted in the salary of care-providers and in the price of the product delivered. This price should represent the true costs of the product and should not be an administrative price. The new pricing system being developed now, called 'Diagnose Behandel Combinaties' (in English: diagnosis trearment combinations), might accommodate this. One should not be surprised if ultimately more resources will be needed, or in the words of Donabedian (1986), "it should be clear to everyone, though sometimes we seem to forget it, that more quality must cost more."

In the interventions evaluated, supervision of the nurse specialist by the medical specialist was given, while the nurse specialist functioned as a consultant towards general practitioners and simultaneously offered general practitioners better access to the medical specialist. Substitution was thus accompanied by collaboration across different levels of care delivery. The structure of the care-network requires shared responsibility, good communication, successfull co-ordination, and democratic relationships between care-providers. Sharing responsibilities implies that the nurse specialist gains more autonomy in care as compared to the traditional situation. Legislation needs to reflect practice in which the nurse specialist performs tasks that belonged to the domain of the physician, including shared responsibility. As an illustration of the uncomfortable current situation, if the nurse specialist, based on the findings from the consultation with the parient, wants to refer to the dietician, authorisarion from the physician is required. The latter, however, is generally only involved in giving his/her signature. Legalised authority for nurses to make certain referrals without asking for the physician's signature is needed. Moreover, when applying a team approach, it seems reasonable to hold different care-providers responsible for the care provided by them. For patients, it should be clear who is ultimately responsible for the delivery of care. For the Netherlands this would require amendments to the Individual Health Care Professionals Act (Wer Beroepen Individuele Gezondheidszorg) and to the Medical Treatment Act (Wer Geneeskundige Behandelings Overeenkomst).

To facilitate or enhance interdisciplinary communication, relationships, and teamwork, it will be necessary to both recognise the potential danger for participants, as well as the potential gains. Professional co-ordination is indispensable to facilitate the necessary conditions, leaving care-providers and patients in the primary process and responsibility with the care-providers. Furthermore, professional comordination should play an important role in quality control and improvement of the delivery of care. Suitable tools like protocols, information technology, electronic patient records, benchmarking and feedback exist, but need to be developed for or tuned to the inte- 
grated care setting and be successfully implemented in daily practice. Without care-providers adopting a transparent and accountable work-environment, quality control and improvement are not feasible.

For wider implementation of the nurse specialist in a central role in the care for patients with a chronic disease, the capacity of the nursing workforce has to increase. In this context, policy makers need to address the following issues: the availability of nurse specialists for substitution, the desirability and possibility of a movement up the nursing skills specrum of the other nurses, and the optimal nurse-physician ratio. Although complex, these issues need to be explored to be able to plan the workforce on both national and local level.

With respect to the suitability of diseases for which an inter-profession model of care delivery can be applied, RA, like diabetes type 2 and COPD, can be managed appropriately. Moreover, with allmost $40 \%$ of outpatients assessed as having stable RA, compared with the percentage of outpatients with stable COPD $-26 \%$ of the population studied in Alkmaar (chapter 6) - RA seems to offer even higher potencial for disease management with the nurse in a central role. Other diseases like heart disease, HIV/AIDS, cancer and depression are also believed to be suitable and relevant for redesigning the care delivery in a more comprehensive way. For the management of these diseases too, (more) scientific research is needed.

\section{Recommendation for further research}

Several recommendations for further research have already been mentioned in the individual chapters of this thesis. The most compelling of these as well as some broader recommendations are mentioned here.

The choice for the research designs applied in the studies presented in this thesis was defined by the local circumstances where the intervention was implemented. More empirical evidence is needed on the merits of various designs in this area of research. To evaluate the consequences of substitution for professions or factors determining the adoption of new roles, both quantitative and qualitative research should be applied to provide complementary information. Moreover, iterative research should be performed.

With regard to the assessment of patient outcomes in people with a chronic disease, preferably longitudinal data have to be gathered. When evaluating structural concepts of chronic care delivery, in addition to disease specific instruments, generic and standardised instruments have to be applied to enable conclusions to be drawn that are broader than individual chronic diseases. With regard to the measurement of disease-specific knowledge and self-care behaviour of patients with a chronic disease, internationally applicable and valid instruments need to be developed. Moreover, the feasibility of these instruments in daily care-delivery needs to be established. Research 
is needed to identify the factors leading to differences in patient satisfaction. "The influences of the several outcomes on each other have to be established.

Research should be initiated into the establishment of the optimal number of consultations for patients with a stable chronic disease. Research should also be initiated to establish the optimal nurse-physician ratio. A related topic is the standardised evaluation of the cost-effectiveness of models in which the nurse specialist has the central role. This implies that consensus has to be reached on the methodological requirements of cost-effectiveness research or Health Technology Assessment of multifacered interventions.

\section{REFERENCES}

Altman D, Bland M (1995). Absence of evidence is not evidence of absence. British Medical Journal $311: 485$.

Cook TD, Campbell DT (1979). Quasi-experimentarion: design and analysis issues in field settings. Houghton Mifflin, Boston, United Srates of America.

Cockroft A, Bagnall P, Heslop A, Andersson N, Heaton R, Barstone J, Allen J, Spencer P, Guz A (1987). Controlled trial of respiratory health worker visiting patients with chronic respiratory disability, British Medicall Journal 294:225-8.

Deenen ThAM (1996). Patient health-education and self-management: a medical-psychological intervention study on severe asthma and COPD in a high altitude clinic. Dissertation. Rijksuniversiteit Groningen, Groulingen.

Divine GW, Brown T, Fraztier LM (1992), The unit of analysis error in studies about physicians" patient care behaviour. Joumal of General Internal Medicine 7:623-9.

Donabedian A (1986). The price of quality and the perplexiries of cure. Centre for Health Administration Studies, University of Chicago, Chicago.

Driessen S, Casparie AF, Van den Bos GAM (1994). Outcome indicators for quality assurance and improvement in the care for the chronically ill fUitkonstindicatoren voor kwaliteitsbewaking en-bevordering in de zorg woor chronisch zieken]. The Hague: Durch Organisation for Scientific Research (NWO), study 4 from research progranme Quality of Care.

Grampian Asthma Study of Integrated Care [GRASSIC] (1994). Integrated care for asthma: a clinical, social, and economic evaluarion. British Medical Journal 308:559-64.

Hollis $\$$, Campbell $\mathbb{F}$ (1999). What is meane by incention to treat analysis? Survey of published randomised controlled trials. British Medical Journal 319:670-4.

Jones PW, Quirk FH, Braveystock CM, Litulejohns P (1992). A self-complete measure of healrh status for chronic airflow limitarion: the St. George Respiratory Questionnaire. The American Review of Respiratory Disease 145:1321-7.

Koppers RLW (2000). Patiënten stemmen ... : kwaliteitsindicatoren vanuil het patièntenperspectief voor shared care zorgmodellen (doctoraalseriptie) [Patients'voices ... indicators of quality for shared care models from the patients" perspective (masters thesis)]. Universiteir Maastrichi, Maastricht.

Laurant M, Sergison M, Sibbald B (2002). Substirucion of doctors by nurses in primary care (Protocol for a Cochrane Review). In: The Cochrane Library, Issue 2. Oxford: Update Software.

Lirtlejohns P, Baveystock CM, Parnell H, Jones P'W (1991). Randomised controlled trial of the effectiveness of a respiratory health worker in reducing impairment, disabiliry, and handicap due to chronic airflow limitation. Thorax 46:559-64. 
Loveman E. Royle P. Waugh N 2002). Specialist nurses in diabetes mellius (Protocol for a Cochrane Review). In: The Cochrane Library, Issue 1. Oxford: Updare Sofware.

Maxwell $\mathrm{C}$ (1978). Sensivivity and accuracy of the visual analogue scale: a psycho-physical classroom experiment. British Joumal of Clinical Pharmacology $6(1): 15-24$.

NHS Centre for Reviews and Dissemination [CRD] (2001). Underaking systemaric rewiews of research on effectiveness. CRD's guidance for those carrying out or commissioning rewiews (report number 4 , 2nd edition). University of York.

Nelson EC, Watson $K_{*}$ Kink J, Keller A, Clark D, Zubkof M (1987). Assessment of function in routine clinical practice: description of the COOP chart method and preliminary findings. Journal of Chronic Diseases 40 (Suppl 1):55\$-64\$.

Pennings-van der Eerden LJM (1992). Self-care behaviour in the treatment of diabetes mellitus. Theory, assessment and determinants of self-care behaviour and diabetes education. Dissertation. Universiteit Utrecht, Utrechit:

Renders CM (2001). Interventions to improve the quality of diabetes care in primary care. Dissertation. Vije Universiteit Amsterdam, Amsterdam.

Richardson G, Maynard A, Cullum N, Kindig D (1998). Skill mix changes: substiturion or service development? Health Policy 45(2):119-32.

Ripken ThMJ, Pennings-van der Eerden L.JM. Schrijwers AJP (1990). Diaberes education in Eindhowen, Type II diabetes patients in the spotlights. [Diabetes educatie in Eindhowen, "Type II diabetespatienten voor het woetlicht]. Medisch Contact 3:88-90.

Roland M, Torgerson Df (1998). Understanding controlled trials. What are pragmatic trials? British Medical Journal 316:285.

Steuten LMG, VrijhoefHJM, van Merode GG, Severens JL, Spreewwenberg C (submirted). Assessing the methodological quality of disease management evaluation studies.

Sum C. Humphreys A, Wheeler D, Cochrane MA, Skodas, Clement S (2000). Nurse management of patients wich minor illnesses in general practice: multicentre, randomized controlled trial. British Medical Journal 320:1038-43.

Temmink D (2000). Transmural dinics: a nursing innovation explored. Dissertation. University of Maastrichr, Maastricht.

Van der Linden, BA (2001). The birth of integration. Explorative studies on the development and implementation of ransmural care in the Netherlands 1994-2000. Dissertation. Universiteit Utrecht, Utrecht.

Van Weel C, Knotmerus JA (1999). Evidence-based interventions and comprehensive treatment. The Lancet $353.916-8$.

Watrs $T$, Jones M. Wainwright P. Williams A. (2001). Methodologies analysing individual practice in bealth care: a systematic review. Journal of Advanced Nursing 35(2):238-56.

Wensing M (1997). Patients evaluate general pracrice. A method for assessing and improwing care. Dissermrion. Katholieke Universiter Nijmegen, Nijmegen. 
SAMENVATTING 
Het hoofddoel van dit onderzoek was het verkrijgen van inzicht in effecten op kwaliteit van de zorg voor patiënten met stabiele diabetes type 2 of stabiele chronische luchtwegobstructie (COPD), wanneer dic zorg worde verschoven van arts naar verpleegkundig specialist. Daarnaast is de haalbaarheid van ondersteuning van de huisarts door de verpleegkundig specialist in de fase van vroege opsporing van COPD onderzocht, terwijl de Disease Acrivity Score (DAS28) is onderzocht op zijn geschiktheid om stabiliteit van reumatoïde artritis (RA) bij patiënten vast te stellen. Verondersteld werd dat de uitkomsten van zorg zouden worden beïnvloed door de centrale positie van de verpleegkundig specialist in de diverse zorgnetwerken. Substitutie van zorg en transmurale zorg worden namelijk beschouwd als manieren om de samenwerking en de afstemming in de zorg voor chronisch zieken te verbeteren alsmede de effectiviteit en efficiency van deze zorg.

In hoofdstuk 2 wordt onderzocht of de DAS28 geschikr is om de mate van stabiliteit van RA door verpleegkundig specialisten vast te stellen en of de hierop gebaseerde criteria voldoende betrouwbaar zijn om patiënten in een stabiele ziektefase uir een poliklinische patiëntengroep te selecteren ter includering in een zorgnetwerk. In vergelijking met diabetes en COPD is er voor RA geen internationaal geaccepteerde parameter om stabiliteit vast te stellen. Patiënten die met regelmaat op de polikliniek reumatologie van her academisch ziekenhuis Maastricht komen, werden uirgenodigd voor het vaststellen van de mate van stabiliteit van hun $R A$. Zesenzestig (66) patiënten deden mee aan het onderzock (completion rate $68 \%$ ) en ondergingen drie metingen met de DAS28-criteria. Met bijna $40 \%$ van de patiënten geclassificeerd als stabiel en een goede overeenstemmingsscore, blijkt dat de DAS28-criteria geschikt zijn om patiënten met stabiele, laag actieve RA te selecteren uit een poliklinische patiëntengroep met RA.

Hoofdstuk 3 beschrijft de resultaten van een literatuurstudie mer tien trials in termen van de effectiviteir en de efficiency van zorgmodellen voor patiënten met diabetes type 2 of COPD waarin de verpleegkundige een centrale rol bezit. De trials laten verschillen zien in de rollen en de taken die de verpleegkundigen uitvoeren en daarmee in zowel de onderzochte als geconstateerde effecten. Overleving, klinische parameters, kwaliteit van leven, zelfzorggedrag, en patiëntrevredenheid worden beschouwd als indicatoren voor effectiviteit, en worden gerelateerd aan medische consumptie en kosten ter bepaling van de efficiency van de modellen voor chronische zorg. De literatuurstudie laat zien dat klinische parameters niet zo vaak verbeteren als verwacht wordt. Verbeteringen in kwaliteit van leven, zelfzorggedrag en patiënttevredenheid treden op, terwijl pariënten een hogere medische consumptie rapporteren wanneer ze zorg krijgen van de verpleegkundig specialist. Verder blijkt uit de literatuurstudie dat, afhankelijk van de samenstelling van de interventie, effectieve en efficiënte modellen voor chronische zorg met een centrale rol voor de verpleegkundige zijn uirgewerkt. Geconstateerd wordt dat evaluatieonderzoek naar de processen en de 
effecten van de zorg voor chronisch zieken nodig zijn om meer inzicht te krijgen op welke wijze goede kwaliteit van zorg kan worden gehandhaafd in de nabije toekomst.

Om de lezer in staat te stellen de belangrijkste eigenschappen en resultaten ten aanzien van de centrale onderzoeksvragen, zoals die zijn gepresenteerd in hoofdscuk 4 , 5 en 6 , te vergelijken met de samengevatte literatuur in hoofdstuk 3 , zijn deze samengevat in rabel 1 en tabel 2.

Hoofdstuk 4 en 5 laten de resultaten zien van twee zorgnerwerken voor patiënten met diaberes type 2 warin een centrale rol wordt vervuld door de verpleegkundig specialist (tabel 1). Hoofdstuk 4 onderzoekt de effecten op kwaliteit van zorg als zorg voor patiënten met stabiele diabetes type 2 wordt verschoven van polikliniek naar huisartsenpraktijk èn van endocrinoloog naar verpleegkundig specialist (diagonale substirutie). De verpleeglkundig specialist, welke het hoogste verpleegkundig kwalificatieniveau heeft en gespecialiseerd is in diabetes, woert taken uit betreffende de directe patiëntenzorg, de organisatie en de coördinatie van zorg aan individuele patiënten, consultatie en de bevordering van experrise. Drie van de aanbevolen driemaandelijkse consulten worden verschoven naar de verpleegkundig specialist, terwijl eén jaarlijks consult aan de endocrinoloog blijft voorbehouden. De interventie is zorgvuldig protocollair vastgelegd en ontving instemming van alle betrokken partijen. Op basis van een non-equivalent control group design blijkt na 12 maanden dat, met uitzondering van de glycaemische controle, patièntgroepen vergelijkbaar zijn qua gezondheidstoestand, zelfzorggedrag, kennis over diabetes, patiënttevredenheid, en consultaties met zorgverleners (tabel 2). Het gemiddelde $\mathrm{HbA}_{1 \mathrm{c}}$ niveau van patiënten die zorg ontvangen wan de verpleegkundig specialist in de huisartsenpraktijk verbetert (met-0.3\% tot $8.3 \%$; $\mathrm{n}=31$ ), terwijl het gemiddelde $\mathrm{Hb} \mathrm{A}_{1 \mathrm{c}}$ niveau van patiënten die zorg ontvangen van de endocrinoloog op de polikliniek verslechtert (met $+0.2 \%$ tot $8.8 \% ; n=23$, p-waarde tussen groepen $=0.001$ ).

Door gebruik te maken van een one-group pretest-postrest design met aanvullende vergelijkingen mer data uit hoofdstuk 4, wordt de verschuiving van zorg van patiënten met stabiele diabetes type 2 van huisarts naar verpleegkundig specialist (verticale substitutie) in hoofdstuk 5 bestudeerd. Met enkele kleine aanpassingen is gebruik gemaakt van het protocol uit het model wan hoofdstuk 4 . Zo lag het aantal door de verpleegkundig specialist te verrichten consulten niet vast, maar de jaarlijkse controle door de huisarts wel. Wederom treedt een statistisch significante verbetering op in glycaemische controle (met- $0.3 \%$ tot $7.7 \% ; \mathrm{n}=158$ ) als ook in gezondheidstoestand, zelfzorggedrag, kennis over diaberes, en patiënttevredenheid. Patiènten rapporteerden een statistisch significante toename in het aantal consulten met zorgverleners. Hoofdstuk 4 en 5 laten zien dat op substitutie gebaseerde zorgnetwerken, waarin tradicioneel door de arts wervulde rollen en taken worden overgenomen door de verpleegkundig specialist, in termen van patiëntuitkomsten resulteren in equivalente kwaliteit van zorg en verbeteringen in glycaemische controle. 


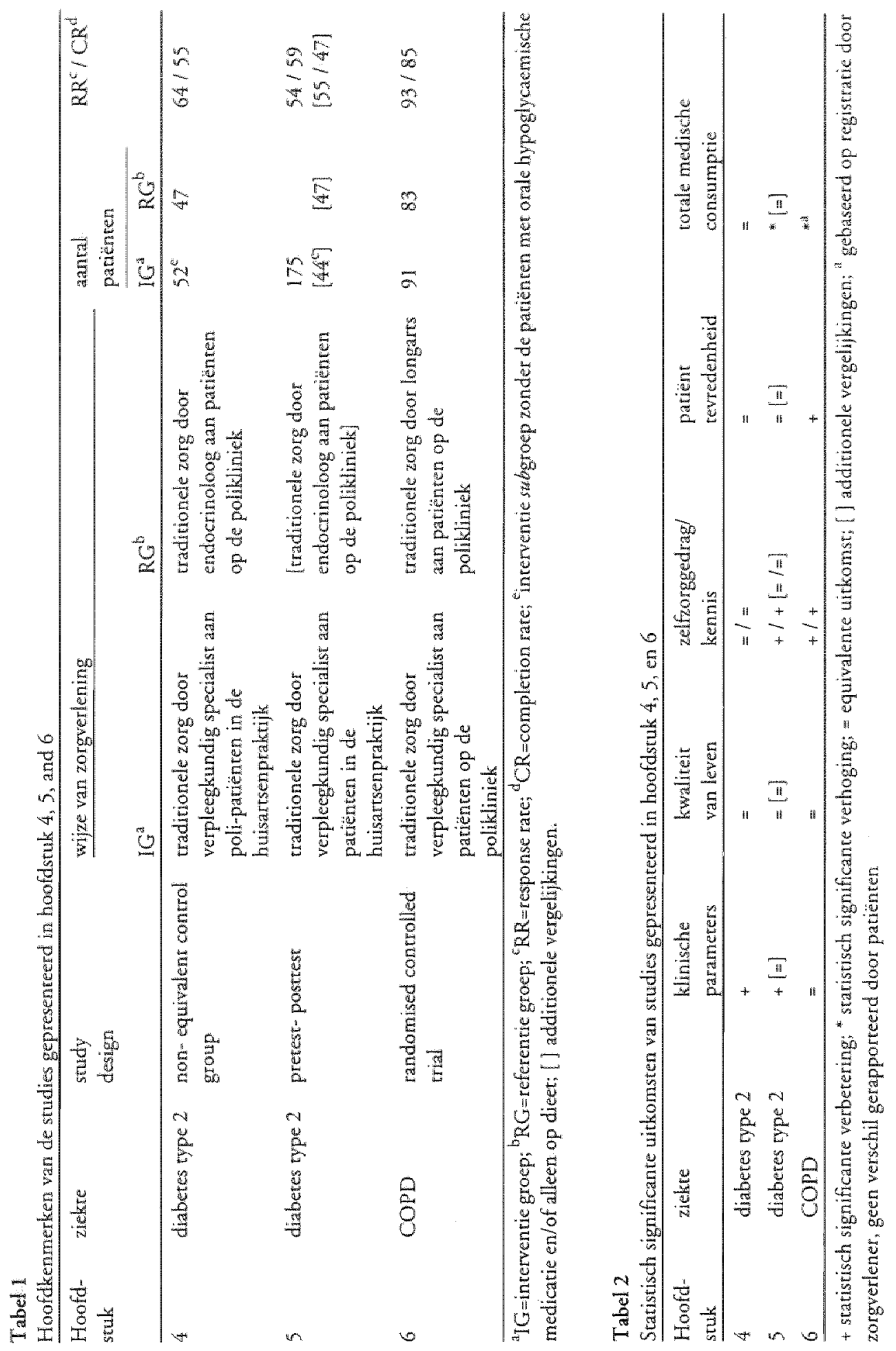


Hoofdsruk 6 en 7 beschriven interventies waarin de verpleegkundig specialist een centrale rol vervult in de zorg aan mnsen met COPD. De effecten op kwaliteit wan zorg, wanneer taken in de zorg voor poliklinisch behandelde patiènten met stabiele COPD worden verschoven wan longarts naar werpleegkundig specialist (verticale substiturie), worden geèvalueerd in hoofdstuk 6. Zorgvetlening vind plaats volgens een protocol op de polikliniek van een algemeen ziekenhuis door de verpleegkundig specialist, welke het hoogste verpleegkundig kwalificatieniveau heeft en gespecialiseerd is in COPD. Door gebruik re maken van een randomised controlled rrial blijkt na 9 maanden dat de groepen (interventie groep $n=91$, controle groep $n=83$ ) vergelijkbaar zijn voor klinische parameters, gezondheidstoestand, kennis over COPD, en zelfzorggedrag, terwijl pariënten die zorg ontvangen van de verpleegkundig specialist meer consultaties krijgen en, eveneens statistisch significant, cen hogere tevredenheid over de zorgverlening rapporteren. De conclusie luidr dat het verschuiven van zorg voor poliklinische behandelde patiènten mer COPD door een protocollair werkende verpleegkundige, in termen van patiëntuitkomsten, een gerechtvaardigd alternatief is voor zorgverlening door een longarts.

Hoofdstuk 7 beschrijft hoe pariënten, die hun huisarts bezochren voor een niet aan een longaandoening gerelateerde reden en die verklaarden (ex)roker te zijn, een diagnostische longfunctie test hebben ondergaan die werd uitgevoerd door een longverpleegkundige in de huisartsenpraktijk. COPD werd vastgesteld onder $7.4 \%$ van de risicopatiènten $(n=231)$, terwijl de betrouwbaarheid van de vroege opsporing door niet-artsen in de huisartsenpraktijk werd bevestigd door de woorspellende waardes van de variabelen pakjaren en kortademigheid onder deze patiënten. Geconcludeerd wordt dat de diensten wan de verpleegkundig specialist ook waardevol zijn in de vroege opsporing van $\mathrm{COPD}$.

In her afsluitende hoofdstuk wordt, na een korte samenvatting van de voornaamste bevindingen van de studies in dit proefschrift, ingegaan op de methodologische beperkingen en worden aanbevelingen gedaan voor beleid en verder onderzoek. Voor het evalueren van de effecren van zorgnetwerken voor chronisch zicken met een centrale rol voor de verpleegkundig specialist is gebruik gemaakt van verschillende onderzoeksdesigns. Het, in verschillende mate, optreden van diverse vormen van bias is derhalve onvermijdelijk, maar levert desondanks belangrijke inzichten op. Het verschuiven wan zorg voor chronisch zieken van arts nar verpleegkundig specialist is in termen van patiëntuitkomsten gerechtwaardigd, maar dient ook op andere gebieden, zoals juridisch en economisch, te worden gerechrvaardigd. Verder onderzoek, met bijzondere aandacht voor de methodologie, is nodig om optimaal gebruik te kunnen maken van de diensten wan de verpleegkundig specialist in de zorg voor het toenemend aantal chronisch zieken. 

DANKWOORD 
Aan de totstandkoming van dit proefschrift hebben diverse mensen een bijdrage geleverd. Voordat ik bepaalde mensen hiervoor meer persoonlijk bedank, wil ik een generaal dankwoord uitspreken aan een ieder die mij in de gelegenheid heeft gesteld om dit werk tot een goed einde te brengen.

Zonder de onderzoeksgegevens van patiënten was een evaluatie van uitkomsten onmogelijk geweest. Daarom veel dank aan alle deelnemers aan het onderzoek. In éen adem met de patiënten dank ik alle zorgverleners die in de zorgnetwerken hebben geparticipeerd. Her is fijn werken met jullie en hoewel we aardig op weg zijn, moer er nog een hoop gebeuren. Ik ben dan ook verheugd dat onze samenwerking een vervolg heeft gekregen. Zonder geldschieters zijn innovatieve activiteiten in de gezondheidszorg onmogelijk; dank aan het Academisch Ziekenhuis Maastricht, Groene Kruis Zorg, Medisch Centrum Alkmaar, de Nationale Commissie Chronisch Zieken, de Stichting Zickenhuizen Noord Limburg, het Stimuleringsprogramma Gezondheidsonderzoek, Synchron, en de Universiteit Maastricht.

Als promovendus van prof. dr. C. Spreeuwenberg zijn deuren voor me opengegaan die voor anderen gesloten blijven. Cor jouw overzicht, durf en doorzettingsvermogen zijn van ongekende omvang en blijven inspireren. Samen met je immer oprechte en openharrige stijl van begeleiden en je vertrouwen in mij, had ik me geen andere promotor willen wensen. Ik ben zeer verheugd dat we ondertussen een vervolg hebben gegeven aan onze samenwerking.

Ook dank aan de co-promotoren: dr. J.P.M. Diederiks en prof. dr. B.H.R. Wolffenbuttel. Jos, door jouw hulp vervlogen de dichtste, methodologische en statistische rookgordijnen als sneeuw voor de zon, in tegenstelling tot die van je sigaren of pijptabak. Het is onder jouw dagelijkse begeleiding dat dit proefschrift tor stand is gekomen. Ik bedank je voor alles wat nodig was en ik verheug me erop dat, zoals het er nu naar uitziet, ook onze samenwerking een vervolg krijgt. Bruce, ik dank je voor je durf om als internist-endocrinoloog met de diabetesverpleegkundige in zee te gaan; een beslissing waar je geen spijt van hebt gekregen. Jouw statuskennis is een ongekende luxe voor een onderzoeker die streeft naar een zo compleet mogelijke dataset.

Dank aan de andere hoofdbetrokkenen wan het eerste uur: Edmée van den Akker, Elleke Knapen, Geertjan Wesseling, Miel Wouters (allen COPD-project), Els Denis, Wilke Ellenbroek, Bea Jöbses (allen diabetes-project), Yvonne van Eijk, Ilse Klein Goldewijk, en Sjef van der Linden (allen RA-project). Dezelfde dankbetuiging aan de hoofdbetrokkenen in de 'buitenprojecten': Jan van den Bergh en Inge Weemhoff (allen COPD-project in het MCA), Hanny Geven, Mia Vorstermans, Toos Vullings, Loek en Maria van Wilderen (allen diabetesproject te Noord-Limburg). Ook dank aan alle nog niet genoemde leden van de diverse begeleidingscommissies en projectgroepen.

Mijn drie paranimfjes: Leonie, Maaike en Marianne. Zonder projectcoördinatoren kunnen zorgverleners en onderzoekers betrokken bij transmurale zorg en disease 
management het wel vergeten. Marianne, dank voor je ondersteuning vanaf het begin rot en met nu en straks. Leonie, dank voor onze als maar toenemende en boeiende samenwerking. Mazike, met jou is het altijd heel gezellig en nooit saai. Dat je me nog veel (levens)wijsheden en spannende verhalen toevertrouwt!

Een bijzonder woord van dank aan Bob Wilkinson. Dear Bob, thanks for your outstanding editorial work. I'm sure you used my original texts as inpur for your own research. Liselotte Klijn en Irmgard Eijkelberg, de collega-onderzoekers van de procesevaluarie bij BEOZ. Beiden dank woor jullie inzet en collegialiteit. Irmgard, als iemand de 'black box' aan het praten kan krijgen, ben jij het wel. De (oud) collega's van de secrie medische sociologie bedank ik voor de plezierige tijd aan her Debeyeplein. Frans, Vonca en studenten, dank voor jullie ondersteuning bij de data-invoer. Silvia en Lillianne, omdat jullie alrijd zo lief zijn. Mijn huidige collega's bij Zorgwetenschappen, in het bijzonder Verplegingswerenschap, en bij Behandel- en Zorgeenheid Transmurale Zorg dank ik eveneens voor hun collegialiteit en samenwerking tijdens de afrondingsfase van het proefschrift. Hans Fiolet, dank voor het structureel inbedden van transmurale zorg voor chronisch zieken via de BZe. Lotte, dank voor de laatste controles van mijn tekst en je ondersteuning tijdens de afrondingsfase.

Medeschuldig aan mijn eerste stappen in de wetenschap is Dr. H. Crijns. Beste Harry, dank hiervoor, als ook voor je aanhoudende belangstelling. Nathalie en Ad: onze vriendschap is me veel waard. Nathalie, dit keer organiseer ik een feestje en ben jij mijn gast. Ad, gaan we dan binnenkort echt(e) bergen beklimmen?

Mijn moeder, broer en oma bedank ik voor hun liefde en steun. Ik ben erg trots en gelukkig dat ik deze zonneschijn met jullie mag delen. Ewa, hartelijke dank woor jouw steun en liefde. Geen afstand is ons te ver, of zoals jij altijd zegt 'van hier tot de maan en terug.' Ewunia, kocham cię!! 

CURRICULUM VITAE 
Bert Vrijhoef was born on March 20, 1971 in Roosendaal. After the first rwo years of primary school in the small village called Huijbergen, together with his parents and his brother he moved back to Roosendaal where he finished primary school and high school. In 1989 he decided to start working as an assistant-accountant. One year later, just before his father died, he started to study Health Policy and Management at the Erasmus University in Rotrerdam. Before his graduation, he participated as a student researcher at the Royal College of Surgeons in Dublin, Ireland. In three months he wrote a chapter of an advisory report for the Irish government on the prevention of coronary heart disease. Back from Dublin he finished his master thesis on the cost-effecriveness of fundusphotography and before he applied for his diploma he worked for about half a year as a research associate for the board of the Foundation of General Practitioners Laboratory in Breda (Srichting Huisartsen Laboratorium).

After his graduation at the Erasmus University in June 1996, he started to work at the Deparment of Medical Sociology of the University of Maastricht on the PhD-project 'Care-networks for chronically ill: a central role for the nurse specialist.' He was involved in teaching and was a member of the execurive board of the department and of the interfaculty committee on science. During the second year of his $\mathrm{PhD}$-project hestarted to work part-time in a private research office with two business partmers, first in Rotterdam and later in Amsterdam. One and a half year later they decided to end their successful office and to specialise each in their own field of professional interest.

In June 2000 he started working as a researcher at the Office for Medical Technology Assessment at the University Hospital Groningen. Three months later he was appointed as a post-doc researcher at the Department of Health Sciences, University of Maastrichr. With professor Spreeuwenberg and professor Van Merode he started working on the new research programme "Health Technology Assessment of disease management."

Since January 2001 he combines this appointment with one at the Department of Integrated Care at the university hospital Mastricht. At this moment he is, as a scientific researcher, involved in numerous projects in the area of the effectiveness and efficiency of integrated care and disease management. In addition, since July 2001 he is chair of the research group of the Association of Diaberes Nurses (Eerste Associatie van Diaberes Verplegkindigen (EADV), Nieuwegein). 